\title{
The early Miocene balaenid Morenocetus parvus from Patagonia (Argentina) and the evolution of right whales
}

\author{
Mónica R. Buono ${ }^{\text {Corresp., }}{ }^{1}$ ， Marta S. Fernández ${ }^{2}$ ， Mario A. Cozzuol $^{3}$ ， José I. Cuitiño ${ }^{1}$ ， Erich M.G. Fitzgerald ${ }^{4,5,6}$ \\ 1 Instituto Patagónico de Geología y Paleontología, Centro Nacional Patagónico, CONICET, Puerto Madryn, Chubut, Argentina \\ 2 División Paleontología Vertebrados, Unidades de investigación Anexo Museo, Facultad de Ciencias Naturales y Museo, UNLP, La Plata, Buenos Aires, \\ Argentina \\ 3 Departamento de Zoologia, Instituto de Ciências Biológicas, Universidade Federal de Minas Gerais, Belo Horizonte, Minas Gerais, Brasil \\ 4 Geosciences, Museums Victoria, Melbourne, Victoria, Australia \\ 5 Department of Vertebrate Zoology, National Museum of Natural History, Smithsonian Institution, Washington DC, United States of America \\ 6 Department of Life Sciences, Natural History Museum, London, United Kingdom \\ Corresponding Author: Mónica R. Buono \\ Email address: buono@cenpat-conicet.gob.ar
}

Balaenidae (right and bowhead whales) are a key group in understanding baleen whale evolution, because they are the oldest surviving lineage of crown Mysticeti, with a fossil record that dates back $\sim 20$ million years. However, this record is mostly Pliocene and younger, with most of the Miocene history of the clade remaining practically unknown. The earliest recognized balaenid is the early Miocene Morenocetus parvus Cabrera, 1926 from Argentina. Morenocetus parvus was originally briefly described from two incomplete crania, a mandible and some cervical vertebrae collected from the lower Miocene Gaiman Formation of Patagonia. Since then it has not been revised, thus remaining a frequently cited yet enigmatic fossil cetacean with great potential for shedding light on the early history of crown Mysticeti. Here we provide a detailed morphological description of this taxon and revisit its phylogenetic position. The phylogenetic analysis recovered the middle Miocene Peripolocetus as the earliest diverging balaenid, and Morenocetus as the sister taxon of all other balaenids. The analysis of cranial and periotic morphology of Morenocetus suggest that some of the specialized morphological traits of modern balaenids were acquired by the early Miocene and have remained essentially unchanged up to the present. Throughout balaenid evolution, morphological changes in skull arching and ventral displacement of the orbits appear to be coupled and functionally linked to mitigating a reduction of the field of vision. The body length of Morenocetus and other extinct balaenids was estimated and the evolution of body size in Balaenidae was reconstructed. Optimization of body length on our phylogeny of Balaenidae suggests that the primitive condition was a relatively small body length represented by Morenocetus, and that gigantism has been acquired independently at least twice (in Balaena mysticetus and Eubalaena spp), with the earliest occurrence of this trait in the late Miocene-early 
Pliocene as represented by Eubalaena shinshuensis. 
1 PeerJ.

2 The early Miocene balaenid Morenocetus parvus from Patagonia (Argentina) and the

\section{3 evolution of right whales}

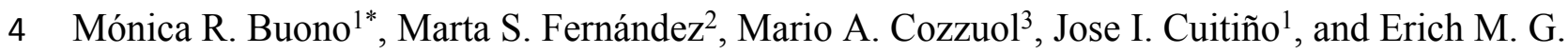

$5 \quad$ Fitzgerald $4,5,6$.

6 1'Instituto Patagónico de Geología y Paleontología, Centro Nacional Patagónico, CONICET,

7 Puerto Madryn, Chubut, Argentina. ${ }^{2}$ División Paleontología Vertebrados, Unidades de

8 investigación Anexo Museo, Facultad de Ciencias Naturales y Museo, La Plata, Buenos Aires,

9 Argentina, CONICET.

$10{ }^{3}$ Departamento de Zoologia, Instituto de Ciências Biológicas, Universidade Federal de Minas

11 Gerais, Belo Horizonte, Minas Gerais, Brazil

$12{ }^{4}$ Geosciences, Museums Victoria, Melbourne, Victoria, Australia

$13{ }^{5}$ Department of Vertebrate Zoology, National Museum of Natural History, Smithsonian

14 Institution, Washington DC, USA

$15{ }^{6}$ Department of Life Sciences, Natural History Museum, London, UK

16

17 *buono@cenpat-conicet.gob.ar 


\section{Abstract}

Balaenidae (right and bowhead whales) are a key group in understanding baleen whale evolution, because they are the oldest surviving lineage of crown Mysticeti, with a fossil record that dates back $\sim 20$ million years. However, this record is mostly Pliocene and younger, with most of the Miocene history of the clade remaining practically unknown. The earliest recognized balaenid is the early Miocene Morenocetus parvus Cabrera, 1926 from Argentina. Morenocetus parvus was originally briefly described from two incomplete crania, a mandible and some cervical vertebrae collected from the lower Miocene Gaiman Formation of Patagonia. Since then it has not been revised, thus remaining a frequently cited yet enigmatic fossil cetacean with great potential for shedding light on the early history of crown Mysticeti. Here we provide a detailed morphological description of this taxon and revisit its phylogenetic position. The phylogenetic analysis recovered the middle Miocene Peripolocetus as the earliest diverging balaenid, and Morenocetus as the sister taxon of all other balaenids. The analysis of cranial and periotic morphology of Morenocetus suggest that some of the specialized morphological traits of modern balaenids were acquired by the early Miocene and have remained essentially unchanged up to the present. Throughout balaenid evolution, morphological changes in skull arching and ventral displacement of the orbits appear to be coupled and functionally linked to mitigating a reduction of the field of vision. The body length of Morenocetus and other extinct balaenids was estimated and the evolution of body size in Balaenidae was reconstructed. Optimization of body length on our phylogeny of Balaenidae suggests that the primitive condition was a relatively small body length represented by Morenocetus, and that gigantism has been acquired independently at least twice (in Balaena mysticetus and Eubalaena spp), with the earliest occurrence of this trait in the late Miocene-early Pliocene as represented by Eubalaena shinshuensis. 


\section{INTRODUCTION}

Balaenidae have been considered a key group in understanding baleen whale (Mysticeti) evolution, because they are the oldest surviving lineage of crown Mysticeti, as suggested by their ancient stratigraphic occurrence (Cabrera, 1926) coupled with an early divergence date estimated from mtDNA data (McGowen, Spaulding \& Gatesy, 2009; Marx \& Fordyce, 2015). Despite their long evolutionary history, living balaenids exhibit relatively low taxonomic richness of four species in two genera (the bowhead whale Balaena and three right whales Eubalaena spp.) — in comparison to at least eight extant balaenopterid species — and share conservative morphology distinguishing them from other mysticetes, including an extremely large head (about one-third the body length), highly arched rostrum with long baleen plates (in right whales present about 2-3m while in bowhead whales are longer with a range between 3 $4 \mathrm{~m}$ ), huge dorsally bowed lower lips and lack of ventral throat grooves (Cummings, 1985; Reeves \& Leatherwood, 1985). Many of these morphological features have been functionally linked to the continuous ram filter (or skim) feeding employed by all balaenids (Bouetel, 2005; Lambertsen et al., 2005). Recent phylogenetic analyses of morphological and molecular data suggest that the origins of extant mysticete families lie between the late Oligocene and early Miocene ( 28-16 Ma) (Steeman et al., 2009; Marx \& Fordyce, 2015). Yet fossil representatives of the living families Balaenopteridae (rorquals), Eschrichtiidae (grey whale), Neobalaenidae (pygmy right whale) and Balaenidae (right whales) are virtually unknown from this interval. The singular exception to this pattern is the early Miocene balaenid Morenocetus parvus Cabrera, 1926 from Patagonia, Argentina. Almost all known fossil balaenids are late Miocene or younger in age, hence Morenocetus establishes a significant earlier history for Balaenidae dating back $\sim 20 \mathrm{Ma}$. Although a late Oligocene ( 28 Ma) stem balaenid was reported from New Zealand 
64 (Fordyce, 2002), it has not been formally described yet, and recent analyses recovered it outside 65 of Balaenidae (Marx \& Fordyce, 2015; Marx, Bosselaers \& Louwye, 2016; Tsai \& Fordyce, 66 2016; Marx \& Kohno, 2016, Marx et al., 2016). This makes Morenocetus the geologically 67 earliest confirmed member of an extant mysticete family (e.g. Bisconti, 2005; Marx \& Fordyce, 2015; Gol'din \& Steeman, 2015), and therefore a pivotal fossil calibration for mysticete molecular clock divergence estimates. Furthermore, being the earliest balaenid, Morenocetus may provide insights into the primitive morphology of Balaenidae and thus shed light on the contentious higher-level relationships within crown Mysticeti; namely, whether the highly specialized Neobalaenidae are more closely related to Balaenidae or Balaenopteroidea (Balaenopteridae + Eschrichtiidae).

Cabrera's (1926) original description of Morenocetus parvus was based on two incomplete crania, a mandible and some cervical vertebrae collected from the lower Miocene Gaiman Formation exposed at the Cerro Castillo locality (Chubut province, Patagonia, Argentina). The original descriptions of both the holotype and referred specimen are brief and do not document phylogenetically significant regions of the cranium such as the basicranium and periotic. This gap in anatomical data on M. parvus is reflected in disparate estimates of this key taxon's phylogenetic position within Balaenidae (e.g. Bisconti, 2005; Churchill, Berta \& Deméré, 2012; Bisconti, Lambert \& Bosselaers, 2017) . Although M. parvus has been included in comprehensive analyses of mysticete phylogeny (Bisconti, 2000; Churchill et al., 2012; Fordyce \& Marx, 2013; Tsai \& Fordyce, 2015; Marx \& Fordyce, 2015; Gol'din \& Steeman, 2015; Bisconti et al., 2017), their character coding was based solely on Cabrera's (1926) illustrations and brief description. In the latter studies, there was limited consideration of periotic morphology, and character data from the informative referred specimen have never been 
87 incorporated in analyses. In the latest analysis Morenocetus was recovered in a clade with

Balaenella + Balaena and sister to Balaenula + Eubalaena, respectively (Bisconti, 2005), outside a Balaenidae + Neobalaenidae clade (Bisconti, Lambert \& Bosselaers, 2017) or in an unresolved position recovered by Churchill, Berta \& Deméré (2012). The early stratigraphic occurrence of Morenocetus hints at a basal position in balaenid phylogeny, which has been corroborated by some recent analyses (Fordyce \& Marx, 2013; Tsai \& Fordyce, 2015; Marx \& Fordyce, 2015). Nonetheless, Gol'din \& Steeman (2015) instead recovered the middle Miocene Peripolocetus as the earliest diverging balaenid.

Here we describe the anatomy of Morenocetus parvus in depth, based on the type and referred specimens, and revise the geologic setting and age of this important fossil mysticete.

Our thorough anatomical description forms the basis for the most complete character analysis of Morenocetus to-date and a new phylogenetic analysis of Balaenidae. The results of our analysis support the basal position of Morenocetus within Balaenidae, which sheds light on the evolutionary history of right whales.

\section{MATERIAL AND METHODS}

\section{Institutional abbreviations}

CNPMAMM - Laboratorio de Mamíferos Marinos, Centro Nacional Patagónico, Puerto Madryn, Chubut, Argentina; FMNH - The Field Museum of Natural History, Chicago, USA; MLP - Museo de La Plata, La Plata, Argentina; NMNZ - Museum of New Zealand Te Papa Tongarewa, Wellington, New Zealand; OCPC - The Cooper Center, Orange County, USA; OU - Geology Museum, University of Otago, Dunedin, New Zealand; USNM - National Museum of Natural History, Smithsonian Institution, Washington DC, USA; ZMT - Fossil mammals 
110 catalogue, Canterbury Museum, Christchurch, New Zealand.

111

\section{Materials}

113 The re-description of M. parvus is based on the holotype (MLP 5-11) and referred

114 specimens (MLP 5-15) described originally by Cabrera (1926) and deposited in the Vertebrate

115 Palaeontology collection of the Museo de La Plata. In addition, Cabrera (1926) referred other

116 material to M. parvus: four cervical vertebrae (MLP 5-30) and a mandible (MLP 5-21). The

117 cervical vertebrae (MLP 5-30) are not included herein as they could not be located in the La

118 Plata Museum collection. Bone characteristics of the mandible (MLP 5-21) (i.e. lower weight

119 and signals of little mineral replacement) clearly differs from MLP 5-11 and 5-15, indicating

120 that it could correspond to a much more recent fossil or even extant balaenid. In order to test if

121 the mandibles could correspond to M. parvus, a collagen and nitrogen analysis were carried out.

122 High concentrations of collagen and nitrogen of the MLP 5-21 $(0.075 \% \mathrm{~N} 0.40 \%$ collagen in the

123 holotype; $1.79 \% \mathrm{~N}$ 9.59\% collagen in MLP 5-21) strongly suggest that MLP 5-21 is not Miocene

124 in age. In consequence, MLP 5-21 is not referable to $M$. parvus and we do not consider it further

125 here. Although the exact age of the specimen cannot be determined at this stage, its collagen

126 concentration and minimal mineral replacement strongly suggest that it dates from the

127 Pleistocene-Holocene.

128 The balaenid specimens used in the comparative and phylogenetic analyses are listed in 129 the supplementary information.

131 Methods

132 Collagen and nitrogen analysis. To determinate nitrogen content of the bone samples of 
133 MLP 5-21 and MLP 5-11 we used the Kjeldahl method (Kjeldahl, 1883). In this method, the

134 nitrogen of the sample is converted to ammonium by reaction with sulfuric acid. The content of

135 ammonium is determined from the amount of ammonia liberated by distillation with a strongly

136 alkalized solution. The collagen concentration is established using the following equation:

137 Protein $(\%)=\% \mathrm{~N} \times 5.36$.

138 Preparation methods and photographs. The specimens MLP 5-11 and MLP 5-15 were 139 prepared in the Museo de La Plata using pneumatic chisels and hand tools. The left ear bone of

140 MLP 5-11 was prepared under magnifying glass but it was not disarticulated from the cranium to 141 avoid its destruction. Photographs were taken with a Nikon D3000 camera and a 55 mm lens.

Anatomical description. The skull anatomical terminology follows that proposed by

143 Mead \& Fordyce (2009) with additions from Fordyce \& Marx (2013), Marx et al., (2016), for

144 those skull anatomical terms more specific for mysticetes (squamosal cleft, squamosal

145 prominence) and Boessenecker \& Fordyce (2015) for bulla anatomical terms (lateral and medial

146 lobe). Most of the measurements were taken following the standard protocols of Perrin (1975).

147 The description is mainly based on the left or right side of the cranium, whichever is more

148 completely preserved, on the holotype. The features not observable on the holotype and/or

149 variable in the two known specimens are indicated. The periotic was described in situ and

150 description focused on the left side. Computed tomography (CT techniques) was used to generate

151 a 3D reconstruction and coronal sections of the skull of the holotype of $M$. parvus to study

152 internal sutures and endocranial features.

$153 \quad$ Nine calf specimens of southern right whales (Eubalaena australis) that stranded near the

154 nursery grounds at Península Valdes, Chubut province, Argentina, were dissected to analyze soft

155 tissue structures (Suplementary Table S1). Disecctions were approved by the Dirección de Fauna 
156 y Flora Silvestre del Chubut (approval number 30/2010).

157 Physical maturity. To estimate the ontogenetic stage of the specimens we analyzed the:

158 degree of cranial suture closure, according to the rating system proposed by Walsh \& Berta

159 (2011); bony texture (e.g. punctuate texture of occipital condyles); and development of the skull

160 crests. The cranial suture closure system originally proposed by Walsh \& Berta (2011) was not

161 tested for balaenids. Nevertheless, we had access to Eubalaena australis skulls at different

162 ontogenetic stages (neonates, calves, juveniles and adults, Table 1) that allowed us to corroborate

163 a similar suture closure pattern in at least this species of Balaenidae.

164 Orientation of the skull. The correct anatomical orientation of the skull in mysticetes is

165 an important issue, especially with respect to comparisons between taxa and also for the

166 interpretation of morphological phylogenetic characters. Yamada et al. (2006) proposed a

167 standardized protocol to orientate the skull of mysticetes (with focus on balaenopterids) in dorsal

168 view. However, accurate anatomical orientation of the skull in extinct balaenids is challenging

169 because most specimens lack the rostrum. To this it must be added that, due to the arched

170 rostrum and a vertically-oriented occipital shield, the condylobasal length of the skull (CBL) of

171 balaenids is not homologous to other cetaceans. Resolving this problem is essential to

172 determining the configuration of important characters. In order to resolve this topic we propose

173 three anatomical landmarks to orientate the crania of fossil balaenids based on observations and

174 dissections of specimens of Eubalaena australis (Fig.1). We did not perform dissections of

175 specimens of Eubalaena glacialis, E. japonica or Balaena mysticetus. However, we analyzed

176 osteological specimens of these species (Supplementary file) to test the first and second

177 anatomical landmarks proposed, showing a similar pattern to Eubalaena australis. Future

178 dissections of these species could further corroborate the position of the landmarks we have used 
179 in this present study and their application.

180 1) The position of the nasal fossa: the nasal fossa, defined as the bony fossa on the dorsal surface

181 of the skull holding the soft structures of the upper nasal passage, epithelium, blowhole and

182 vestibule, is located in the posterodorsal region of the cranium (Buono et al., 2015). Detailed

183 anatomical analysis of the nasal complex in Eubalaena australis shows that, in dorsal or anterior

184 view, the posteriormost region of the nasal fossa floor (where the blowhole is located) is parallel

185 to the horizontal plane of the skull (Fig. 1A). This character is also evident in Balaena

186 mysticetus, where the skull is strongly arched in a dorsoventral direction, with the posteriormost

187 region of the nasal floor oriented parallel to the horizontal plane of the skull. This character could

188 not be applied to Morenocetus because the rostral bones are not preserved.

189 2) The orientation of the postglenoid process of the squamosal: The anatomical exploration of

190 the skull and soft structures associated in Eubalaena australis, demonstrated that orientation of

191 the postglenoid process is also an accurate landmark for skull orientation. The postglenoid

192 process is posteroventrally directed, defining an acute angle of approximately $50-55^{\circ}$ (pointing

193 back) with the horizontal plane of the skull (Fig. 1B).

194 3) The position of the foramen magnum: this anatomical point is a significant landmark as it

195 allows orientation of the skull in relation to the vertebral column. Dissections of extant balaenids

196 permit a precise determination of the location and course of the spinal cord within the foramen

197 magnum and its path to the braincase. The spinal cord leaves the skull through the foramen

198 magnum in a dorsal position and the foramen magnum is deflected ventrally forming an acute

199 angle of approximately $30^{\circ}$ with the horizontal plane of the skull (Fig. 1C-D).

200 Phylogenetic analysis. Phylogenetic analyses were carried out on a combined data

201 matrix based on a recent mysticete dataset (Marx \& Fordyce, 2015). As our contribution is 
202 focused on balaenids, this dataset was modified as follows: unpublished specimens were

203 excluded; the taxonomic sample of balaenopteroids and cetotheriids was reduced; additional

204 balaenid taxa were sampled with the inclusion of the three species of Eubalaena (E. australis, E.

205 glacialis and E. japonica); and the list of characters was modified (see the supplementary file 1

206 for the complete list of taxa and characters). Balaenula balaenopsis was not included in our

207 analysis because the taxonomic status of this taxon needs to be carefully revised. There are

208 serious doubts that all of the skeletal elements referred by Van Beneden (1872) to B. balaenopsis

209 actually represent one individual, let alone one taxon.

210 Our thorough anatomical description of Morenocetus was used for completing and/or

211 correcting previous character scoring of this taxon. Modifications to the character coding of

212 Morenocetus as well as in other balaenids are detailed in Supplementary file 1.

213 The total-evidence dating analysis was conducted with the addition of the molecular

214 dataset from McGowen, Spaulding \& Gatesy (2009), which was pruned to match our taxon

215 sample.

216 Heuristic parsimony analysis of the dataset was performed in TNT version 1.5 (Goloboff

$217 \&$ Catalano, 2016) using the traditional search under equal and implied weights $(\mathrm{K}=3 ; \mathrm{K}=6$;

$218 \mathrm{~K}=10$ ). Some characters were treated as ordered (see supplementary file) The analysis was

219 performed using 1000 replicates of Wagner trees (using random addition sequences), tree

220 bisection reconnection (TBR) branch swapping holding 10 trees per replicate. The best trees

221 obtained at the end of the replicates were subjected to a final round of TBR branch swapping.

222 The resulting most parsimonious trees (MPTs) were summarized using strict consensus trees

223 with zero-length branches collapsed (i.e., 'rule 1' of Coddington \& Scharff, 1994). Branch

224 support was calculated using the decay index. To identify unstable taxa we used the IterPCR 
225 procedure (Pol \& Escapa, 2009) over the entire set of MPTs. This procedure allows the

226 identification of the set of characters that positively support alternative positions of the unstable

227 taxon from the set of characters scored with missing entries that may diminish the instability of

228 each taxon (Pol \& Escapa, 2009; Escapa \& Pol, 2011).

Estimation of the body size. In order to estimate the total length (TL) of Morenocetus

parvus and other extinct balaenids, we used two alternative methods of estimating body length:

1) the regression equation proposed by Pyenson \& Sponberg (2011) for stem mysticetes: [log $(\mathrm{TL})=0.92 *(\log (\mathrm{BZW})-1.72)+2.68]$ based on the bizygomatic width $(\mathrm{BZW})$. We decided

to use this equation, despite not being specific for balaenids, because Pyenson \& Sponberg (2011) developed an alternative approach using phylogenetic relationships and multiple cranial metrics to address this issue. Application of this approach significantly increased the accuracy of reconstructed body length in Neoceti. However, because Pyenson \& Sponberg (2011) analysis did not include balaenids in their dataset, we applied the regression equation of Lambert et al. (2010), which includes extant balaenids in their dataset: [y (TL) $=8.209 * x(B Z W)+66.69]$. In Morenocetus BZW is not completely preserved in any of the referred specimens; thus the TL could be underestimated. For comparative purpose we estimated the total length in the balaenids, of which the BZW was available from literature: Balaenula astensis (BZW=700mm; Bisconti, 2000), Balaena montalionis (estimated BZW= 820mm from Bisconti 2000, Table 2 p:41), measure is an underestimate ), Eubalaena shinshuensis (estimated BZW=1490mm, Kimura, 
The total lengths were optimized onto the cladogram obtained here using a modified

247 version of the body size classes proposed by Fitzgerald (2010): small body size ( $<6 \mathrm{~m}$ long),

248 large body size (6-12 m long), and very large body size ( $>12 \mathrm{~m}$ long).

\section{GEOLOGICAL SETTING}

250 The holotype of Morenocetus parvus was collected from the "...El Castillo in front of

251 Trelew locality...”(sic) “...in the marine Patagonian Formation...” (Cabrera, 1926: 364). The E1

252 Castillo locality is located about $10 \mathrm{~km}$ south of Trelew city, in the southern margin of the Lower

253 Valley of the Chubut River, Chubut province (Fig. 2). Along the southern margin of this valley a

254200 m-thick, subhorizontal sedimentary succession is exposed, comprising Paleogene-Neogene

255 continental and marine units (Scasso \& Castro, 1999; Scasso \& Bellosi, 2004), including the

256 "marine Patagonian Formation" mentioned by Cabrera (1926: 364). The latter corresponds to an

257 informal unit also known as Patagoniense, rooted in the literature since the nineteenth century

258 (Ameghino, 1906; Frenguelli, 1935; Simpson, 1935; Feruglio, 1949). Currently it comprises

259 several lithostratigraphic units in Patagonia, ranging in age from the late Oligocene to the early

260 Miocene (e.g., Cuitiño et al., 2017). These units were all deposited in shallow marine to

261 estuarine environments, during a major marine transgression that flooded a large part of

262 Patagonia (Scasso \& Castro, 1999; Malumián \& Náñez, 2011; Cuitiño et al., 2017). The

263 Patagoniense beds that crop out in the Lower Valley of the Chubut River and along the coastal

264 cliffs of eastern Chubut Province were assigned to the Gaiman Formation (Mendia \& Bayarsky,

265 1981). In Cerro Castillo this unit is nearly 100 m-thick (Fig.3) and unconformably overlies the

266 Trelew Member of the Sarmiento Formation, composed of continental yellowish to whitish-grey,

267 sandy tuffs and tuffs with terrestrial mammals (Fleagle \& Bown, 1983; Scasso \& Bellosi, 2004).

268 In turn, the Gaiman Formation is conformably overlain by a $30 \mathrm{~m}$-thick succession of cross- 
269 bedded sandstones and heterolithic deposits referred to the Puerto Madryn Formation (Fig. 3A),

270 which accumulated in estuarine environments.

271 Unfortunately, Cabrera (1926) did not provide precise geographic or stratigraphic

272 information on which horizon the specimen was collected from. However, field inspection of the

273 area south of Trelew city provide insights about the stratigraphic provenance of the specimens.

274 In Cerro Castillo, the basal stratum of the Gaiman Formation is a thin transgressive shell bed

275 with bones and teeth from marine vertebrates (Figure 3A; Cione, 1978; Scasso \& Castro, 1999).

276 The marine sediments overlying this basal stratum correspond to the lower half ( $\sim 50$ meters $)$ of

277 the Gaiman Formation. It is composed of white, tuffaceous, thoroughly bioturbated mudstones

278 with occasional thin oyster horizons, deposited in a shallow shelf (Scasso \& Castro, 1999). In

279 contrast to the upper part of Gaiman Formation, the lower beds produce several disarticulated

280 cetacean remains suggesting that Morenocetus was probably collected in this part of the unit.

281 The age of the Gaiman Formation is based on stratigraphic correlations to other

282 absolutely-dated sections in Patagonia and biostratigraphic data. The "Patagoniense" marine

283 deposits, equivalent to the Gaiman Formation, were dated in the Austral Basin (Santa Cruz

284 Province, Patagonia) by means of U-Pb and Sr-Sr methods as early Miocene (Aquitanian-

285 Burdigalian; 23-18 Ma) (Parras et al., 2012; Cuitiño et al., 2012; Cuitiño et al., 2015a).

286 Equivalent beds in the Comodoro Rivadavia region (Chubut province), dated by the Sr-Sr

287 method, comprise a younger depositional age, spanning from the early to the middle Miocene

288 (19.69 and 15.37 Ma; Burdigalian-early Langhian) (Cuitiño et al., 2015b). The initial flooding

289 phase of the Patagoniense transgression occurred in the Aquitanian to early Burdigalian (e.g.,

290 Cuitiño et al., 2015b), whereas the younger deposits of the regressive interval extends only

291 locally to the Langhian stage (Cuitiño et al., 2015b). The Cerro Castillo beds analyzed here are 
292 part of the lower beds of the Gaiman Formation and can be considered as the initial phase of the

293 "Patagoniense" marine cycle. Based on regional correlations, an early Miocene (Aquitanian-

294 Burdigalian) age is proposed for these cetacean bearing beds. An early Miocene age for the

295 lower part of the Gaiman Formation is also suggested by the Colhuehuapian mammal fauna

296 recovered from the underlying Trelew Member of the Sarmiento Formation (Flynn \& Swisher,

297 1995; Dunn et al., 2013). The age of the Colhuehuapian fauna was estimated between ca. 21.0

298 and 20.5 Ma (late Aquitanian) at Gran Barranca (Dunn et al., 2013). Based on this information,

299 the age of the overlying Gaiman formation should not be older than late Aquitanian. In addition,

300 evidence from marine vertebrates in the Gaiman Formation (i.e., fishes and penguins) (Cione et

301 al., 2011) as well as a palynological assemblage recovered from the study area (Palazzesi,

302 Barreda \& Scasso, 2006) also indicates an early Miocene age (Burdigalian).

303

304 RESULTS

305 Systematic palaeontology

306 Cetacea Brisson, 1762

$307 \quad$ Neoceti Fordyce \& Muizon, 2001

308 Mysticeti Gray, 1864 sensu Cope, 1869

309 Chaeomysticeti Mitchell, 1989

$310 \quad$ Balaenidae Gray, 1825

311 Morenocetus Cabrera, 1926

312 Type species by monotypy. Morenocetus parvus Cabrera, 1926.

313 Diagnosis. As for type and only species.

314 Morenocetus parvus Cabrera, 1926 
315 Holotype. MLP 5-11, incomplete cranium including the left periotic and incomplete right

316 periotic in articulation with the basicranium, but lacking the rostrum (Figs.4-11; Table 2-3).

317 Referred specimens. MLP 5-15, cranium including the left periotic (Figs. 5 and 6; Table 2).

318 Type locality, horizon and age. The holotype and referred specimens were collected by

319 Cremonessi at the Cerro Castillo locality, in front of Trelew city, Chubut province, central

320 Patagonia, Argentina; Gaiman Formation (early Miocene, Burdigalian; Mendia \& Bayarsky,

321 1981, Scasso \& Castro, 1999) (Figs.2 and 3).

Emended diagnosis. Morenocetus is a small sized balaenid (aproximatly $5.2-5.6 \mathrm{~m}$ in

323

324

325

326

327

328

329

330

331

332

333

334

335

336

337

total length) which differs from all other Balaenidae in the following unique combination of apomorphies: narrow exposure of the squamosal lateral to the exoccipital (in posterior view the transverse width of squamosal is less than $15 \%$ of the distance between sagittal plane and lateral edge of the exoccipital) and dorsal extension of the tensor tympani muscle as a deep canal on the medial side of the anterior process of the periotic.

Morenocetus differs from Peripolocetus in having a zygomatic process of the squamosal dorsoventrally expanded, in the lack of a distinct ridge delimiting the insertion surface of the tensor tympani muscle on the medial side of the anterior process, and in the lack of a dorsal deflection of the anterodorsal corner of the anterior process of the periotic.

Morenocetus differs from Balaenula sp., Balaenula astensis, Balaenella, Eubalaena and Balaena in having a transversely short supraorbital process of the frontal (the transverse length represents up to twice the anteroposterior length of the supraorbital process), paired tubercles on the supraoccipital limited to low ridges forming the lateral edges of a medial fossa (except Eubalaena australis and E. japonica), and straight lateral edges of the supraoccipital. Morenocetus further differs from Balaenula sp., Balaenula astensis and Balaenella in 
338 having a postorbital process of the frontal oriented posteriorly, in having a crest-like parieto-

339 squamosal suture, and in having a compound posterior process of the periotic posterolaterally

340 oriented with respect to the longitudinal axis of the anterior process; from Balaenula sp. and

341 Balaenula astensis in having the anterior edge of the supraorbital process of the frontal pointing

342 posteriorly, presence of supramastoid crest of zygomatic process; from Balaenella in having a

343 dorsal margin of the orbit located roughly halfway between the vertex and the ventral surface of

344 the postglenoid process, in the lack of a narial process of the frontal separating the posterior

345 portion of the nasals, in the lack of a tubercle at the junction of the parieto-squamosal and

346 supraoccipital sutures, lack of a lateral tuberosity of the periotic, and in the lack of a ridge

347 delimiting the insertion for tensor tympani muscle.

348 Differs from Balaena ricei and B. mysticetus in having a short anterior process of

349 periotic, in the lack of a lateral tuberosity on the periotic and a distinct ridge delimiting the

350 insertion surface for tensor tympani muscle on the medial side of the anterior process of periotic,

351 and in the lack of a hypertrophied suprameatal fossa; from Balaena myticetus and B. montalionis

352 in having a compound posterior process of the periotic exposed on the lateral skull wall; Balaena

353 mysticetus in having the anterior edge of the supraorbital process of the frontal pointing

354 posteriorly, optic canal ventrally open, apex of the zygomatic process of squamosal

355 anteroventrally deflected, presence of a supramastoid crest along the dorsal surface of the

356 zygomatic process of squamosal (but does not reach the tip of the zygomatic process),

357 postglenoid process ventrally oriented, the proximal opening of facial canal, internal acoustic

358 meatus and aperture for cochlear aqueduct aligned anteroposteriorly; from Balaena montalionis

359 in the lack of a tubercle at the junction of the parieto-squamosal-supraoccipital sutures, and

360 pterygoid sinus fossa located anterior to the foramen pseudovale. 
362 frontal gradually sloping away ventrolaterally from the skull vertex, posteriorly oriented

363 postorbital process, orbit positioned at half of the vertical distance between the vertex and the

364 ventral surface of the postglenoid process, thicker orbital rim with a flat lateral surface,

365 zygomatic process of squamosal anteroventrally deflected, ventrally oriented postglenoid

366 process, foramen pseudovale not raised above the lateral portions of the squamosal; from

367 Eubalaena australis, E. japonica and E. glacialis in having a ventrally open optic canal; a

368 supramastoid crest along the dorsal surface of the zygomatic process of the squamosal; pterygoid 369 sinus fossa located anterior to the foramen pseudovale; in lacking a distinct ridge delimiting the 370 insertion surface of the tensor tympani muscle on the medial side of the anterior process of the

371 periotic; compound posterior process of the periotic posterolaterally oriented with respect to the

372 longitudinal axis of the anterior process, a rounded and short anterior process of the periotic,

373 caudal tympanic process of the periotic with a ventrally oriented ventral border, compound

374 posterior process of periotic exposed in the lateral skull wall, in lacking a hypertrophied

375 suprameatal fossa and lateral tuberosity on the periotic; from Eubalaena australis, E. japonica,

376 E. glacialis and E. shinshuensis in the posteriormost point of the exoccipital located more

377 anteriorly than the posterior edge of the occipital condyle.

\section{Description}

Preservation. MLP 5-11 is an incomplete skull with a well-preserved cranium, lacking: magnum; both jugals and palatines; the anterior portion of the vomer; the right alisphenoid; 
384

385

386

387

388

389

390

391

392

393

394

395

396

397

398

399

400

401

402

403

404

405

406

much of the presphenoid and mesethmoid; most of the right postglenoid process and glenoid fossa; the apex of the zygomatic process of the squamosal; both tympanic bullae; and most of the right pericotic. Most of the ventral surface of the cranium is eroded and broken. However, both periotics are preserved articulated with the skull. The specimen MLP 5-15 shows a similar state of preservation to the holotype, with the difference that the zygomatic and postglenoid processes of the left squamosal are complete.

Physical maturity. In MLP 5-11 and MLP 5-15 the basioccipital/exoccipital and supraoccipital/exoccipital sutures are completely fused (SR4). In Eubalaena australis, the supraoccipital/exoccipital suture (the last occipital suture to fuse during ontogeny in Balaenopteroidea; Walsh \& Berta, 2011) is already completely fused in subadults (Buono, 2014). In MLP 5-11 fractures in the ventral surface of the median basicranium approximate the position of the basioccipital/basisphenoid suture, which is closed (SR3; the suture is clearly obliterated in the floor of the cranial cavity). In MLP 5-15 this suture is completely fused in ventral view (SR4). In both MLP 5-11 and MLP 5-15 the basisphenoid/presphenoid suture is wide open. Other sutures of the cranium of the holotype specimen (pterygoid/vomer/squamosal/alisphenoidsquamosal/pterygoid/parietal) are closed, but visible (SR3). Additional adult features of the Morenocetus crania include: occipital condyles with smooth external surfaces (punctate in juvenile mysticetes); compact bone forming the external surface of cranial elements; and a sharp, salient nuchal crest. The latter features are characteristic of demonstrably adult specimens of Balaenidae, e.g., USNM 267612 (Eubalaena australis), USNM 23077 (E. glacialis) and USNM 257513 (Balaena mysticetus). Together, these observations suggest that MLP 5-11 and 5-15 are not juveniles and probably represent at least subadult, but not physically mature individuals.

Body size. Based on the equation of Pyenson \& Sponberg (2011), a conservative estimate 
407 for the total body length of Morenocetus is $5.2 \mathrm{~m}$ (based on BZW of the holotype specimen). In

408 MLP 5-15 the left zygomatic process is completely preserved, which allows an estimated BZW

409 of $\sim 620 \mathrm{~mm}$. In this case, the estimated total length is $5.6 \mathrm{~m}$. This value is slightly lower than

410 those of Late Miocene and Pliocene balaenids such as: Balaenula astensis $6.6 \mathrm{~m}$; Balaena

411 montalionis $7.2 \mathrm{~m}$; Balaenella brachyrhynus $7.9 \mathrm{~m}$; Eubalaena shinshuensis $12.5 \mathrm{~m}$ and

412 Eubalaena ianitrix $13.8 \mathrm{~m}$.

413 On the other hand, the estimated total body length of Morenocetus based on the

414 regression equation of Lambert et al (2010) is $5.34 \mathrm{~m}$ for the holotype and 5.64 $\mathrm{m}$ for MLP 5-15.

415 For the other extinct balaenids the values obtained are: Balaenula astensis $6.41 \mathrm{~m}$; Balaena

416 montalionis $7.39 \mathrm{~m}$; Balaenella brachyrhynus $8.05 \mathrm{~m}$; Eubalaena shinshuensis $12.89 \mathrm{~m}$ and

417 Eubalaena ianitrix $14.29 \mathrm{~m}$. These values are similar to those obtained with the Pyenson \&

418 Sponberg (2011) equation. In Balaenella the total length could be underestimated because both

419 zygomatic processes are incomplete.

420 General shape of the skull. The skull of the holotype and MLP 5-15 are comparable in

421 size. The bizygomatic width is $570+\mathrm{mm}$ in MLP $5-11$, which corresponds to $\sim 25 \%$ of the

422 bizygomatic width of extant physically mature balaenids. In dorsal view, the occipital shield is

423 anteroposteriorly elongated and triangular-shaped with the anterior margin rounded. It extends to

424 a point posterior to the level (anteroposteriorly) of the anterior edge of the orbit. The orbits open

425 dorso-laterally and are positioned high on the skull. The supraorbital process of the frontal,

426 gradually sloping from the vertex of the skull, is transversely short and anteroposteriorly broad

427 and it is mainly transversely oriented with respect to the sagittal axis of the skull in dorsal view.

428 The anterodorsal portion of the parietal overlaps the posterodorsal region of the frontal,

429 extending forward until the level of the anterior margin of the occipital shield. The zygomatic 
430 process is short, anterolaterally oriented and ventrally deflected.

431 Supraoccipital. In dorsal view (Fig. 4), the supraoccipital does not reach the level of the

432 preorbital process of the supraorbital process of the frontal. It has a triangular outline with a

433 rounded anterior apex. Its lateral margins are almost straight in dorsal view forming a $\sim 45^{\circ}$

434 angle; the lambdoid suture with the parietal and squamosal is exposed in dorsal and lateral views.

435 The lateral margins of the supraoccipital form a pronounced nuchal crest. The anterior margin of

436 the supraoccipital contacts with the frontal through an observable joint (state SR3) and is not

437 raised as in Balaenella (Bisconti, 2005). The dorsomedial surface of the supraoccipital bears a

438 low, triangular and anteroposteriorly oriented (Length $=90 \mathrm{~mm}$ ) depression that does not reach the

439 anterior margin of the supraoccipital (extending to $75 \mathrm{~mm}$ from this margin) — here termed the

440 external occipital fossa (new term). There is no external occipital crest. In lateral view (Fig. 5)

441 the supraoccipital is dorsally convex and obliquely oriented forming an acute angle with the

442 sagittal plane of the skull. In posterior view (Fig. 6A and B) the supraoccipital is not extensively

443 exposed above the dorsal margin of the foramen magnum: in Morenocetus the posterior aspect of

444 the supraoccipital is approximately twice the height of the foramen magnum, while in Eubalaena

445 its height is about fourfold that of the foramen magnum (e.g. USNM 267612 Fig. 1B,

446 CNPMAMM 774). The suture with the exoccipital is not observable (stage SR4).

447 Exoccipital. The exoccipital is completely fused anteriorly to the supraoccipital via a

448 closed suture (SR4) (Fig. 6A and B). Ventrolaterally it contacts the squamosal through a distinct

449 occipitosquamosal suture (stage SR3). This suture begins at the lateral margin of the exoccipital,

450 where its outline is convex, and then curves ventrally continuing inside the periotic fossa where

451 it becomes indistinct.

452 In dorsal view (Fig. 4) the posterior surface of the exoccipital is slightly concave in the 
453 sagittal plane and the posterior margins are laterally oriented forming an almost right angle with

454 the sagittal plane of the skull. In posterior view (Fig. 6A), the exoccipital is transversely wide

455 (representing $84 \%$ of the bizygomatic width) forming most of the occipital shield. The occipital

456 condyles form the ventral-ventrolateral margins of the foramen magnum and are large in

457 comparison with the size of the cranium: the maximum width of the occipital condyles represents

$45828 \%$ of the bizygomatic width (Table 2) (unlike extant balaenids where it represents $\sim 15 \%$ ).

459 Both occipital condyles are well preserved, ovoid-shaped and in dorsal view are not as convex in

460 the sagittal plane as in extant balaenids (e.g. Eubalaena australis USNM 267612; E. glacialis

461 USNM 23077 and Balaena mysticetus USNM 257513). In lateral view, the transverse axis of the

462 occipital condyles is oriented forming an acute angle with the horizontal plane of the skull. The

463 occipital condyles are separated in the ventromedial portion by a shallow and narrow

464 intercondylar notch (length $=60 \mathrm{~mm}$; minimal width $=4 \mathrm{~mm})$. The foramen magnum has an

465 almost circular outline $(75 \times 75 \mathrm{~mm})$. Posterior to the nuchal crest in the dorsolateral margin of

466 each exoccipital there is a well defined transversely oriented groove. Anterodorsal to the

467 occipital condyle there is a distinct dorsal condyloid fossa. There is no distinct ventral condyloid

468 fossa. The lateral margin of the exoccipital is convex and the ventral margin forms a deep jugular

469 notch and short paroccipital process. Medial to the jugular notch, there is a small and rounded

470 ventral projection, the medial exoccipital crest (Fig. 6A), similar to that observed in extant

471 balaenids (Eubalaena australis USNM 267612, E. glacialis USNM 23077 and Balaena

472 mysticetus USNM 257513), as well as in the toothed mysticete Aetiocetus weltoni (Deméré \&

473 Berta, 2008). The small paroccipital process is located lateral to the jugular notch and dorsal to

474 the basioccipital crest. The paroccipital process is triangular, dorsoventrally short, and its

475 posterior surface is flat. In ventral view (Fig. 7), the compound posterior process of the 
476 tympanoperiotic contacts the exoccipital through a visible (SR3), straight and posterolaterally

477 oriented suture. The suture between the exoccipital and basioccipital is obliterated (SR4). The

478 contribution of the exoccipital to the formation of the basioccipital crest could not be established

479 due to the advanced fusion of the exoccipital-basioccipital suture. The paroccipital process is

480 anterior to the occipital condyles and its ventromedial surface is smooth and triangular marking

481 the presence of the posterior sinus fossa. The articulation of the stylohyal could not be

482 determined because the ventral surface of the paroccipital process is eroded. Medial to the

483 paroccipital process there is a deep and anteroposteriorly oriented sulcus that corresponds to the

484 path of the hypoglossal (XII), glossopharyngeal (IX), vagus (X) and spinal (XI) nerves and the

485 jugular vein and the external carotid artery that exit the cranium through the jugular notch. The

486 posterior margin of the exoccipital extends anterior to the occipital condyles.

Basioccipital. The basioccipital is divided into a medial horizontal portion or basilar

part, forming the floor of the cranium, and two ventrolateral projections forming the prominent

basioccipital crests (Fig. 7). The basilar part is slightly concave in posterior view and its anterior

contact with the basisphenoid is hidden by the posterior extension of the vomer. However, in the

dorsal surface of the basioccipital a rugose surface of bone is visible that corresponds to the

basisphenoid-basioccipital suture. In MLP 5-15 the vomer is absent, thus the basisphenoid-

basioccipital suture is visible in ventral view (SR3 stage). In posterior view (Fig. 6), the

basioccipital crest is bulbous being mediolaterally and dorsoventrally thickened. The medial

surface of the process is anteriorly convex and posteriorly flat; the ventral margin has a rugose

texture suggesting the presence of cartilage. In MLP 5-15 the ventro-medial surface of the 
499

500

501

502

503

504

505

506

507

508

509

510

511

512

513

514

515

516

517

518

519

520

521

anteriorly with the middle pterygoid lamina through a closed but observable suture (stage SR3).

Basisphenoid-Presphenoid. Posteriorly, the basisphenoid contacts the basioccipital,

laterally with the middle pterygoid lamina and anteriorly with the presphenoid (Figs. 7 and 8).

The dorsal carotid foramen is not observable in the dorsal surface of the basisphenoid. The

presphenoid is elongated anteroposteriorly and contacts laterally with the frontal and posteriorly

with the basisphenoid through an open basisphenoid-presphenoid fissure (width $=73 \mathrm{~mm}$;

lenght $=7 \mathrm{~mm}$ ). The suture with the orbitosphenoid is indistinct. Most of the ventral surface of the

presphenoid is eroded; the preserved lateral portions of the presphenoid suggest a triangular

shape in ventral view as in other balaenids. Its posterolateral portion contributes to the

delimitation of the orbital fissure and the well-defined notch for the passage of the optic nerve.

Vomer. Only the posterior portion of the vomer is preserved. As the palatines and

pterygoid hamulus are not preserved, the posterior part of the vomer is exposed on the ventral

wall of the cranium. The preserved portion of the vomer corresponds to the dorsal and

dorsomedial wall of the internal nasal passage (Figs. 7 and 8). It is horizontally orientated with

respect to the sagittal plane of the skull and placed ventral to the basisphenoid and basioccipital

underlapping the basioccipital/basisphenoid suture. The vomer extends from the level of the

anterior margin of the pterygoid sinus fossa until the anterior $2 / 3$ of the medial lamina of the

pterygoid. However, the posterior margin is not preserved, therefore the posterior extent could

not be determined. It is wide anteriorly and becomes narrower posteriorly. The lateral edges of

the vomer are sharp. The median vomerine crest does not reach the preserved posterior margin of the vomer.

Pterygoid. The preserved portions of the pterygoid correspond to the medial, and dorsal laminae and part of the lateral (Fig. 8) and a small portion of the ventral lamina in MLP 5-15. 
522 The pterygoid hamuli are not preserved; therefore the medial and dorsal laminae of the pterygoid

523 are exposed in the ventral surface of the skull. The medial lamina is anteroposteriorly oriented

524 and medially contacts the basioccipital and basisphenoid for $\sim 80 \mathrm{~mm}$ of its length, anteriorly

525 with the basisphenoid and posteriorly with the medial and anterolateral surface of the

526 basioccipital crest. The dorsal lamina extends laterally and contacts the squamosal through a

527 visible and irregular suture (length of the suture along which the pterygoid and squamosal

528 contact $\sim 40 \mathrm{~mm}$ ), and posteriorly where it contacts with the basioccipital. In Morenocetus the

529 dorsal lamina of the pterygoid is posteriorly elongated, resulting in the pterygoid sinus fossa

530 being anteroposteriorly longer than it is dorsoventrally deep. This contrasts with the condition in

531 extant balaenids (e.g., Eubalana australis: CNPMAMM 774, NMNZ 2239), where the pterygoid

532 sinus fossa is principally developed dorsoventrally. One-third of the pterygoid sinus fossa is

533 located anterior to the level of the foramen pseudovale. A well-defined foramen followed by a

534 short posterolateral fissure is identified on the dorsal lamina of the pterygoid, $51 \mathrm{~mm}$ from the

535 pterygoid-basioccipital suture. The same structures are present in the medial lamina of the

536 pterygoid of neonates (e.g., USNM 500860, CNPMMAM 746) and adult specimens

537 (CNPMAMM 774, NMNZ 2239) of Eubalaena spp. Observations in neonate specimens shows

538 that this fissure connects with the basisphenoid, and therefore could be homologized with the

539 path of the internal carotid artery into the cranial cavity (R. E. Fordyce pers. comm.). The strict

540 ventral carotid foramen in the basisphenoid is not present in neonate specimens of Eubalaena

541 spp., and the foramen in the pterygoid is provisionally referred to here as the "secondary ventral

542 carotid foramen" (Fig. 7B). The dorsal opening of the internal carotid artery is nonpatent in the

543 dorsal surface of the basisphenoid. The pharyngeal crest, which separates the pharyngeal and ear

544 regions of the skull, is formed anteriorly by the medial lamina of the pterygoid and is continuous 
545 posteriorly with the basioccipital crest; this crest is dorsoventrally lower than in Eubalaena (e.g.,

546 CNPMAMM 774, NMNZ 2239).

547 Alisphenoid. In ventral view (Figs 7 and 8), the alisphenoid contacts along its dorsal

548 surface with the parietal and ventrally it is overlapped in its posteromedial portion by the dorsal

549 lamina of the pterygoid and posterolaterally by the squamosal through well-defined sutures. The

550 alisphenoid is small with a maximum with of $\sim 41 \mathrm{~mm}$ and a length of $\sim 56 \mathrm{~mm}$. It presents a well-

551 defined lateral and triangular-shaped projection that extends $\sim 28 \mathrm{~mm}$ over the parietal that does

552 not reach the lateral margin of the skull; therefore it is not exposed in the medial wall of the

553 temporal fossa. Most of the ventral surface of the alisphenoid is eroded. The lateral projection of

554 the alisphenoid delimits the posteroventral margin of the optic canal. The alisphenoid contacts

555 anteriorly with the parietal through a visible suture that extends mediolaterally. Posterolaterally,

556 the alisphenoid contacts the squamosal through a convex suture and posteromedially with the

557 pterygoid. The foramen pseudovale does not perforate the alisphenoid externally, but is instead

558 confined to the squamosal (Fig. 8).

559 Squamosal. The squamosal is a massive bone primarily developed in the sagittal plane

560 and also forming the short and anterolaterally oriented zygomatic process.

561 In lateral view (Fig 5), the squamosal is clearly elongated dorsoventrally. In posterior view the

562 squamosal-exoccipital suture has a laterally convex profile. In MLP 5-15 a robust laterally-

563 directed supramastoid crest forms the dorsal surface of the zygomatic process of the squamosal

564 (Figs. 5D and 6D). A small squamosal prominence is present. The zygomatic process is short,

565 has a rounded apex, is anterolaterally oriented and ventrally deflected (Fig. 5D). Based on the

566 combined morphology of holotype and referred specimen we infer that the apex of the zygomatic

567 process of the squamosal is placed posterior to the postorbital process, but not apposed to it. The 
568 postglenoid process is better preserved in MLP 5-15; it is dorsoventrally high, posteroventrally

569 directed in lateral view (Fig. 5D), and ventrally oriented in posterior view. In dorsal view (Fig.

570 4B), the squamosal forms the posterolateral wall of the temporal fossa. The temporal fossa has an

571 approximately triangular shape. There is no squamosal cleft. The glenoid fossa is positioned

572 anteriorly to the level of the posterior apex of the nuchal crest (Fig. 5D). In ventral view (Fig. 8),

573 the squamosal forms the anterior, dorsal and lateral walls of the periotic fossa. This fossa is deep,

574 with a transverse diameter extending from the base of the falciform process to the anteromedial

575 margin of the external auditory meatus. The external auditory meatus is a deep excavation

576 located in the posterolateral margin of the skull, dorsal to the postglenoid process. The posterior

577 margin is almost straight and defined by the posterior meatal crest that makes contact along a

578 straight and observable suture (state SR3) with the compound posterior process of the

579 tympanoperiotic. The medial apex of the external auditory meatus forms the pointed spiny

580 process of the squamosal, which extends anteromedially to overhang the lateral margin of the

581 periotic fossa. The ventral surface of the external auditory meatus is concave, and the surface of

582 its medial half is deep with smooth bone texture correlated with the position in vivo of the sac-

583 shaped tympanic membrane or "glove finger" (Buono, 2014). The falciform process is better

584 preserved in MLP 5-15; it is robust and posteromedially oriented. Medial to the falciform process

585 there is a broad and deep notch (width $=12 \mathrm{~mm})$ (=foramen pseudovale) posteriorly oriented (as

586 is observed in extant balaenids) for the passage of the mandibular branch of the trigeminal nerve

587 (V3). The glenoid fossa is almost flat to slightly concave and broad, and anteromedially defined

588 by a distinct ridge as in extant balaenids (e.g. Eubalaena australis CNPMAMM 748, MLP

589 1508). The high position of the orbits with respect to the postglenoid process (viewed laterally)

590 indicates that the position of the glenoid fossa must be posterior to the postorbital process of the 
591 frontal.

592 Parietal. In dorsal view (Fig. 4), the parietals are not in contact on the midline of the 593 vertex of the skull, but due to their anteriorly extended position a small portion is visible lateral 594 to the cranial vertex. In lateral view (Fig. 5), the parietal forms part of the lateral skull wall and 595 contacts the frontal anteriorly forming the coronal suture. The latter begins at the level of the 596 anterior apex of the supraoccipital, continuing posteriorly above the posterodorsal margin of the 597 frontal, then bends ventrally and ends at a well-developed notch. Posteriorly, the parietal contacts 598 the squamosal via a parieto-squamosal suture that runs dorsoventrally in the medial wall of the 599 temporal fossa The parietosquamosal suture has a posteriorly convex outline and forms a salient

600

601

602

603

604

605

606

607

608

609

610

611

612

613

crest. Dorsally, the parietal contacts the supraoccipital and contributes to the laterally protruding nuchal crest. The anterodorsal portion of the parietal projects on the posteromedial corner of the supraorbital process of the frontal. In this region the external surface of the parietal is strongly concave (transversely) and smooth.

In ventral view (Fig. 7), the parietal has a small exposure in the posteromedial portion of the optic canal where it contacts anteriorly with the frontal and posteriorly with the squamosal. In this region, the parietal is partly overlapped by the alisphenoid and forms a well-defined notch anteriorly, and a pointed lateral projection posteriorly.

Frontal. The frontals form the interorbital region, the supraorbital process of the frontal and the orbital wall. In dorsal view (Fig. 4), exposure of the frontals in the vertex is clearly observed extending anteroposteriorly for $52 \mathrm{~mm}$. The anterior portion of the frontal is exposed due to the disarticulation of nasals, maxillae and premaxillae, exposing the ridges and grooves that characterize the rostrum-cranium interdigitation. In the anterodorsal surface of the frontal, there is a medial fossa for the reception of nasal bones, laterally bounded by a complex of 
614 longitudinal ridges that form the articulation surfaces for premaxillae and maxillae (Fig. 9A and

615 B). The sutural surface of the frontal for the maxilla suggest the presence of a broadly triangular

616 ascending process of the maxilla (a condition shared with extant balaenids; Marx et al., 2013)

617 (Fig. 9D). Posterior to this region, the dorsal exposure of the frontal presents a rounded anterior

618 margin with a low but distinct ridge (Fig. 9B and D), also observed in Eubalaena spp. which

619 does not correspond to the posteriormost extension of the fronto-maxilla suture. This ridge, here

620 named frontal ridge (new term), is not considered as an anterior extension of the orbitotemporal

621 crest, as is observed in other mysticetes (e.g., Parietobalaena and Pelocetus). Dissection of the

622 temporalis muscle in Eubalena australis (CNPMAMM 748; Supplementary figure 1) show that

623 this muscle extends anteriorly until the anteriormost extension of the fronto-parietal suture, but

624 never reaches the frontal ridge. In addition, dissection of facial and nasal muscles does not show

625 that any of these muscles are attached with this ridge (Buono et al., 2015). In the region of

626 contact between the right and left frontal the surface of the bone is rugose, which could

627 correspond to the interfrontalis suture. The frontal gradually slopes ventrolaterally from the

628 vertex of the skull forming the supraorbital process. It is principally developed in the transverse

629 plane. The supraorbital process is longer transversely than anteroposteriorly: the transverse width

630 of the supraorbital process is about twice its anteroposterior length (Table 2). The anterior

631 margin is straight and forms an acute angle $\left(67^{\circ}\right)$ with the sagittal plane of the skull, while its

632 posterior margin is slightly concave. The dorsal surface of the process is roughly flat. In lateral

633 view (Fig. 5), the dorsal margin of the orbit opens laterally at a level dorsal to that of the

634 zygomatic process of the squamosal; the vertical distance between the dorsal margin of the orbit

635 and the ventral margin of the postglenoid process is $185 \mathrm{~mm}$. The antero-posterior length of the

636 orbit (measured between the apex of the preorbital and postorbital process) compared with 
637 bizygomatic width is $23 \%(\mathrm{OL} / \mathrm{BW})$, close to the toothed archaic mysticete Aetiocetus weltoni 638 (27\%, Deméré \& Berta, 2008 P: 323), but greater than in extant balaenids such as Eubalaena 639 australis and E. glacialis (mean value of $\mathrm{OL} / \mathrm{BW}=9 \%, \mathrm{~N}=10$; supplementary information Table 640 S2). The dorsal margin of the orbit is thickened and formed anteriorly by the incomplete 641 preorbital process and posteriorly by the postorbital process. The postorbital process is robust 642 and posteriorly directed in dorsal view, with a rounded outline. In lateral view, the 643 anteroposterior axis of the orbit is parallel to the horizontal plane of the skull. The ventral margin 644 of the orbit is not preserved due to the lack of the maxilla and jugal. The orbitotemporal crest is 645 present on the anterodorsal surface of the supraorbital process of the frontal but it is poorly 646 developed.

647 In dorsal view, the supraorbital margin of the orbit is roughly straight while it is dorsally 648 concave in lateral view. The external surface of the frontal is smooth in the interorbital region 649 and in the dorsal surface of the supraorbital process, however in the supraorbital margin of the 650 orbit the bone is rugose/porous indicating the presence of cartilage, as has been observed in 651 calves of E. australis (CNPMAMM 748 and other specimens dissected by M.R.B.). In ventral 652 view (Fig. 7), the optic foramen, the exit of the optic cranial nerve (II), is a notch that opens 653 lateral to the basisphenoid-presphenoid fissure. From that point, the optic canal, the sulcus for the 654 transmission of the optic nerve (II), extraocular muscles and blood vessels, extends laterally 655 along the posteroventral margin of the supraorbital process. The optic canal of Morenocetus does 656 not occupy the entire anteroposterior length of the ventral surface of the supraorbital process.

657 Instead, it is developed in the posterior two thirds of the supraorbital process $(\sim 70 \%$ of the 658 anteroposterior length of the process). It is bounded posteromedially by the parietal. The optic 659 canal is deep and narrow in its medial portion (width=35mm) and widens laterally (width= 
$66050 \mathrm{~mm})$. The anterior margin of the optic canal is completely preserved in its lateral half;

661 therefore we infer that the canal remained open ventrally along its entire length. The dorsal wall

662 of the optic canal is pierced by a large single ethmoidal foramen for the exit of the ethmoidal

663 nerve and blood vessels, and by small frontal foramina. The presence of the orbitosphenoid in the

664 optic canal is difficult to establish due to tightly closed sutures of this element with the frontal

665 and presphenoid. The ventral surface of the frontal presents two well defined and symmetrical

666 fossae placed in the contact between the presphenoid and the frontal, and dorsal to the level of

667 the supraorbital process of the frontal, which might correspond to the common meatus.

668 Periotic. Both periotic bones are preserved in situ sutured against the squamosal. The

669 left periotic is completely preserved unlike the right one which is broken at the anterior and

670 lateral tuberosity. In ventral view (Fig. 10), the anterior process is shorter than the

671 anteroposterior length of the pars coclearis, and presents a rounded anterior apex (Table 3). The

672 small anterior pedicle for the articulation of the tympanic bulla is located on the ventral surface

673 of the anterior process, and it is defined by a sharp crest flanked by two furrows. Lateral to the

674 anterior process, the body of the periotic, lateral to the pars cochlearis is hypertrophied

675 (maximum transverse width of the body of periotic is $62 \%$ larger than the maximum width of

676 pars cochlearis, Table 3), and develops ventrolaterally with a rounded lateral margin. There is no

677 distinct lateral tuberosity. Posteromedially, in the body of the periotic, the mallear fossa is

678 represented by a poorly defined concavity. The site of attachment of the tensor tympani muscle is

679 inferred to be a slight depression medial to the anterior process, with a dorsal extension of the

680 muscle attachment on the medial side of the anterior process via a distinct ridge (Fig. 10B). The

681 pars cochlearis is anteroposteriorly oriented, with the lateral margin forming an acute angle with

682 the sagittal plane of the skull. The medial face is defined by small bone projections that give it an 
683 irregular profile. The ventral face of the pars cochlearis is strongly convex in the transverse plane 684 and longer than wide $(\mathrm{W} / \mathrm{L}=0.58)$. The promontorial groove is a shallow and anteromedially 685 developed sulcus in the ventromedial surface of the pars coclearis. A small and oval foramen of 686 uncertain homology opens in the ventral surface of the periotic, anterior to the mallear fossa. The 687 compound posterior process of the tympanoperiotic is posterolaterally oriented forming an 688 obtuse angle $\left(\sim 115^{\circ}\right)$ with the anteroposterior axis of the pars cochlearis. Ventromedially, it 689 presents a well developed posterior pedicle for the articulation of the tympanic bulla. The dorsal 690 face of the process is tightly articulated with the squamosal along its entire length; contacts the 691 squamosal anteriorly through the posterior meatal crest forming a groove; contacts the 692 exoccipital posteriorly through a visible suture (state SR4); and contacts the squamosal laterally 693 through an interdigitated suture. The medial margin of the posterior process is concave. The 694 stylomastoid fossa is deep and defined by ventral and dorsal margins; it extends from the 695 posterior face of the pars cochlearis onto the dorsomedial surface of the base of the posterior 696 process.

In posterior view (Fig. 11A and B), the fenestra rotunda is higher than wide (Table 3),

698

699

700

701

702 703

704 705 and reniform in outline. In the medial margin of the fenestra rotunda are medial and lateral sulci separated by a rounded crest. Within the aperture of the fenestra rotunda, the basal part of the laminar gap for the basilar membrane is visible (Geisler \& Luo, 1996). The caudal tympanic process is the posteriormost point on the pars cochlearis, lateral to the fenestra rotunda and medial to the facial sulcus. It is, thin, triangular in posteromedial view and the dorsal surface is concave and posteroventrally oriented. The dorsal surface of the caudal tympanic process forms the floor of the stapedial muscle fossa, which is deep and oval-shaped. In lateral view part of the stapes can be seen in situ, occluding the aperture of the fenestra ovalis. The facial sulcus for the 
706

707

708

709

710

711

712

713

714

715

716

717

718

719

720

721

722

723

724

725

726

727

728

ventral path of the facial nerve (VII) continues as a deep groove onto the ventromedial side of the posterior process of the periotic. In dorsomedial view (Fig. 11C and D ), the endocranial foramina are defined by the elevated dorsomedial rim of the promontorium. Anteriorly is the internal auditory meatus that is divided by a low transverse crest into two foramina: the smaller and circular proximal opening of facial nerve canal (VII); and the larger and circular foramen for the vestibulocochlear cranial nerve (VIII) (dorsal vestibular area). Both foramina are aligned anteroposteriorly. Posterior to the internal auditory meatus, is the small and rounded aperture for the cochlear aqueduct. The aperture for the cochlear aqueduct and the aperture for the endolymphatic duct are not aligned anteroposteriorly. Dorsolateral to the internal acoustic meatus is a well defined but shallow suprameatal fossa. This fossa is lined laterally by a well developed crest that corresponds to the superior process.

\section{Comparative skull morphology}

One of the most distinctive features of the skull of Morenocetus is the orbital region that clearly differs from other balaenids. Morenocetus has a transversely short and slightly ventrolaterally-oriented supraorbital process of the frontal, whereas in Balaenula, Balaenella, Balaena and Eubalaena the supraorbital process is transversely long and strongly directed posteroventrally. The orbit of Morenocetus is positioned relatively high on the cranium (viewed laterally, half the vertical distance between the vertex of the skull and the base of the postglenoid process), unlike other balaenids where the orbit is positioned lower on the cranium (see discussion). The optic canal is developed only in the posterior two thirds of the supraorbital process, unlike the condition observed in the other balaenids where the optic canal occupies the entire anteroposterior width of the ventral surface of the process. In addition, the canal remains open along its entire length, whereas in Balaena mysticetus, Balaenula sp. and Eubalaena spp. 
729 the optic canal is ventromedially enclosed. Another striking character is the lack of a narial

730 process of the frontal separating the posterior portions of the nasals as observed in all remaining

731 balaenids.

732 The temporal region of Morenocetus also differs in morphology from other balaenids. In

733 Morenocetus the parietal forms an extensive area of the external surface of the braincase,

734 covering the posteromedial corner of the supraorbital process of the frontal and, in lateral view,

735 the frontal-parietal suture is concave posteriorly as in Balaenula astensis. In contrast, in Balaena

736 and Balaenella the spreading of the parietal is less pronounced and the suture between the frontal

737 and parietal is almost straight. In Eubalaena australis the spreading of parietal is very

738 pronounced with a well-defined anteromedial projection, and the fronto-parietal suture is

739 sinusoidal. The squamosal prominence is present but less developed than in Eubalaena spp. and

740 Balaena mysticetus. The apex of the zygomatic process is ventrally deflected as in Balaenula sp.,

741 but unlike the remaining balaenids. The postglenoid process is ventrally oriented in posterior

742 view whereas in Balaena mysticetus, Balaenula astensis, and Eubalaena it is ventromedially

743 directed.

744 The occipital region of Morenocetus differs from other balaenids by having: an occipital

745 shield that is long and triangular-shaped with straight lateral margins (unlike other balaenids

746 where the lateral margins are convex); and a short exposure of the squamosal lateral to the

747 exoccipital (all other balaenids have a broadly exposed squamosal lateral to the exoccipital).

748 In the basicranium of Morenocetus, the pterygoid sinus fossa is located anterior to the

749 foramen pseudovale unlike the condition in all other balaenids where the pterygoid sinus fossa

750 extends to a point approximately in line with the anterior edge of the foramen pseudovale. The

751 periotic of Morenocetus has a short anterior process (similar to Peripolocetus) whereas in 
752 Balaenula sp., Balaena mysticetus and B. ricei, as well as extant species of Eubalaena, the 753 anterior process is longer than the pars cochlearis. Morenocetus lacks a lateral tuberosity of the

754 periotic (similar to Peripolocetus) whereas in remaining balaenids the lateral tuberosity is

755 distinctly hypertrophied. The foramina of the internal acoustic meatus and aperture for the 756 cochlear aqueduct are anteroposteriorly aligned unlike Balaena mysticetus and Balaenula sp. The

757 suprameatal fossa is not hypertrophied in Morenocetus, a feature shared with Peripolocetus, but 758 unlike Balaena and Eubalaena. The compound posterior process is oriented posterolaterally 759 (forming an obtuse angle; $\sim 115^{\circ}$ ) with respect to the long axis of the anterior process (with the 760 periotic in situ), a condition shared with Balaena and Peripolocetus, but unlike Eubalaena, 761 Balaenella and Balaenula where it forms a right angle with the anterior process.

762 Phylogenetic analysis

763 Morphological data. The equal weight parsimony analysis of the morphological data partition 764 recovered 3 most parsimonious trees (MPT) of 842 steps [consistency index $(\mathrm{CI})=0.41$; 765 retention index $(\mathrm{RI})=0.72]$ (Fig. 12A). Application of IterPCR procedure over the entire set of 766 MPTs did not identify any taxa as unstable.

The results of our morphological phylogenetic analysis are congruent with the results of

768

769

770

771

772

773

774

previous morphological and total evidence studies in recovering Balaenidae as the sister group of Plicogulae (e.g. Fordyce \& Marx, 2013; Marx \& Fordyce, 2015; Gol'din \& Steeman, 2015).

Within chaeomysticetes, Balaenidae is recovered as a well supported group based on the following synapomorphies: posterior border of zygomatic process of the squamosal and lateral edge of exoccipital confluent (67: 1); zygomatic process of squamosal anterolaterally directed (86: 2); squamosal higher than long (92:1); body of periotic lateral to pars cochlearis hypertrophied lateroventrally (146:1); lateral furrow on the tympanic bulla oriented 
775 anteroventrally (178:1); lack of a crest connecting medial and lateral lobes of the tympanic bulla

776 (188:1); anteriormost point of the involucral ridge in line with the anterior border of the bulla

777 (189:1).

778 In contrast to the phylogenetic analysis of Marx \& Fordyce (2015), and in agreement

779 with Gol'din \& Steeman (2015), Peripolocetus is recovered as the earliest diverging balaenid.

780 Contrary to previous interpretations of Morenocetus as a taxon deeply nested within Balaenidae

781 (Bisconti 2000, 2005), forming a polytomy at the base of Balaenidae (Churchill, Berta \&

782 Deméré, 2012), or even outside Balaenidae (Bisconti, Lambert \& Bosselaers, 2017),

783 Morenocetus was estimated as sister to all balaenids more crownward than Peripolocetus in all

784 MPTs. Morenocetus possesses several features that unequivocally identify it as a balaenid: the

785 posterior margin of the zygomatic process of squamosal and lateral edge of the exoccipital

786 forming a continuous lateral skull border (character 67: 1); anterolaterally directed zygomatic

787 process of the squamosal (character 86: 2); squamosal that is higher dorsoventrally than long

788 anteroposteriorly (character 92: 1); and the body of the periotic lateral to the pars cochlearis is

789 laterally and ventrally hypertrophied (character 146: 1). The recent hypothesis that Morenocetus

790 falls outside Balaenidae sensu stricto (Bisconti, Lambert \& Bosselaers, 2017) is not supported by

791 our results. The latter authors' phylogenetic hypothesis rests on 17 putative synapomorphies

792 (only three unambiguous), none of which can be scored in Morenocetus because they are

793 characters of bones currently unknown for this taxon (tympanic bulla, rostrum, mandible and

794 vertebrae).

795 Morenocetus and Peripolocetus share a combination of characters in the periotic that,

796 according to this analysis, are interpreted as plesiomorphic: anterior process of the periotic

797 shorter than the anteroposterior length of the pars cochlearis (character 139: 0); lack of a lateral 
798 tuberosity of the periotic (character 144:0); suprameatal area of the periotic not hypertrophied

799 (character 162: 0); and compound posterior process of the tympanoperiotic oriented

800 posterolaterally with respect to the longitudinal axis of the anterior process (character 170:0).

801 However, Morenocetus is more specialized than Peripolocetus in having a zygomatic process of

802 the squamosal dorsoventrally expanded (character 85:1); a dorsal extension of the tensor tympani

803 on the medial side of the anterior process (character 149:1) and a narrow exposure of the

804 squamosal lateral to the exoccipital (character 95:1). The incompleteness of the Peripolocetus

805 holotype prevents a more detailed comparison with Morenocetus. Although IterPCR analysis did

806 not identify Peripolocetus or Morenocetus as unstable taxa, it must be noted that the

807 completeness of character scoring in these taxa is relatively low (77\% and 55\% missing data,

808 respectively) and that the branch support for the node from which Peripolocetus and

809 Morenocetus diverge is low. Thus, more information provided by new specimens of

810 Peripolocetus (Deméré \& Pyenson, 2015) as well as a new late Miocene balaenid from

811 Argentina (Buono, 2014) might change the proposed phylogenetic position of these taxa.

812 One synapomorphy supported the Morenocetus + Balaenula + Balaenella + Balaena +

813 Eubalaena clade: zygomatic process of squamosal higher dorsoventrally than wide transversely

814 (85:1). In Peripolocetus the zygomatic process is broken and the morphology of the base

815 suggests that it is not dorsoventrally expanded. In contrast, the zygomatic process of

816 Morenocetus was reassessed in this analysis based on our study of the referred specimen (MLP

817 5-15). In this taxon, as well as in remaining balaenids, the zygomatic process is dorsoventrally

818 expanded.

819 Balaenula astensis was recovered as the sister taxon of the clade including Balaenula sp.,

820 Balaenella, Balaena and Eubalaena based on the following synapomorphies: width of the 
821 supraorbital process of the frontal more than twice the length above the orbit $(37: 2)$; posterior

822 portion of the nasals separated posteriorly along the cranial midline by narial process of frontal

823 (66:0); lack of paired tubercles on the supraoccipital (99:0); compound posterior process of the

824 periotic oriented at a right angle to the axis of the anterior process (170:1, with reversal to the

825 state 0 in Balaena mysticetus and B. montalionis). This sequence of clade divergence differs

826 from Bisconti (2005) Churchill, Berta \& Deméré (2012), Marx \& Fordyce (2015) and Bisconti,

827 Lambert \& Bosselaers (2017). The paraphyly of Balaenula spp. reflects the need for a modern

828 thorough anatomical description and taxonomic revision of specimens referred to this genus. The

829 re-interpretation of many characters of the vertex of Balaenella (Marx \& Fordyce, 2015) and the

830 increased taxonomic sampling of balaenids (this analysis) results in a new phylogenetic position

831 of Balaenella supported by: anterior edge of supraorbital process posteriorly oriented (character

832 31:1) and orbital rim thickened with a rounded lateral surface (character 40: 2). Finally, a clade

833 including a polytomy of Balaena and a Eubalaena spp. clade is supported by the following

834 synapomorphies: parieto-squamosal suture forms a crest (93:1); compound posterior process of

835 the periotic not exposed on lateral skull wall (172:0); and well defined transverse creases on the

836 dorsal surface of the involucrum of the tympanic bulla (191: 1). The Eubalaena clade is

837 diagnosed by one synapomorphy: foramen pseudovale raised above the lateral portion of the

838 squamosal (119:1). The relationships amongst Eubalaena species are resolved, with E. belgica

839 placed as sister to a clade including E. glacialis, E. shinshuensis, E. japonica and E. australis. In

840 agreement with Churchill, Berta \& Deméré (2012), E. japonica and E. australis were recovered

841 as sister taxa based on one synapomorphy: body coloration with the presence of a dorsal blaze

842 (256:1). This analysis failed to resolve relationships within Balaena, but its monophyly is

843 supported by one synapomorphy: portion of rostrum anterior to nasals raised above the level of 
844 the supraoccipital $(2: 2)$.

845 The implied weight analysis $(\mathrm{K}=3)$ results in four most parsimonious trees with a fit of

846 83.13. The strict consensus tree depicts Morenocetus forming a clade with Peripolocetus (Fig.

847 12B). Unlike equal weight parsimony analysis, the internal relationships of remaining balaenids

848 were not more clearly established. The implied weight analyses with $K=6$ and $K=10$ (six most

849 parsimonious trees; fit of 54.73 and 37.82, respectively) result in the same topology obtained

850 under equal weight analysis, except in the recovery of Morenocetus in a basal polytomy with

851 Peripolocetus and a clade of all other balaenids.

852 Combined data. The parsimony analysis of the combined matrix in TNT resulted in 24 trees

853 with a tree length of 7603 . The total-evidence analysis does not result in a better resolution of

854 relationships within Balaenidae (Supplementary figure 2).

855

856 DISCUSSION

857 Specimens referred to Morenocetus by Cabrera (1926)

858 In the original description of Morenocetus parvus, Cabrera (1926) referred other

859 materials to this species, two of which (i.e. MLP 5-30 four cervical vertebrae and MLP 5-21 a

860 mandible) are not figured. As has been previously mentioned, the cervical vertebrae were not

861 located in the La Plata Museum collection and the collagen and nitrogen analysis of the

862 mandibles of MLP 5-21 indicate that this specimen is, at least, not Miocene, and therefore could

863 not be confidently referred to Morenocetus parvus.

864 The specimen MLP 5-21 is clearly identified as a Balaenidae based on the twisted

865 anterior end of the mandible and the presence of a mylohyoidal sulcus. One of the most

866 conspicuous characters of this specimen is the presence of a very broad coronoid process, which 
867 is very similar to neonate and juvenile specimens of E. australis. The morphology of the

868 coronoid region of MLP 5-21 has been discussed in Marx et al. (2013) in order to shed light on

869 the debated relationship between balaenids and Caperea. In this sense, the coronoid morphology

870 observed in the balaenid indet. MLP 5-21 and juvenile specimens of Eubalaena australis are

871 very different to those observed in Caperea juveniles (Marx et al., 2013). Although MLP 5-21

872 cannot be referred to Morenocetus, it is clearly a balaenid with a coronoid morphology that could

873 be considered close to Eubalaena juveniles, and completely different to Caperea, giving

874 additional support to the hypothesis that neobalaenines are not closely related to balaenids.

\section{Orientation of the skull}

The orientation of the skull of extinct balaenids has been problematic due to the arching

877 of the rostrum. To this it must be added that, in most of the fossil balaenid specimens, the

878

rostrum is not preserved. Incorrect skull orientation in the past may have misled some character

interpretations and, consequently, their scoring for phylogenetic analysis. Cranial reconstructions

based upon application of the proposed landmarks are summarized in Fig. 13A. The correct

orientation of the skull affects the topography of bones and sutures in the temporal and orbital

region, and also the reconstruction of rostrum shape. The orientation of the squamosal depends

strongly on the orientation of the cranium as a whole. Among balaenids, the squamosal is

posteriorly directed in Balaena species whereas it is anteriorly directed in Morenocetus,

Balaenula, and Eubalaena. In Balaenella the squamosal has been traditionally interpreted as

posteriorly directed (and hence this character has been proposed to support a close relationship

between Balaena and Balaenella) (Bisconti, 2005; Churchill, Berta \& Deméré, 2012). A re- 
Another interesting result of the orientation proposed herein relates to the orbit location.

891 The orbits of Morenocetus were located approximately at half the vertical distance between the

892 vertex of the skull and the base of the postglenoid process (Fig. 13A). This position is relatively

893 high in comparison to other balaenids, and similar to that of Balaenopteridae and Caperea. Thus,

894 in Balaenella, Balaenula astensis, Balaenula balaenopsis, extant Eubalaena and Balaena

895 mysticetus the orbits are placed at $2 / 3$ the vertical distance from the vertex of the skull to the base

896 of the postglenoid process (Fig. 13B and C). In addition, the position of the postorbital process of

897 the frontal is very close to the the zygomatic process of the squamosal. As orbits have not been

898 preserved in Peripolocetus, it is not clear if this condition is unique to Morenocetus among stem

899 balaenids. Also in Morenocetus, the orbits are more laterally directed, which differs from the

900 posteroventral direction of the orbits in Pliocene-Recent balaenids.

901 Noteworthy changes in the orbit orientation appear tightly coupled to an increase in the

902 arching of the rostrum and the vertical orientation of the occipital shield. The reconstruction of

903 the rostrum of Morenocetus suggests it is moderately arched dorsoventrally while in extant

904 balaenids it is strongly arched dorsoventrally (Fig. 13). In the same way, changes of the vertical

905 orientation of the occipital shield are evident in the skull when viewed laterally. In Morenocetus

906 the occipital shield is oriented forming an acute angle with the anteroposterior axis of the skull

$907\left(\sim 25^{\circ}\right)$ while in extant balaenids, the occipital shield is more vertically oriented, this angle being $908 \sim 35^{\circ}$.

909 The evolution of skull structure in balaenids, characterized by a general trend toward the 910 arching of the skull, has functional implications for vision. Experimental and behavioral

911 observations on both odontocetes and mysticetes demonstrate that, contrary to traditional

912 hypotheses (Weber, 1886; Walls, 1942), vision plays an important role for orientation and 
913 navigation, coordination of group movements, identification of conspecific individuals, and

914 communication (Madsen \& Herman, 1980). In Cetacea field of vision is permitted by smooth

915 eyeball movements by means of completely developed oculomotor muscles and nerves (Madsen

$916 \&$ Herman, 1980; Dawson, 1980) and fat surrounding the eyeballs (Ninomiya \& Yoshida, 2007;

917 Buono, Fernández \& Herrera, 2012). The eyeball movements, coupled with a peculiar retinal

918 organization with two best vision areas, compensate for the restricted mobility of the head of

919 cetaceans and provide acute vision in various parts of the visual field (Mass \& Supin, 1995;

920 1997). Reconstruction of the Morenocetus skull, and comparison with the skull profile of more

921 advanced balaenids, indicates that the increase in skull arching throughout Balaenidae evolution

922 would have reduced the field of vision if the bony orbits were to remain in a high position on the

923 cranium, as exemplified by Morenocetus. A functional resolution to compensate for this trade-off

924 could have been the ventral displacement of the orbits and eyeballs in crown Balaenidae.

Morenocetus: a primordial balaenid?

With an early Miocene age, Morenocetus is the oldest balaenid so far reported with the potential to provide insights into the origin of specialized morphology of right whales. Morenocetus exhibits primitive characteristics that support its basal position within balaenids, 930 such as a short and rounded anterior process of the periotic; lack of a lateral tuberosity and a 931 hypertrophied suprameatal area, a compound posterior process of the tympanoperiotic oriented

932 posterolaterally with respect to the longitudinal axis of the anterior process, an optic canal 933 ventrally open; a pterygoid sinus fossa extending anterior to the foramen pseudovale, and a

934 foramen pseudovale not raised above the ventral surface of the squamosal. In addition, 935 Morenocetus clearly differs from geologically younger and more crownward balaenids (i.e. 
936 Balaenula, Balaenella, Balaena and Eubalaena), in having a relatively narrow and short

937 supraorbital process and in the lack of a narial process separating the posterior margins of the

938 nasals, thus supporting its early divergence within balaenids.

939 Yet, although Morenocetus possesses some primitive features of the cranium, it exhibits

940 derived morphology uniquely shared with other balaenids and rather disparate from all other

941 chaeomysticetes. The periotic morphology clearly differs from described stem Chaeomysticeti

942 and closely resembles modern right whales in the presence of a hypertrophied body of the

943 periotic, an indistinct mallear fossa, and a distinct ridge delimiting the insertion surface for the

944 tensor tympani muscle. In addition Morenocetus shares with modern balaenids a dorsoventrally

945 expanded zygomatic process of the squamosal, a parieto-squamosal suture shaped like a crest, a

946 foramen pseudovale located within the squamosal and opening posteriorly, and a short ascending

947 process of the maxilla. Given the geologic antiquity of Morenocetus, it is clear that specialized

948 morphological traits that characterize all living balaenids were acquired early in the evolutionary

949 history of the clade, without significant changes between the early Miocene and Recent.

950 The geologic age and phylogeny of Morenocetus has bearing on the broader evolution

951 of the major mysticete clades. The origin of living families of baleen whales has been estimated

952 around the late Oligocene based on molecular divergence data (Steeman et al., 2009; Marx \&

953 Fordyce, 2015; McGowen, Spaulding \& Gatesy, 2009). However the fossil record of mysticetes

954 reveals an important late Oligocene-early Miocene gap (Fig. 14). Mysticete fossils from this

955 stratigraphic interval are globally scarce (Table 4). With an early Burdigalian age, Morenocetus

956 is among the oldest crown Mysticeti known, reinforcing the idea that the timing for the

957 diversification for crown lineages must have occurred no later than the late Oligocene.

958 Strikingly, stem balaenopteroids are better represented than stem balaenids for the late 
959 Oligocene-early Miocene (Fig. 14). It is not clear if this gap in the balaenid fossil record is real

960 or reflects uneven sampling. Molecular sequence data have been used to estimate that balaenids

961 diverged during the late Oligocene (29-26 Ma, Steeman et al., 2009; 23 Ma, Marx \& Fordyce,

962 2015), implying that fossils of stem balaenids should occur in strata dating to this time. The

963 study of late Oligocene specimens, previously reported as putative balaenids (Fordyce, 2002),

964 may help to fill the gap in the evolutionary history of the group and confirm whether all stem

965 balaenids were characterized by the surprisingly modern-looking morphology described here in

966 Morenocetus.

967

968 Evolution of Balaenidae body size

969 The estimated total length of Morenocetus $(<6 \mathrm{~m})$ is smaller than that obtained in

970 Pliocene balaenids (e.g., Balaenella, Balaenula astensis, Balaena montalionis and Eubalaena

971 shinshuensis) (6-12 m). These estimated total lengths approximate the body length estimates of

972 Bisconti, Lambert \& Bosselaers (2017) for Morenocetus (4.8-6.2m), Balaenula astensis (4.8-

$9736.4 \mathrm{~m})$, Balaena montalionis (7.5-10m), Eubalaena shinshuensis (9.6-12.8 m), Balaenella (3.3-

$9744.4 \mathrm{~m})$ and Eubalaena ianitrix $(5-7 \mathrm{~m})$. The most remarkable differences between our estimates of

975 body length and those of Bisconti, Lambert \& Bosselaers (2017) are in Balaenella (3.3-4.4 m)

976 and Eubalaena ianitrix $(5.0-7.0 \mathrm{~m})$. The previous estimate of body length in Balaenella is

977 probably erroneous because it is based on skull length (Bisconti, Lambert \& Bosselaers, 2017),

978 which may yield underestimated values due to uncertain orientation of the cranium and

979 incomplete preservation of the rostrum. In the case of Eubalaena ianitrix, the discrepancy in

980 body length estimates could be related to the different approaches used in each analysis. The

981 estimated body length for Eubalaena ianitrix by Bisconti, Lambert \& Bosselaers (2017), has a 
982 value very close to the body length estimated in this study for Morenocetus. However,

983 comparisons of the byzygomatic width (BZW) of both taxa, shows an important difference in

984 skull size (Morenocetus $\mathrm{BZW}=570 \mathrm{~mm}$; Eubalaena ianitrix BZW $=1660 \mathrm{~mm}$ ). It is unlikely

985 that both taxa with such disparity in skull size occupied a similar range of body length.

986 Currently, there are no published equations that are based on a mysticete cranial

987 measurement dataset including a large sample of balaenid specimens. It is outside the aims of 988 this study to assemble such a dataset. We therefore used two different published equations by 989 Pyenson \& Sponberg (2011) and Lambert et al. (2010) to estimate body size. As discussed by 990 Bisconti et al (2017) there are some limitations to these approaches due to inadequate sampling 991 of total length + cranial metrics data from Balaenidae. Nonetheless, because our results using 992 two different approaches are very close (one of them based on regression equations including 993 extant balaenids; Lambert et al., 2010), and also our estimations yield similar results (with 994 some exceptions) and generally approximate the estimates obtained by Bisconti, Lambert \& 995 Bosselaers (2017) using different proxies (i.e. supraoccipital length; skull/body ratio), we think 996 that our body size estimates from these two approaches are plausible.

997 Traditionally, an increase in body size has been cited as a major unidirectional 998 evolutionary trend within Mysticeti (McLeod, Whitmore \& Barnes, 1993; Fordyce \& Barnes, 999 1994; Fordyce \& Muizon, 2001; Sanders \& Barnes, 2002; Pyenson \& Sponberg, 2011; Pyenson 1000 \& Vermeij, 2016; Tsai \& Kohno, 2016; Slater et al., 2017). However, optimization on recently 1001 estimated phylogenies suggest that considering a gradual increase in body length, from small1002 toothed mysticetes to large body size in Chaeomysticeti, is an oversimplification (Fitzgerald, 2010; Tsai \& Kohno 2016). Among balaenids, the oldest record of gigantism is represented by 1004 the late Miocene-early Pliocene balaenid Eubalaena shinshuensis. In the particular case of 
1005 balaenids, a broad outline of body size evolution suggests that the primitive condition was a

1006 relatively small body length represented by Morenocetus (Fig. 15). Although the body length for

1007 the middle Miocene Peripolocetus cannot be estimated, comparable preserved elements of the

1008 latter taxon and Morenocetus suggests Peripolocetus had a body length similar to that of

1009 Morenocetus. Throughout the Pliocene, fossil records document the co-occurrence of balaenid

1010 taxa of different sizes ranging approximately from 6 to $12 \mathrm{~m}$ with the last occurrence of small

1011 forms (i.e. Balaena montalionis) by the end of the Pliocene. This pattern is consistent with a

1012 recent analysis of body size evolution in mysticetes, which suggested that the attainment of

1013 gigantic body sizes is a recent event (Plio-Pleistocene) in mysticete history (Slater et al., 2017).

1014 Pending issues

1015 Improvements to knowledge of balaenid evolution may be driven both by new

1016 discoveries in the field as well as by reexamination of fossils already in museum collections. In

1017 this sense, one of the most striking features of the fossil record of balaenids is the apparent

1018 scarcity of Miocene fossils. This contrasts with the large number of balaenopteroid mysticete

1019 taxa described from the Miocene, especially in the northern hemisphere. Is the sparse record of

1020 balaenids in the Miocene a real biological signal or is it merely an artifact of uneven collection

1021 effort? During the last century, richly fossiliferous marine Miocene strata of Patagonia, New

1022 Zealand and Australia have been scarcely prospected (e.g Fitzgerald, 2004; 2012; Buono et al.,

1023 2014; Boessenecker \& Fordyce, 2017). On the contrary, Northern Hemisphere Miocene strata

1024 have been extensively explored for fossil cetaceans since the first decades of the 20th Century

1025 (e.g. Barnes, 1976; Kellog, 1965, 1968, 1969).

1026 A possible scenario is that the scarce fossil record of balaenids reflects a real evolutionary

1027 pattern and that the comparatively low diversity of the group during the Miocene mirrors their 
1028 extant low diversity. The apparent increase of balaenid diversity during the early Pliocene

1029 (Kimura, 2009) should be cautiously interpreted as a biological signal, due to some historically

1030 significant European forms, including Balaenula balaenopsis and Balaena primigenia, needing

1031 modern taxonomic revisions.

1032 Acknowledgments

1033 We thank E. Crespo and N. Garcia (CESIMAR, Centro Nacional Patagónico), and C. W. Potter,

1034 D. J. Bohaska and N. D. Pyenson (National Museum of Natural History), R. E. Fordyce (Otago

1035 Museum), Marcelo Reguero and Alejo Scarano (Museo de La Plata) for allowing M. R. Buono

1036 and E. M. G. Fitzgerald to examine specimens in their care and for assistance during their visits.

1037 Juan Jose Moly and Leonel Acosta Burllaile (Museo de La Plata) are thanked for the preparation

1038 of the specimens. We thank F. Marx, R. E. Fordyce, M. Churchill and O. Lambert for providing

1039 photographs of balaenid specimens. We thank F. Marx and R. E. Fordyce for helpful discussions

1040 of Morenocetus and Balaenidae morphology. Dr. Eduardo Tonni is thanked for their help with

1041 collagen analysis of MLP 5-30. We are extremely grateful to the personnel and volunteers of the

1042 Stranding Network at Península Valdés (V. Rowntree, M. Sironi, M. Uhart, A. Chirife, M. Di

1043 Martino), Lucia Alzugaray, and H. Ruiz for their valuable help and support during dissections in

1044 the field and in the lab. M. T. Dozo (CENPAT-CONICET) is thanked for her assistance during

1045 this study. J. Sterli (Mef) is thanked for her assistance with the combined phylogenetic analysis.

1046 The authors are grateful to Jorge Velez-Juarbe, Robert Boessenecker and an anonymous

1047 reviewer and editor (J. Thewissen); their suggestions greatly improved the quality of this article.

1048 This contribution used TNT version 1.5, a program made freely available thanks to a subsidy by

1049 the Willi Hennig Society. This article is part of doctoral research of Monica R. Buono at

1050 Universidad de La Plata and Centro Nacional Patagónico (CENPAT-CONICET). 
1051

1052

1053

1054

1055

1056

1057

1058

1059

1060

1061

1062

1063

1064

1065

1066

1067

1068

1069

1070

1071

1072

1073

\section{References}

Ameghino F. 1906. Les formations sédimentaires du Crétacé supérieur et du Tertiaire de Patagonia, avec un paralèlle entre leurs faunes mammalogiques et celles de l'ancien continent. Anales del Museo Nacional de Buenos Aires 15:1-568.

Barnes LG. 1976. Outline of eastern North Pacific fossil cetacean assemblages. Systematic Zoology 25: 321-343.

Bisconti M. 2000. New description, character analysis and preliminary phyletic assessment of two Balaenidae skulls from the Italian Pliocene. Palaeontographia Italica 87:37-66.

Bisconti M. 2002. An early Late Pliocene right whale (genus Eubalaena) from Tuscany (Central Italy). Bollettino della Società Paleontologica Italiana 41:83-91.

Bisconti M. 2003. Evolutionary history of Balaenidae. Cranium 20:9-50. DOI: 10.1128/JVI.76.7.3382

Bisconti M. 2005. Skull morphology and phylogenetic relationships of a new diminutive balaenid from the lower Pliocene of Belgium. Palaeontology 48:793-816. DOI: 10.1111/j.1475-4983.2005.00488.x

Bisconti M, Lambert O, Bosselaers M. 2017. Revision of “Balaena” belgica reveals a new right whale species, the possible ancestry of the northern right whale, Eubalaena glacialis, and the ages of divergence for the living right whale species. PeerJ 5:e3464. DOI:

10.7717/peerj.3464Bouetel V. 2005. Phylogenetic implications of skull structure and feeding behavior in balaenopterids (Cetacea, Mysticeti). Journal of Mammalogy 86:139_ 146.

Boessenecker RW., Fordyce RE. 2017. Cosmopolitanism and Miocene survival of 
1074

1075

1076

1077

1078

1079

1080

1081

1082

1083

1084

1085

1086

1087

1088

1089

1090

1091

1092

1093

1094

1095

1096

Eomysticetidae (Cetacea: Mysticeti) revealed by new fossils from New Zealand. New Zealand Journal of Geology and Geophysics 8306:1-13. DOI:

10.1080/00288306.2017.1300176.

Buono MR, Fernández MS, Herrera Y. 2012. Morphology of the eye of the southern right whales (Eubalaena australis). Anatomical Record 295:355-368. DOI: 10.1002/ar.21541

Buono MR, Dozo MT, Marx FG, Fordyce RE. 2014. A Late Miocene potential neobalaenine mandible from Argentina sheds light on the origins of the living pygmy right whale. Acta Palaeontologica Polonica 59: 787-793. DOI: 10.4202/app.2012.0122

Cabrera A. 1926. Cetáceos fósiles del Museo de La Plata. Revista del Museo de la Plata 29:363411.

Churchill M, Berta A, Deméré T. 2012. The systematics of right whales (Mysticeti: Balaenidae). Marine Mammal Science 28:497-521. DOI: 10.1111/j.1748-7692.2011.00504.x

Cione AL. 1978. Aportes paleoictiológicos al conocimiento de la evolución de las paleotemperaturas en el área austral de América del Sur durante el Cenozoico. Aspectos zoogeográficos y ecológicos conexos. Ameghiniana 15:183-208.

Cione AL, Cozzuol MA, Dozo MT, Acosta Hospitaleche C. 2011. Marine vertebrate assemblages in the southwest Atlantic during the Miocene. Biological Journal of the Linnean Society 103:423-440. DOI: 10.1111/j.1095-8312.2011.01685.x

Coddington J, Scharff N. 1994. Problems with zero-length branches. Cladistics 10:415-423. DOI: 10.1111/j.1096-0031.1994.tb00187.x

Cuitiño JI, Dozo MT, del Río CJ, Buono MR, Palazzesi L, Fuentes S, Scasso RA. 2017. Miocene marine transgressions: sedimentary and paleontological records. In: Bouza P, Bilmes A, eds. Late Cenozoic of Península de Valdés, Patagonia Argentina: an interdisciplinary 
approach. Springer Earth System Sciences, 47-84. DOI: 10.1007/978-3-319-48508-9_3

1098

1099

1100

1101

1102

1103

1104

1105

1106

1107

1108

1109

1110

1111

1112

1113

1114

1115

1116

1117

1118

1119

Cuitiño JI, Pimentel MM, Ventura Santos R, Scasso RA. 2012. High resolution isotopic ages for the "Patagoniense" transgression in southwest Patagonia: stratigraphic implications. Journal of South American Earth Sciences 38:110-122. DOI:

10.1016/j.jsames.2012.06.008

Cuitiño JI, Ventura Santos R, Alonso Muruaga PJ, Scasso RA. 2015a. Sr-stratigraphy and sedimentary evolution of early Miocene marine foreland deposits in the northern Austral (Magallanes) Basin, Argentina. Andean Geology 42:364-385. DOI:

10.5027/andgeoV42n3-a05

Cuitiño JI, Scasso RA, Ventura Santos R, Mancini L. 2015b. Sr ages for the Chenque Formation in the Comodoro Rivadavia región (Golfo San Jorge Basin, Argentina): stratigraphic implications. Latin American Journal of Sedimentology and Basin Analysis 22:3-12.

Cummings WC. 1985. Right whales Eubalaena glacialis (Müller, 1776) and Eubalaena australis (Desmoulins, 1822). In: Ridgway SH, Harrison RJ eds. Handbook of marine mammals, Vol. 3: The Sirenians and baleen whales. Academic Press, London and Orlando, 275-301.Dawson WW. 1980. The cetacean eye. In: Herman LM, ed. Cetacean behavior. New York: John Wiley and Sons, 53-100.

Deméré T, Berta, A. 2008. Skull anatomy of the Oligocene toothed mysticete Aetiocetus weltoni (Mammalia; Cetacea): implications for mysticete evolution and functional anatomy. Zoological Journal of the Linnean Society 154:308-352.

Deméré TA, Pyenson ND. 2015. Filling the miocene 'balaenid gap'-the previously enigmatic Peripolocetus vexillifer Kellogg, 1931 is a stem balaenid (Cetacea: Mysticeti) from the middle Miocene (Langhian) of California, USA. Society of 
Vertebrate Paleontology, 75th Annual Meeting, Dalas, USA, 115.

1121

1122

1123

1124

1125

1126

1127

1128

1129

1130

1131

1132

1133

1134

1135

1136

1137

1138

1139

1140

1141

1142

Dunn RE, Madden RH, Kohn MJ, Schmitz MD, Strömberg CAE, Carlini AA, Ré GH, Crowley

J. 2013. A new chronology for middle Eocene-early Miocene South American Land

Mammal Ages. Geological Society of America Bulletin 125:539-555. DOI:

10.1130/B30660.1

Escapa IH, Pol D. 2011. Dealing with incompleteness: new advances for the use of fossils in phylogenetic analysis. Palaios 26:121-124. DOI: 10.2110/palo.2011.S02

Feruglio, E. 1949. Descripción geológica de la Patagonia 2. Buenos Aires: Yacimientos Petrolíferos Fiscales.

Fitzgerald EMG. 2004. A review of the Tertiary fossil Cetacea ( Mammalia ) localities in Australia. Memoirs of Museum Victoria 61:183-208.

Fitzgerald EMG. 2010. The morphology and systematics of Mammalodon colliveri (Cetacea: Mysticeti), a toothed mysticete from the Oligocene of Australia. Zoological Journal of the Linnean Society 158:367-476. DOI:10.1111/j.1096-3642.2009.00572.x

Fitzgerald EMG. 2012. Possible neobalaenid from the Miocene of Australia implies a long evolutionary history for the pygmy right whale Caperea marginata (Cetacea, Mysticeti ). Journal of Vertebrate Paleontology 32:976-980.

Fleagle JG, Bown TM. 1983. New primate fossils from late Oligocene (Colhuehuapian) localities of Chubut Province, Argentina. Folia Primatologica 41:240-266.

Flynn JJ, Swisher CC. 1995. Cenozoic South American Land Mammal Ages: correlation to global geochronologies. In: Berggren WA, Kent DV, Aubry MP, eds. Geochronology, time scales and global stratigraphic correlation. Society of Economic Mineralogists and Geologists Special Publication, 54:317-333. 
1143 Fordyce RE. 2002. Oligocene origin of skim-feeding right whales: a small archaic balaenid from

1144

1145

1146

1147

1148

1149

1150

1151

1152

1153

1154

1155

1156

1157

1158

1159

1160

1161

1162

1163

1164

1165

New Zealand. Journal of Vertebrate Paleontology 22:54(A).

Fordyce RE, Barnes LG. 1994. The evolutionary history of whales and dolphins. Annual Review of Earth and Planetary Sciences 22:419-455.

Fordyce RE, de Muizon C. 2001. Evolutionary history of cetaceans: a review. In: Mazin J-M, de Buffrenil V, eds. Secondary adaptations of tetrapods to life in water. Proceeding of the International Meeting, Poitiers, 1996. Munich: Verlag Dr. Friederich Pfeil P, 169-233.

Fordyce RE, Marx FG. 2013. The pygmy right whale Caperea marginata: the last of the cetotheres. Proceedings of the Royal Society of London Biological sciences 280:20122645. DOI: 10.1098/rspb.2012.2645

Frenguelli J. 1935. El perfil de Gaiman (Chubut). Notas del Museo de La Plata, Geología 1:177192.

Geisler JH, Luo Z. 1996. The petrosal and inner ear of Herpetocetus sp. (Mammalia: Cetacea) and their implications for the phylogeny and hearing of archaic mysticetes. Journal of Paleontology 70:1045-1066.

Gol'din P, Steeman ME. 2015. From problem taxa to problem solver: A new Miocene family, Tranatocetidae, brings perspective on baleen whale evolution. PLoS One 10:e135500. DOI: 10.1371/journal.pone.0135500

Goloboff P, Catalano S. 2016. TNT version 1.5, including a full implementation of phylogenetic morphometrics. Cladistics 32:221-238. DOI: 10.1111/cla.12160

Kellogg, R. 1934. The Patagonian fossil whalebone whale, Cetotherium moreni (Lydekker). Carnegie Institution of Washington 447: 64-81.Kellogg AR. 1965. A new whalebone whale from the Miocene of Calvert Formation. United States National Museum Bulletin 
1167 Kellogg AR. 1968. Fossil marine mammals from the Miocene Calvert Formation of Maryland and Virginia (part 5). Miocene Calvert mysticetes described by Cope. United States National Museum Bulletin 247:103-132.

1170

1171

1172

1173

1174

1175

1176

1177

1178

1179

1180

1181

1182

1183

1184

1185

1186

1187

1188

Virginia. United States National Museum Bulletin 294:1-40.

Kjeldahl J. 1883. A new method for the determination of nitrogen in organic matter. Zeitschrift für Analytische Chemie 22:366-382.

Kimura T. 2009. Review of the fossil balaenids from Japan with a re-description of Eubalaena shinshuensis (Mammalia, Cetacea, Mysticeti). Quaderni del Museo di Storia Naturale di Livorno 22:3-21.

Lambert O, Bianucci G, Post K, de Muizon C, Salas-Gismondi R, Urbina M, Reumer J. 2010. The giant bite of a new raptorial sperm whale from the Miocene epoch of Peru. Nature 466:105-108.

Lambertsen RH, Rasmussen KJ, Lancaster WC, Hintz RJ. 2005. Functional morphology of the mouth of the bowhead whale and its implications for conservation. Journal of Mammalogy 86:342-352. DOI: 10.1644/BER-123.1

Lydekker R. 1894. Cetacean skulls from Patagonia. Anales del Museo de La Plata 2:1-13.

Madsen CJ, Herman LM. 1980. Social and ecological correlates of cetacean vision and visual appearance. In: Herman LM, editor. Cetacean behavior mechanisms and functions. New York: John Wiley \& Sons, 101-147.

Malumián N, Náñez C. 2011. The Late Cretaceous-Cenozoic transgressions in Patagonia and the Fuegian Andes: foraminifera, palaeoecology, and palaeogeography. Biological Journal of 
the Linnean Society 103:269-288. DOI: 10.1111/j.1095-8312.2011.01649.x

1190

1191

1192

1193

1194

1195

1196

1197

1198

1199

1200

1201

1202

1203

1204

1205

1206

1207

1208

1209

1210

1211

Marx FG, Buono MR, Fordyce RE, Boessenecker RW. 2013. Juvenile morphology: A clue to the origins of the most mysterious of mysticetes? Naturwissenschaften 100:257-261. DOI: 10.1007/s00114-013-1012-y

Marx FG, Fordyce RE. 2015. Baleen boom and bust: a synthesis of mysticete phylogeny, diversity and disparity. Royal Society Open Science 2:140434. DOI: 10.1098/rsos.140434

Marx FG, Kohno N. 2016. A new Miocene baleen whale from the Peruvian desert. Royal Society Open Science 3:160542. DOI: 10.1098/rsos. 160542

Marx FG, Bosselaers MEJ, Louwye S. 2016. A new species of Metopocetus (Cetacea, Mysticeti, Cetotheriidae) from the Late Miocene of the Netherlands. PeerJ 4:e1572. DOI: $10.7717 /$ peerj. 1572

Mass AM, Supin AY. 1995. Ganglion cells topography of the retina in the bottlenosed dolphin, Tursiops truncatus. Brain, Behavior and Evolution 45:257-265.

Mass AM, Supin AY. 1997. Ocular anatomy, retinal ganglion cell distribution, and visual resolution in the gray whale, Eschrichtius gibbosus. Aquatic Mammals 23:17-28.

McGowen MR, Spaulding M, Gatesy J. 2009. Divergence date estimation and a comprehensive molecular tree of extant cetaceans. Molecular Phylogenetics and Evolution 53:891-906.

McLeod SA, Whitmore JFC, Barnes LG. 1993. Evolutionary relationships and classification. In: Burns JJ, Montague JJ, Cowles CJ, eds. The bowhead whale. Special Publication Number 3 Society for Marine Mammalogy, 45-70.

Mead JG, Fordyce, RE. 2009. The therian skull. A lexicon with emphasis on the odontocetes. Smithsonian Contributions to Zoology 627:1-248. DOI: 10.5479/si.00810282.627

Mendía JE, Bayarsky A. 1981. Estratigrafía del Terciario del valle inferior del río Chubut. Actas 
1213 Ninomiya H, Yoshida E. 2007. Functional anatomy of the ocular circulatory system: vascular corrosion casts of the cetacean eye. Veterinary Ophthalmology 10:231-238.

1215

1216

1217

1218

1219

1220

1221

1222

1223

1224

1225

1226

1227

1228

1229

1230

1231

1232

1233

1234 deposits: Austral Basin, southern Patagonia (Argentina). Journal of South American Earth Sciences 37:122-135. DOI: 10.1016/j.jsames.2012.02.007

Palazzesi L, Barreda VD, Scasso RA. 2006. Early Miocene spore and pollen record of the Gaiman Formation (Northeastern Patagonia, Argentina): correlations and paleoenvironmental implications. 4th Latin American Congress on Sedimentology and 11th Argentinean Meeting of Sedimentology, Bariloche, Argentina, 161.

Perrin WF. 1975. Variation of spotted and spinner porpoise (Genus Stenella) in the Eastern Tropical Pacific and Hawaii. Bulletin of the Scripps Institution of Oceanography 21:1206.

Pol D, Escapa IH. 2009. Unstable taxa in cladistic analysis: identification and the assessment of relevant characters. Cladistics 25:515-527. DOI: 10.1111/j.1096-0031.2009.00258.x

Pyenson ND, Sponberg SN. 2011. Reconstructing body size in extinct crown Cetacea (Neoceti) using allometry, phylogenetic methods and tests from the fossil record. Journal of Mammalian Evolution 18:269-288. DOI: 10.1007/s10914-011-9170-1

Pyenson ND, Vermeij GJ. 2016. The rise of ocean giants: maximum body size in Cenozoic marine mammals as an indicator for productivity in the Pacific and Atlantic Oceans. Biology Letters 12:20160186. DO: 10.1098/rsbl.2016.0186

Reeves, R.R. and Leatherwood, S. 1985. Bowhead whale - Balaena mysticetus Linnaeus, 1758. In: Ridgway SH, Harrison R, eds. Handbook of Marine Mammals. Vol. 3. The Sirenians 
and Baleen Whales. Academic Press, London and Orlando, 305-344.

1236

1237

1238

1239

1240

1241

1242

1243

1244

1245

1246

1247

1248

1249

1250

1251

1252

1253

1254

1255

1256

1257

Rugh DJ, Shelden KEW. 2009. Bowheads. In: Perrin WF, Würsig B, Thewissen JGM, eds. Encyclopedia of marine mammals, 2nd ed. San Diego: Academic Press, 131-133.

Sanders AE, Barnes LG. 2002. Paleontology of the late Oligocene Ashley and Chandler Bridge formations of South Carolina 3: Eomysticetidae, a new family of primitive Oligocene mysticetes (Mammalia: Cetacea), from South Carolina, USA. Smithsonian Contributions to Paleobiology 93:313-356.

Scasso RA, Castro LN. 1999. Cenozoic phosphatic deposits in North Patagonia, Argentina: Phosphogenesis, sequence-stratigraphy and paleoceanography. Journal of South American Earth Sciences 12:471-487.

Scasso RA, Bellosi ES. 2004. Cenozoic continental and marine trace fossils at the Bryn Gwyn Paleontological Park, Chubut. In: Scasso RA, Bellosi ES, eds. Bryn Gwyn Guidebook, I International Congress on Ichnology. Trelew, 1-19.

Schulte HVW, Smith MDF. 1918. The external characters, skeletal muscles, and peripheral nerves of Kogia breviceps (Blainville). Bulletin of American Museum of Natural History 38: 7-72.

Simpson GG. 1935. Early and Middle Tertiary geology of the Gaiman Region, Chubut, Argentina. America Museum Novitates 775:1-29.

Slater GJ, Goldbogen JA, Pyenson ND. 2017. Independent evolution of baleen whale gigantism linked to Plio-Pleistocene ocean dynamics. Proceeding of Royal Society B 284: 20170546. DOI: http://dx.doi.org/10.1098/rspb.2017.0546

Steeman ME, Hebsgaard MB, Fordyce RE, Ho SY, Rabosky DL, Rahbek C, Glenner H, Sørensen MV, Willerslev E. 2009. Radiation of extant cetaceans driven by restructuring 
of the oceans. Systematic Biology 58:573-585. DOI: 10.1093/sysbio/syp060

1259 Tsai C-H, Fordyce RE. 2015. The earliest gulp-feeding mysticete (Cetacea: Mysticeti) from the Oligocene of New Zealand. Journal of Mammalian Evolution 22:535-560. DOI:

1261 10.1007/s10914-015-9290-0

1262

1263

1264

1265

1266

1267

1268

1269

1270

1271

1272 1273

1274

1275

1276

1277

1278

Tsai C, Fordyce R. 2016. Archaic baleen whale from the Kokoamu Greensand: earbones distinguish a new late Oligocene mysticete (Cetacea: Mysticeti) from New Zealand. Journal of the Royal Society of New Zealand 46:117-138. DOI: $10.1080 / 03036758.2016 .1156552$

Tsai CH, Kohno N. 2016. Multiple origins of gigantism in stem baleen whales. The Science of Nature 103:89. DOI: 10.1007/s00114-016-1417-5

Tomilin AG. 1967. Cetacea (Vol. XIX). In: Heptner VG, ed. Mammals of the USSR and adjacent countries. Jerusalem: Israel Program for Scientific Translations, 1-756.

Van Beneden PJ. 1872. Les baleines fossiles d'Anvers. Bulletin de l'Academie Royal de Belgique 34:6-20.

Walls GL. 1942. The vertebrate eye and its adaptive radiation. New York: Hafner.

Walsh BM, Berta A. 2011. Occipital ossification of balaenopteroid mysticetes. Anatomical Record 294:391-398. DOI: 10.1002/ar.21340

Weber M. 1886. Beitra "ge zur Anatomie und Phylogenie der Cetaceen. In Gustav Fischer, editor. Studien u "ber Sa "ugethiere. Ein Beitrag zur Frage nach den Ursprung der Cetaceen. Jena: Gustav Fischer, 132-142. 


\section{Table $\mathbf{1}$ (on next page)}

List of specimens of Eubalaena australis analyzed for cranial suture closure.

Abbreviations: BE., basisphenoid; BO., basioccipital; BZ., bizygomatic width, TL.,total length;

EX., exoccipital; SO., supraoccipital. 


\begin{tabular}{|c|c|c|c|c|c|}
\hline Collection number & Age & $\mathrm{BZ}(\mathrm{cm})$ & $\mathrm{TL}(\mathrm{m})$ & $\begin{array}{l}\text { Cranial } \\
\text { suture }\end{array}$ & $\begin{array}{l}\text { State of close suture } \\
\text { according to } \\
\text { Walsh \& Berta (2011) }\end{array}$ \\
\hline CNPMAMM 748 & Neonate & 54 & 3.64 & $\begin{array}{l}\mathrm{BO} / \mathrm{BE} \\
\mathrm{BO} / \mathrm{EX} \\
\mathrm{SO} / \mathrm{EX}\end{array}$ & $\begin{array}{c}\text { SR1 } \\
\text { SR1 (SR2?) } \\
\text { SR2 }^{\mathrm{a}}\end{array}$ \\
\hline CNPMAMM 746 & Calf & $\sim 70$ & - & $\begin{array}{l}\mathrm{BO} / \mathrm{BE} \\
\mathrm{BO} / \mathrm{EX} \\
\mathrm{SO} / \mathrm{EX}\end{array}$ & $\begin{array}{l}\text { SR1 } \\
\text { SR1 } \\
\text { SR1 }\end{array}$ \\
\hline CNPMAMM 742 & Calf & - & - & $\begin{array}{l}\mathrm{BO} / \mathrm{BE} \\
\mathrm{BO} / \mathrm{EX} \\
\mathrm{SO} / \mathrm{EX}\end{array}$ & $\begin{array}{l}\text { SR3 } \\
\text { SR4 } \\
\text { SR4 }\end{array}$ \\
\hline Without number ${ }^{b}$ & Juvenile & - & 11.40 & $\mathrm{BO} / \mathrm{EX}$ & SR4 \\
\hline USNM 267612 & adult & 216 & 13.7 & $\begin{array}{l}\mathrm{BO} / \mathrm{EX} \\
\mathrm{SO} / \mathrm{EX}\end{array}$ & $\begin{array}{l}\text { SR4 } \\
\text { SR4 }\end{array}$ \\
\hline CNPMAMM 774 & adult & 256 & 14.45 & $\begin{array}{l}\mathrm{BO} / \mathrm{EX} \\
\mathrm{SO} / \mathrm{EX}\end{array}$ & $\begin{array}{c}\text { SR3 (right side)-SR4 } \\
\text { (left side) } \\
\text { SR4 }\end{array}$ \\
\hline
\end{tabular}

${ }^{\mathrm{a}}$ The closure of the suture is in a medial direction from the lateral edges.

${ }^{\mathrm{b}}$ Specimen in exhibition in "Centro de Interpretación Istmo Ameghino", Península Valdés, Chubut Province, Argentina. 


\section{Table 2 (on next page)}

Skull measurements of the holotype (MLP 5-11) and referred specimens (MLP 5-15) of Morenocetus parvus in $\mathrm{mm}$. 
Measurement

Bizygomatic width

Width of the skull at the level of the exoccipitals

Supraoccipital width anterior to foramen magnum

Supraoccipital width at mid-lenght

Supraoccipital width at $10 \mathrm{~cm}$ to the anterior margin

Supraoccipital length

Transverse diameter of left occipital condyle

Idem right

Dorsoventral diameter of left occipital condyle

Idem right

Transverse diameter of foramen magnum

Distance between lateral border of left occipital condyle and

lateral border of exoccipital

Width of the occipital condyles plus foramen magnum

Anteroposterior diameter of the supraorbital process of the

frontal in the distal edge

Transverse diameter of the supraorbital process of the frontal

Anteroposterior diameter of the supraorbital process of the

frontal in the constriction

Width of the optic canal in its medial portion

Width of the optic canal in its lateral portion

Length of the optic canal

Orbital length (between preorbital and postorbital process)

Length of the interorbital region

Length of the optic canal

Anteroposterior diameter of the temporal fossa
MLP 5-11 MLP 5-15

$+570+530$

$470 \quad+385$

$320+340$

$220 \quad 220$

$195 \quad 185$

$270 \quad 280$

$65 \quad 75$

$65 \quad 75$

$130 \quad 140$

$130 \quad 145$

$75 \quad 70$

155

130

155

200 


\section{Table 3(on next page)}

Measurements of the left periotic of the holotype of Morenocetus parvus, (MLP 5-11) in $\mathrm{mm}$. 
Measurement

MLP 5-11

Length of the posterior process of the periotic

Length of anterior process of periotic 31

Width of anterior process of periotic

Maximum transverse width of the body of periotic

Anteroposterior diameter of pars cochlearis 36

Transverse width of the pars cochlearis

Dorsoventral diameter of the fenestra cochlear

Transverse diameter of the fenestra cochlear

1

2

3 


\section{Table 4(on next page)}

Early Miocene (Aquitanian-Burdigalian) fossil records of mysticetes. 


\section{Manuscript to be reviewed}

1

Taxon

cf. Waharoa OU 22744

Unnamed balaenopteroid

ZMT 67

Unnamed balaenopteroid

OU 22705

Aglaocetus moreni

(MLP 5-1; MLP 5-14; FMNH

13407)

Diorocetus chichibuensis

Diorocetus shobarensis

Isanacetus laticephalus
Age

Aquitanian (22.28-22.8Ma);

Hakataramea Quarry, New Zealand

Aquitanian (23-21.7 Ma); South

Canterbury, New Zealand

Aquitanian (21.7-20.5 Ma), South

Canterbury, New Zealand

Burdigalian, Cerro Castillo,

Chubut, Argentina

(1934); this study (see

Geological context for a

discussion of the age of

Gaiman Formation)

Late Burdigalian-Langhian (16.4- $\quad$ Marx \& Fordyce (2015)

15.1 Ma), Saitama Prefecture,

Japan

Late Burdigalian-Langhian (17-4.9 Marx \& Fordyce (2015)

Ma), Hiroshima Prefecture, Japan

Late Burdigalian (17.5-16 Ma),

Marx \& Fordyce (2015)

Gifu Prefecture, Japan 
4

Parietobalaena palmeri

Parietobalaena yamaokai

Titanocetus sammarinensis

Unnamed aetiocetid

OCPC 1178
Late Burdigalian-

Langhian (16.4-14.5 Ma),

Maryland, Virginia, USA

Late Burdigalian-

Langhian (17.0-14.9 Ma),

Hiroshima Prefecture, Japan

Late Burdigalian-

Marx \& Fordyce (2015)

Langhian (16.4-14.7 Ma), Monte

Titano, Republic of San Marino

Early-late Burdigalian (18.8-17.2

Marx \& Fordyce (2015)

Marx \& Fordyce (2015)

Marx \& Fordyce (2015)

Ma), Orange County, USA

1

2

3 


\section{Figure 1}

Anatomical landmarks proposed to orient the crania of fossil balaenids.

Skull of Eubalaena australis in (A) anterior (CNPMAMM 774) (B) lateral (CNPMAMM 774) and (C) posterolateral and (D) lateral view (MACN 54.119, CNPMAMM 774 respectively) showing the three proposed anatomical landmarks to orientate the crania in fossil balaenids. 

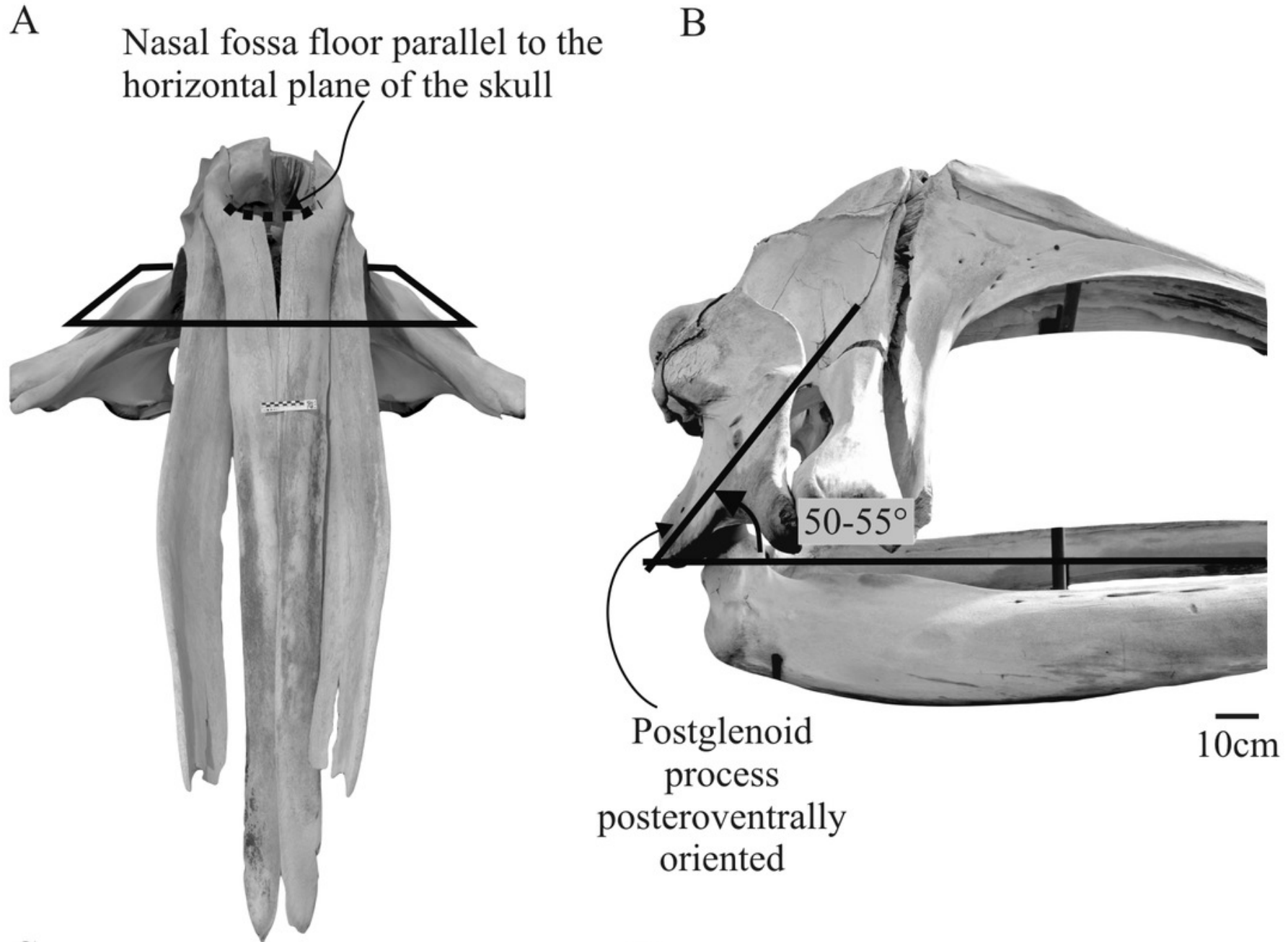

C

Foramen

D
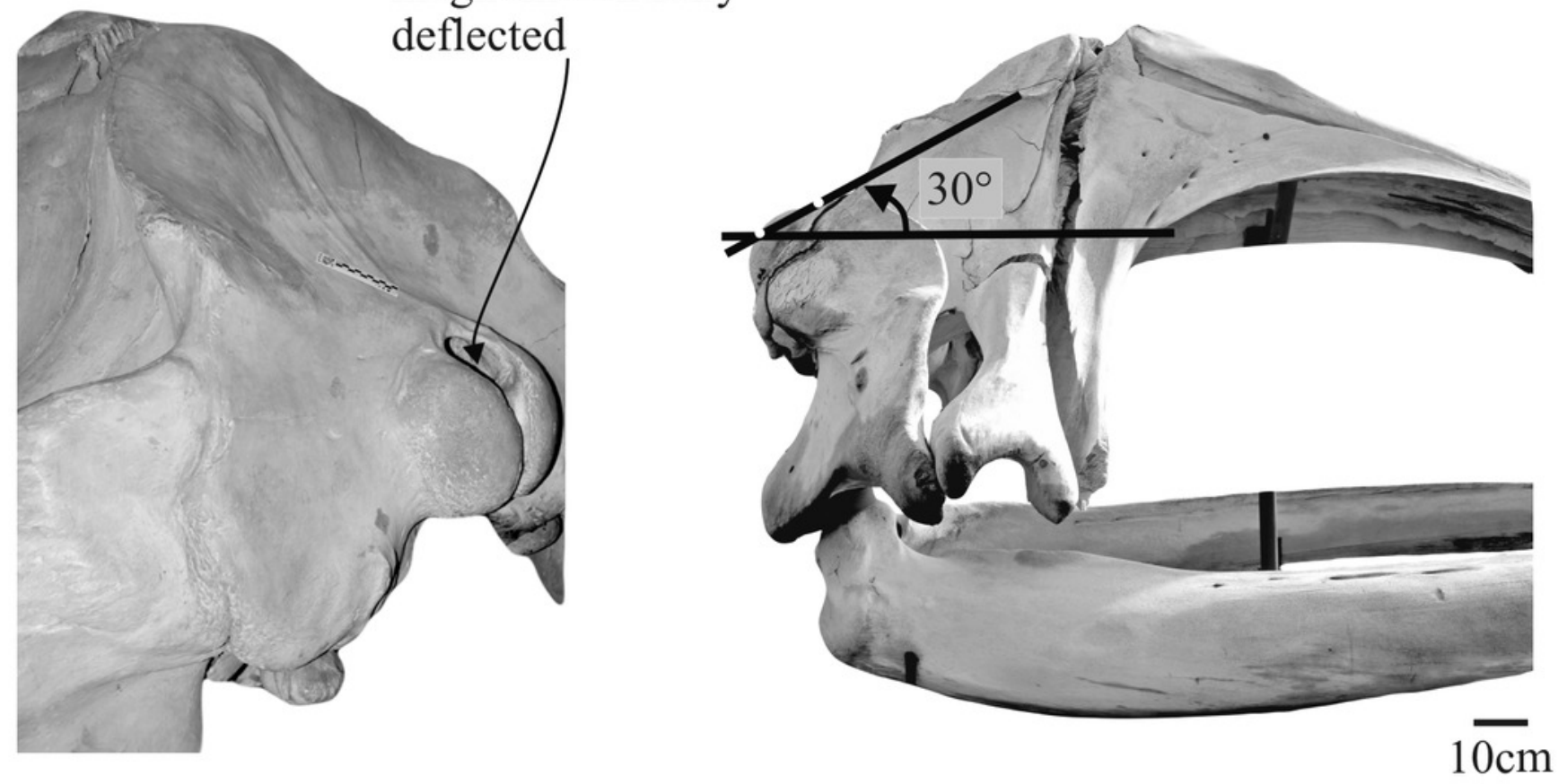
Figure 2

Locality map for Morenocetus parvus.

(A) Regional map showing the location of the study area. (B) Type locality (red star) for the holotype and referred specimens of Morenocetus parvus. Only Neogene sedimentary units are mapped. 

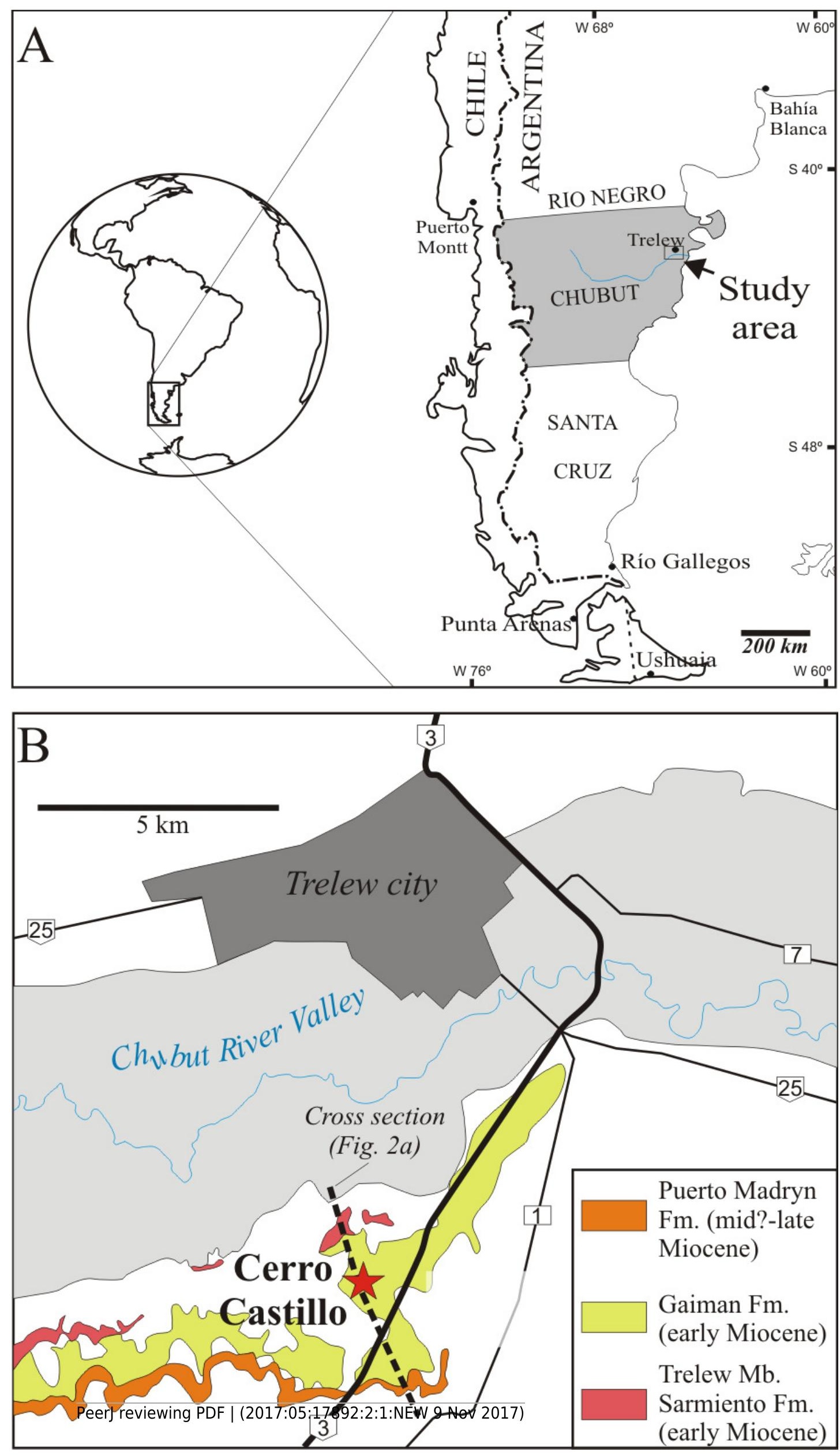


\section{Figure 3}

Stratigraphic section for the type and referred specimens of Morenocetus parvus.

(A) Stratigraphic section of Neogene deposits at Cerro Castillo area (south of Trelew city) (indicated in figure 2) modified from Scasso \& Castro, (1999). (B) General view to the northwest of the Gaiman Formation exposure at the Lower Valley of Chubut river; red rectangle indicates the locality of Cerro Castillo. (C) Cerro Castillo. 

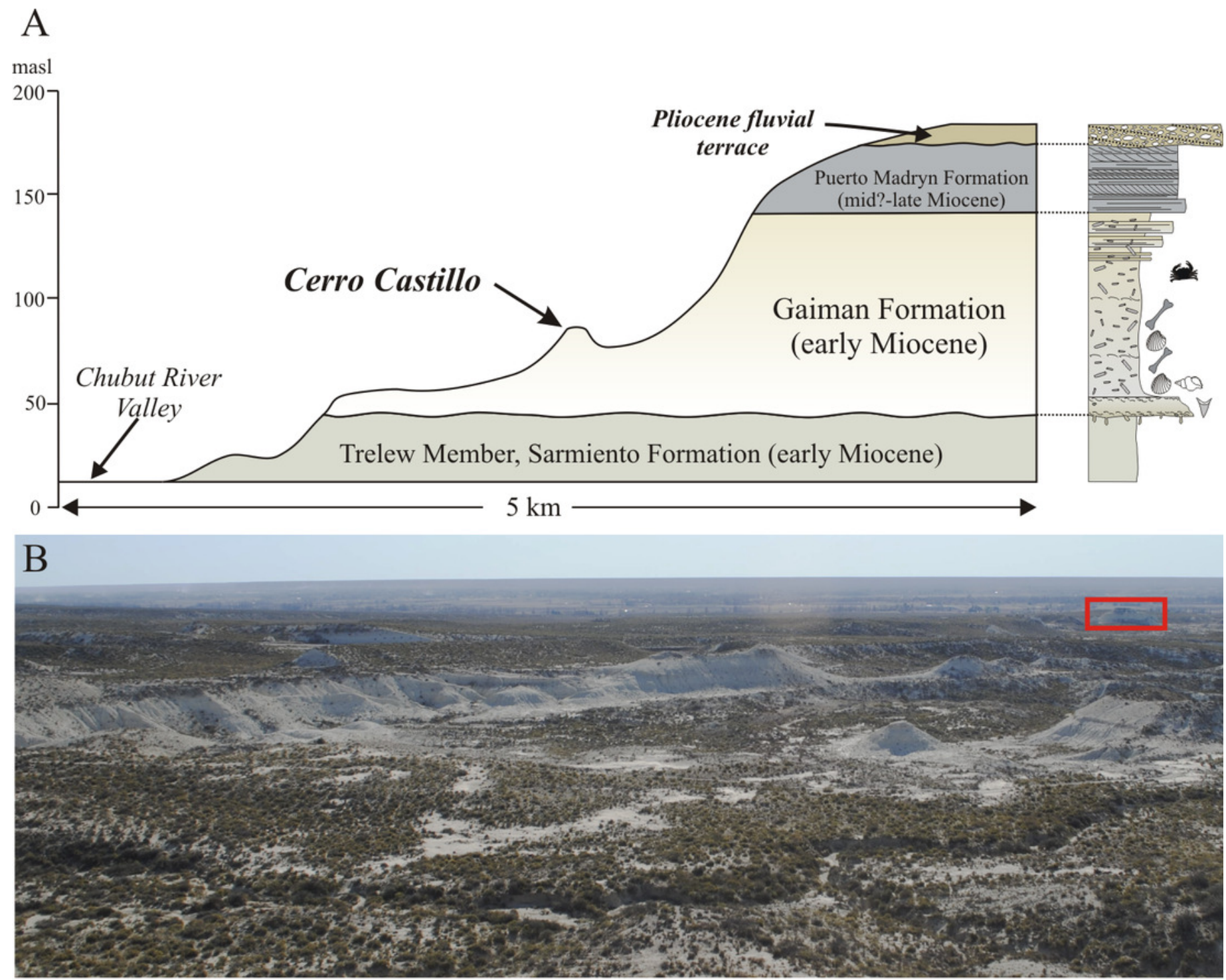

C

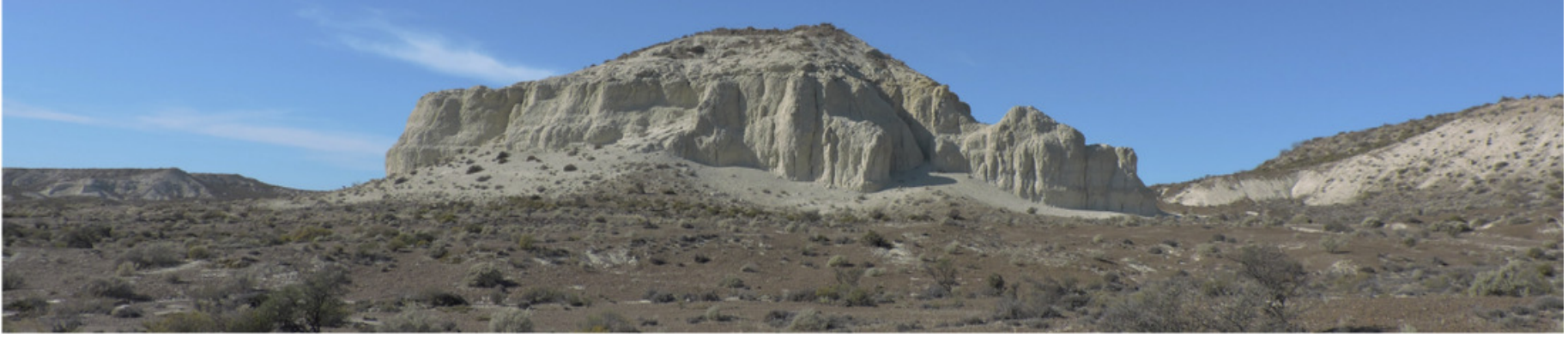


Figure 4

Morenocetus parvus, holotype, MLP 5-11, cranium.

(A) Dorsal view. (B) Key features in dorsal view. Hatching indicates major breaks. 
A

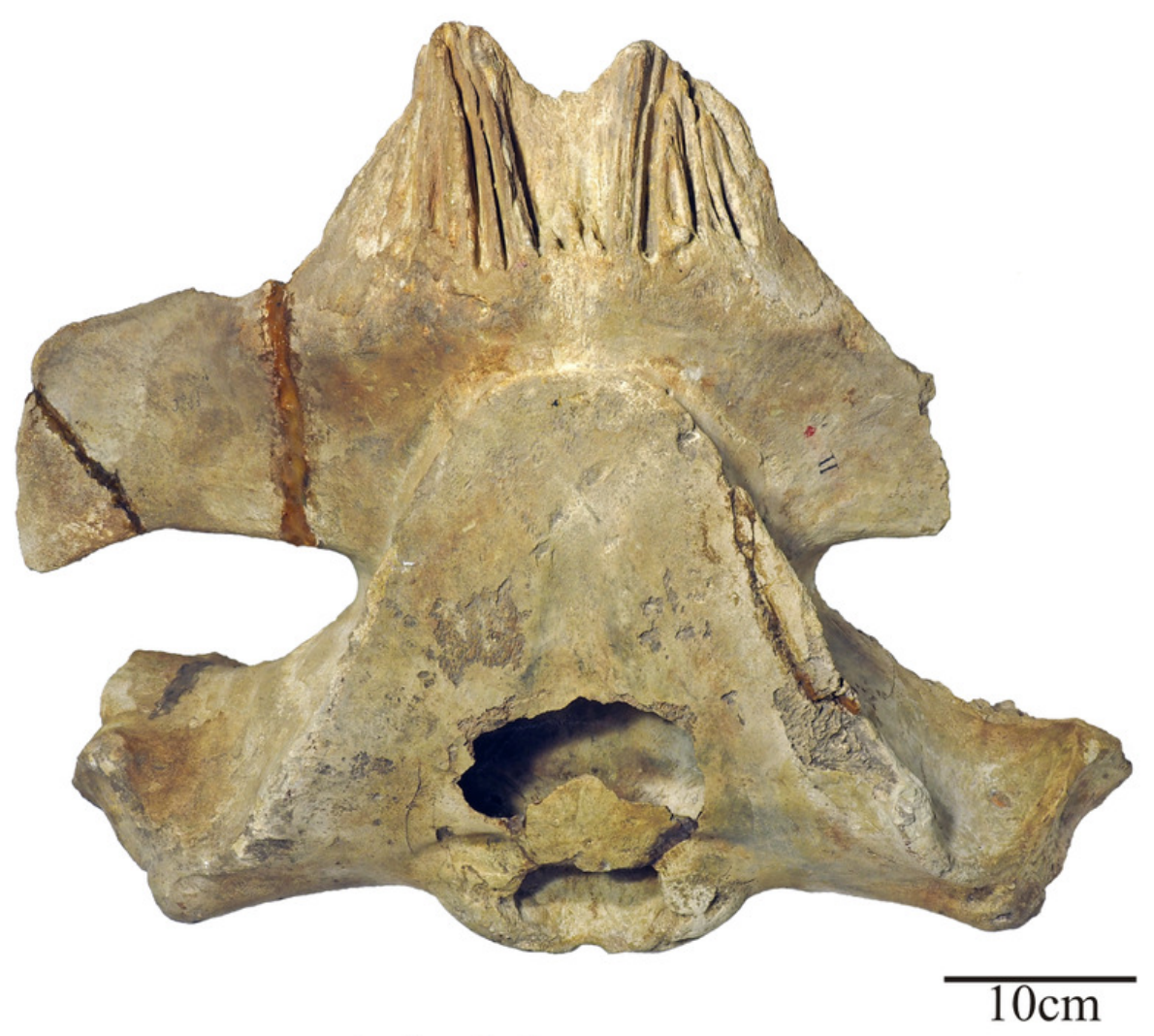

B

Articulation

surface for

premaxillae Frontal,

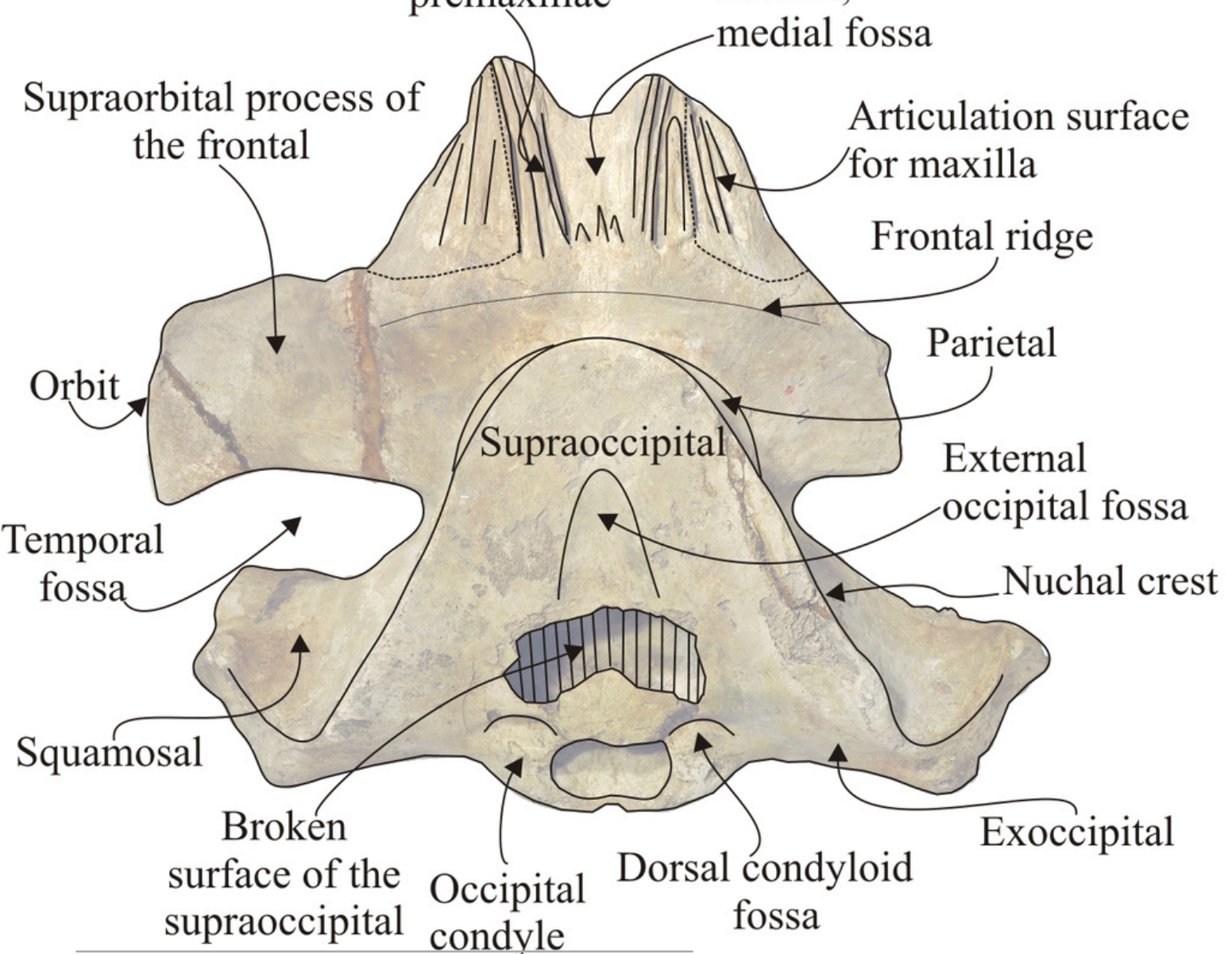




\section{Figure 5}

Morenocetus parvus, crania.

(A) Holotype, MLP 5-11, cranium in lateral view. (B) Key features in lateral view. (C) Referred specimen, MLP 5-15, lateral view. (D) Key features in lateral view. 


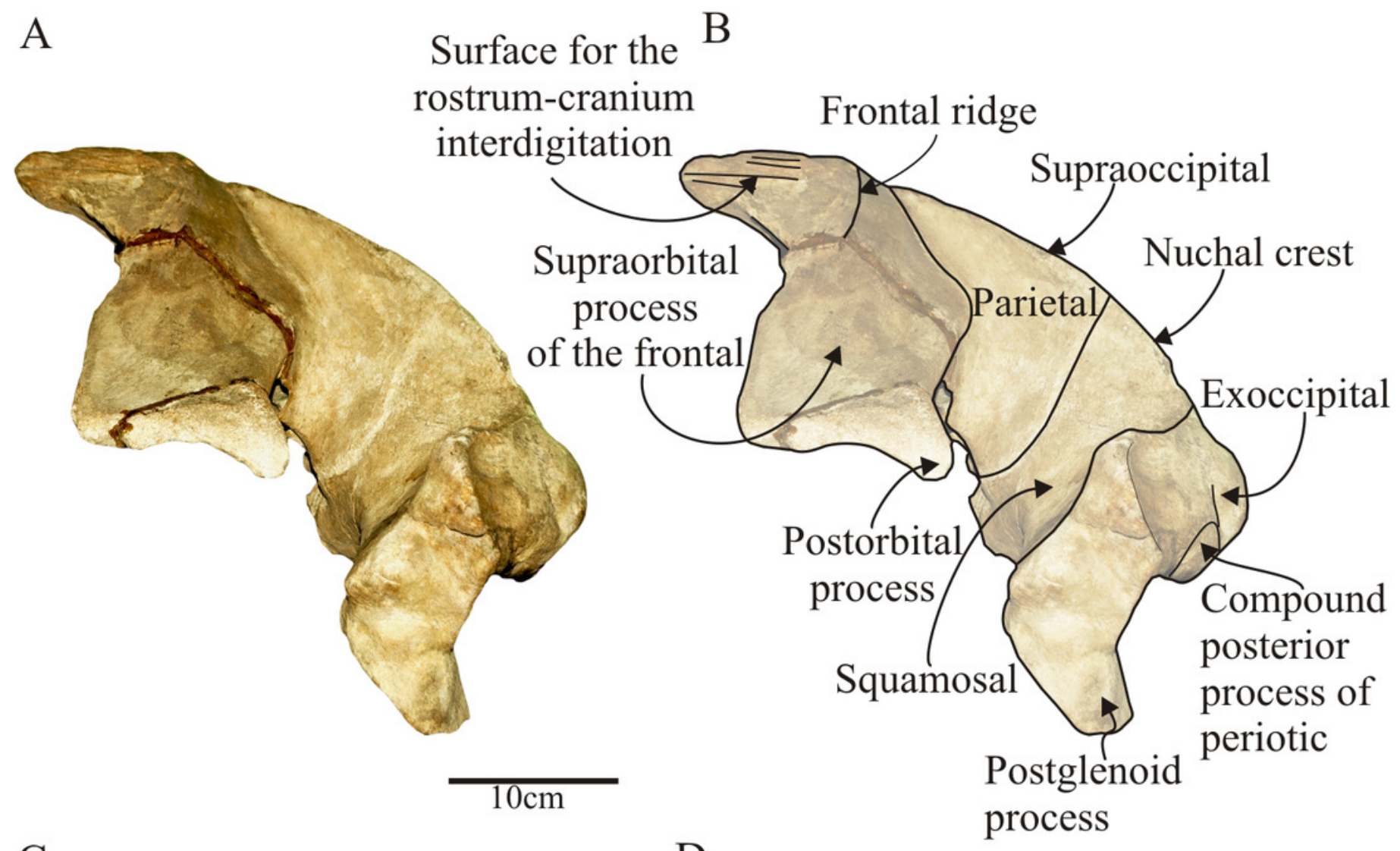

C

D

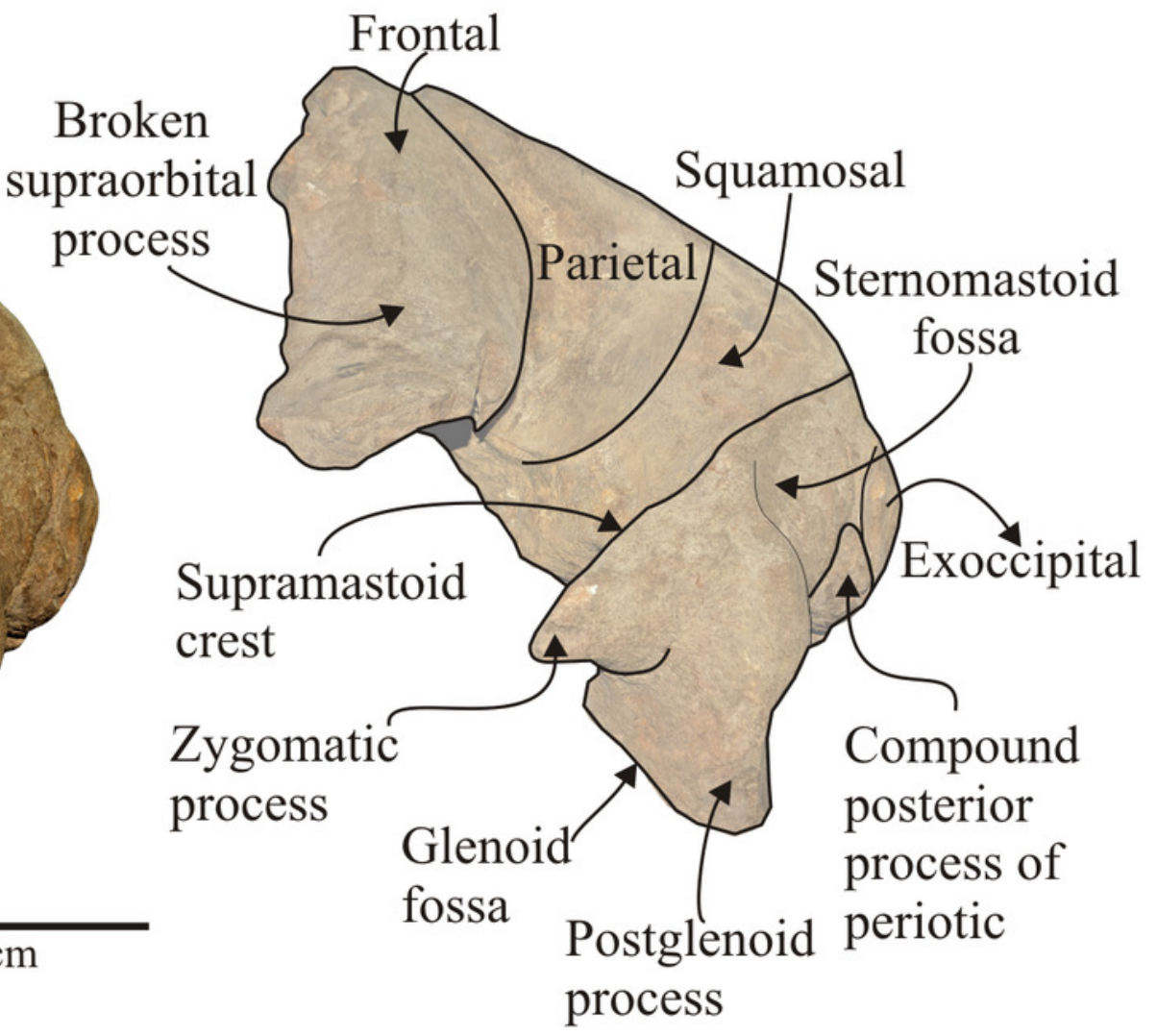




\section{Figure 6}

Morenocetus parvus, crania.

(A) Holotype, MLP 5-11, posterior view. (B) Key features in posterior view. (C) Referred

specimen, MLP 5-15, posterolateral view (D) Key features in left posterolateral view.

Abbreviations: Bc., basioccipital crest; Pa., parietal; Sp., squamosal. Hatching indicates major breaks. 


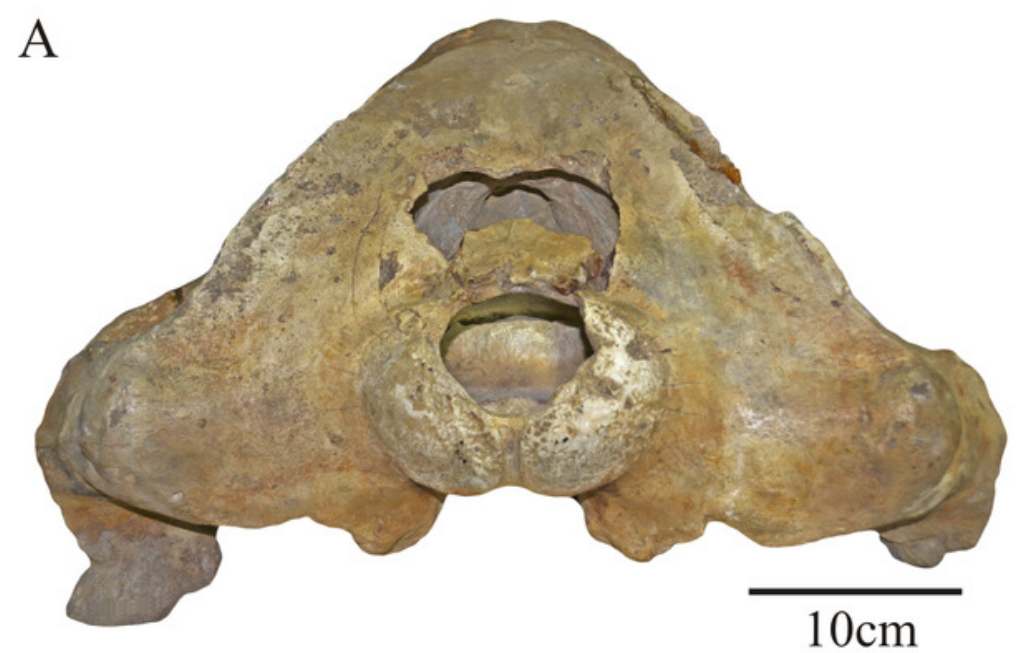

External occipital

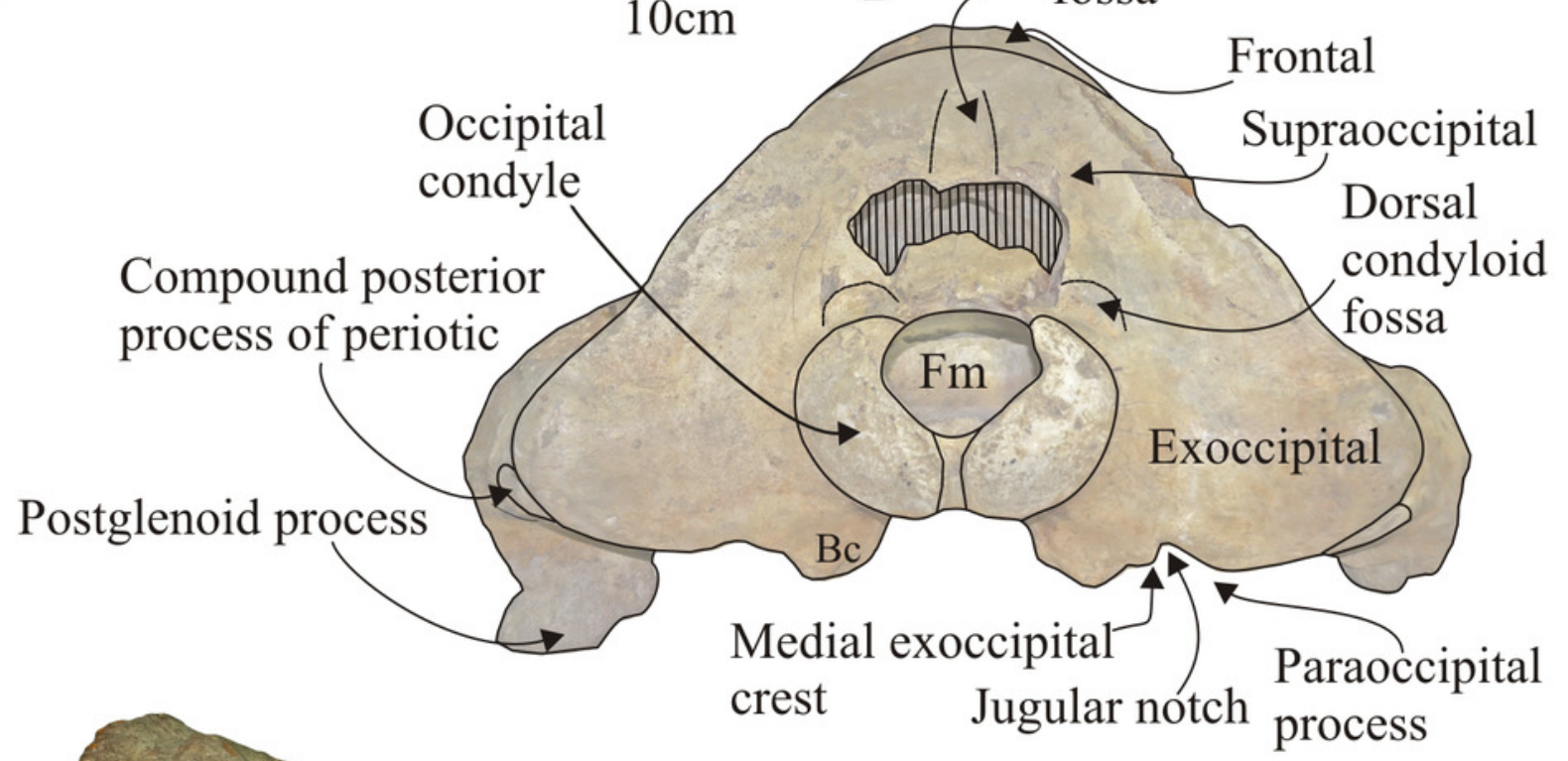

C
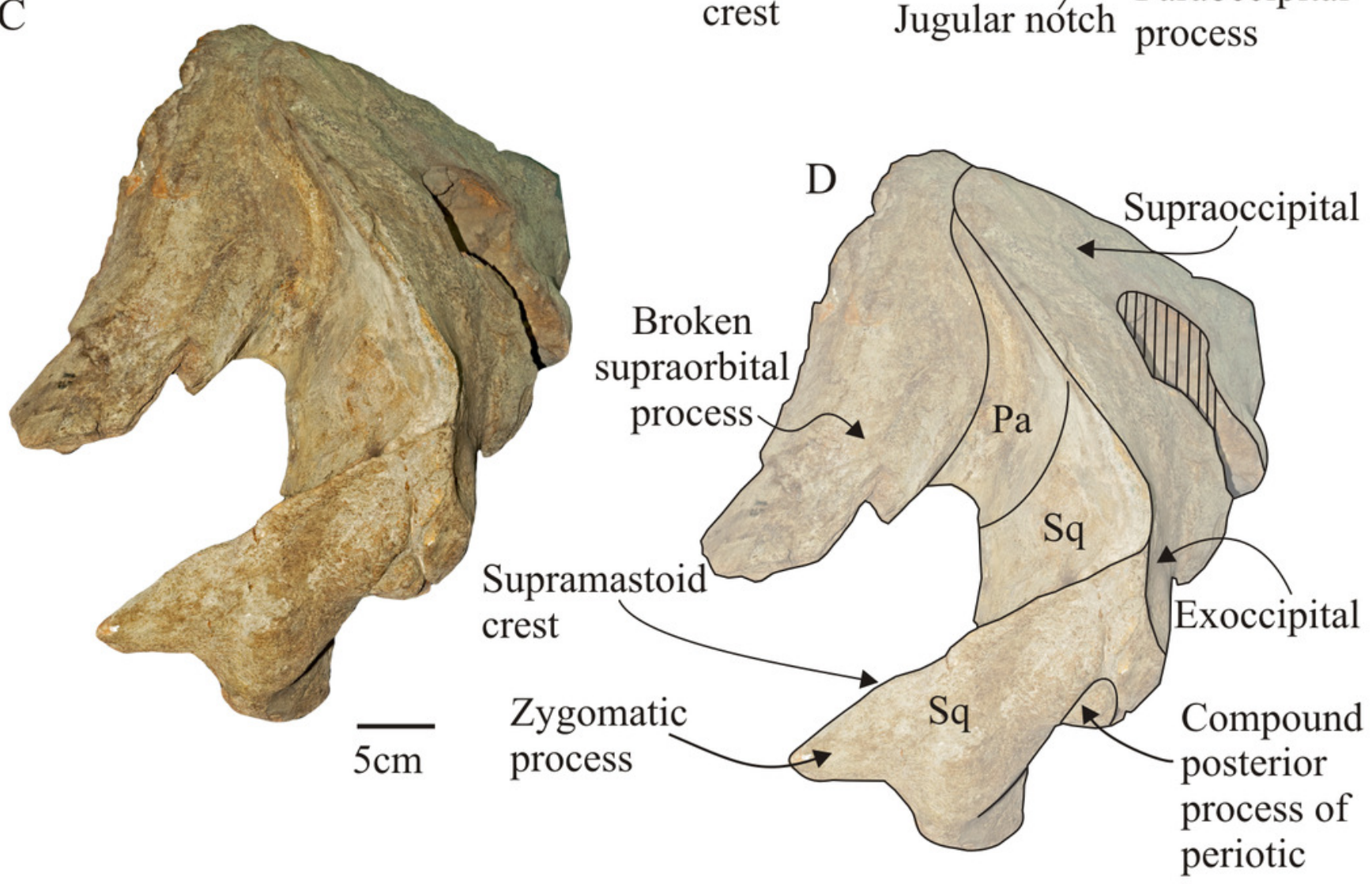
Figure 7

Morenocetus parvus, holotype, MLP 5-11, cranium.

(A) Ventral view. (B) Key features in ventral view. Abbreviations: Al., alisphenoid; Pt., pterygoid. Hatching indicates major breaks. 
A

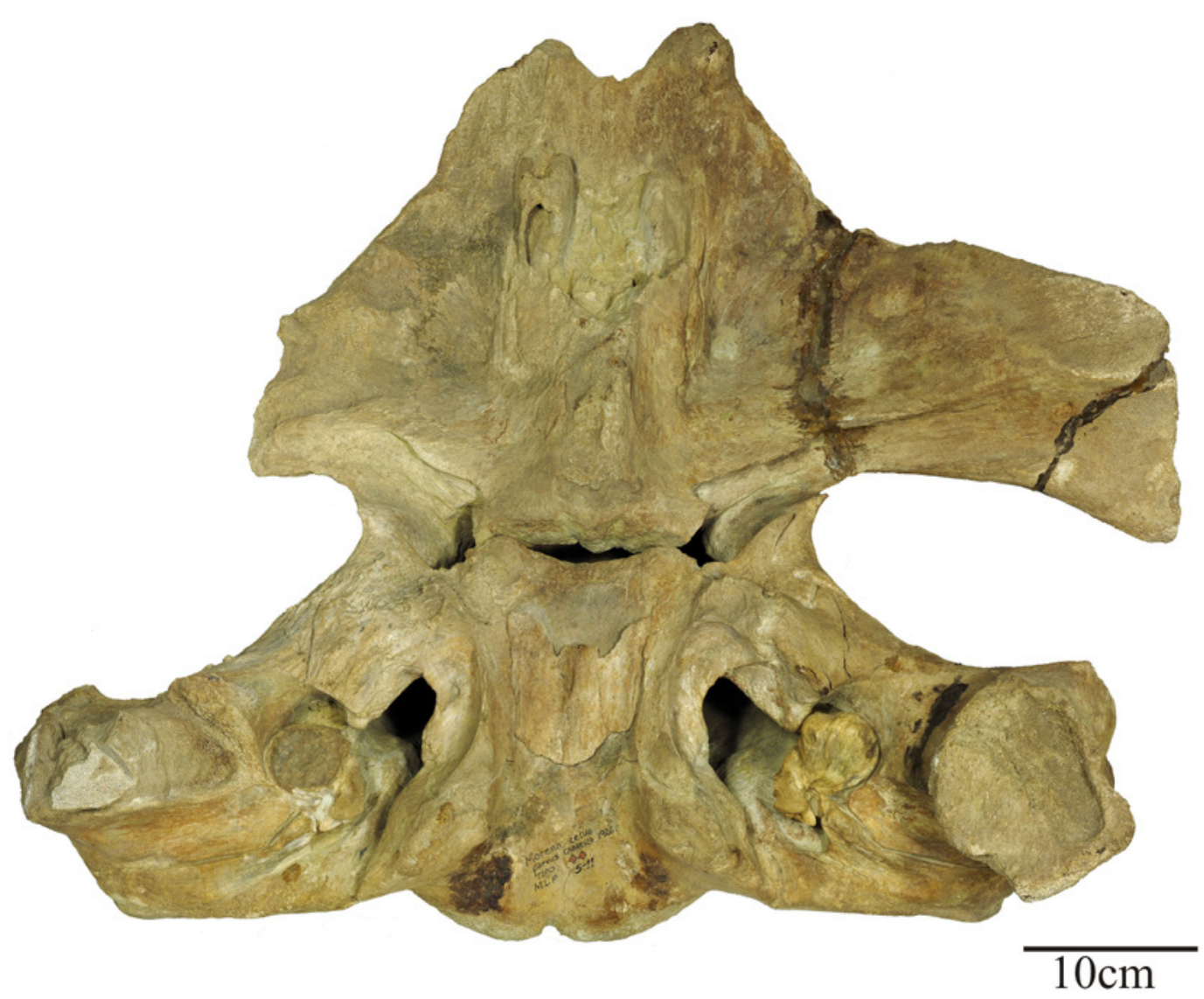

B

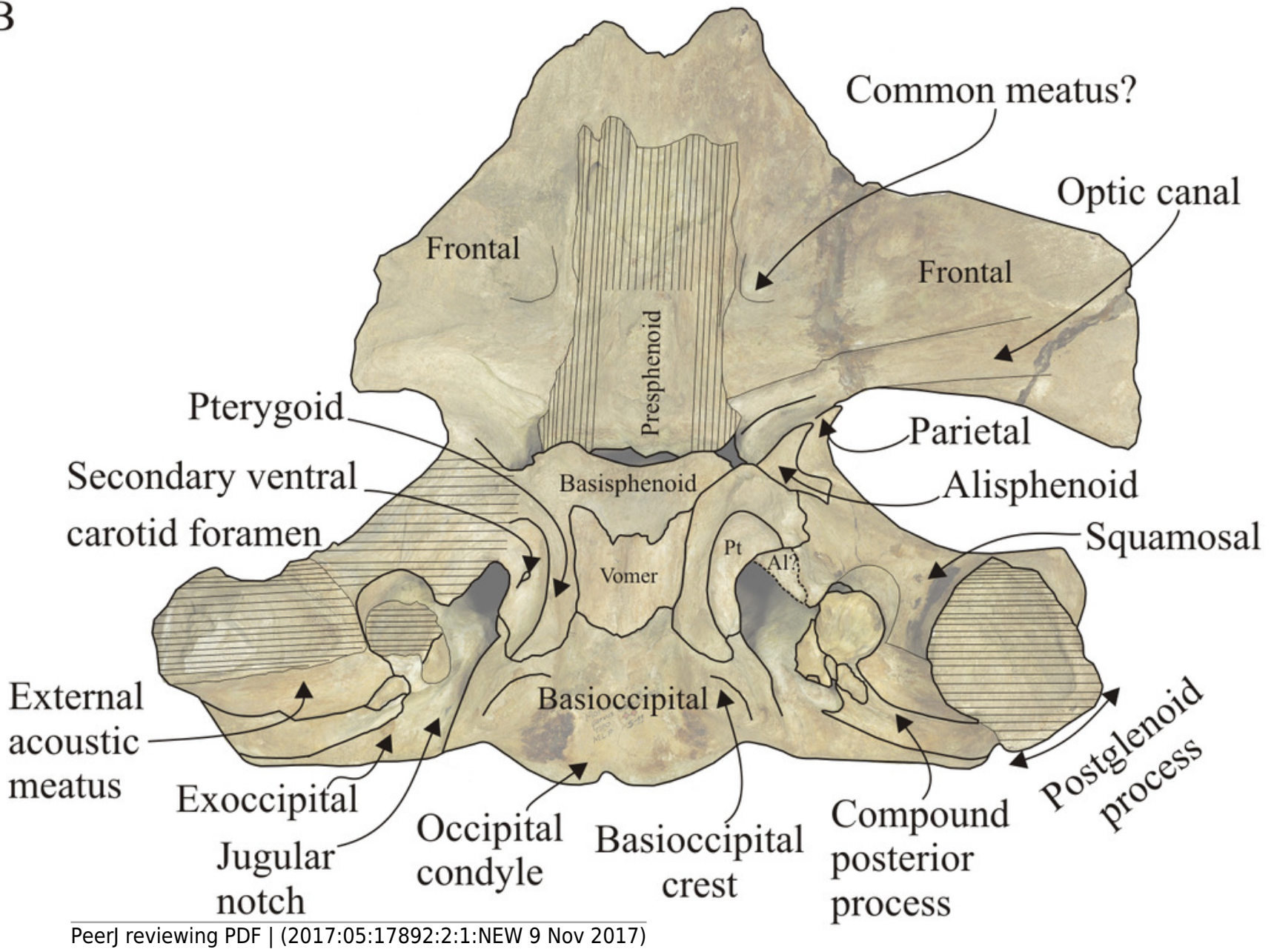


Figure 8

Morenocetus parvus, holotype, MLP 5-11, basicranium.

(A) Ventral view showing the articulated left periotic. (B) Key features in ventral view. Abbreviations: Sq., squamosal. 
A

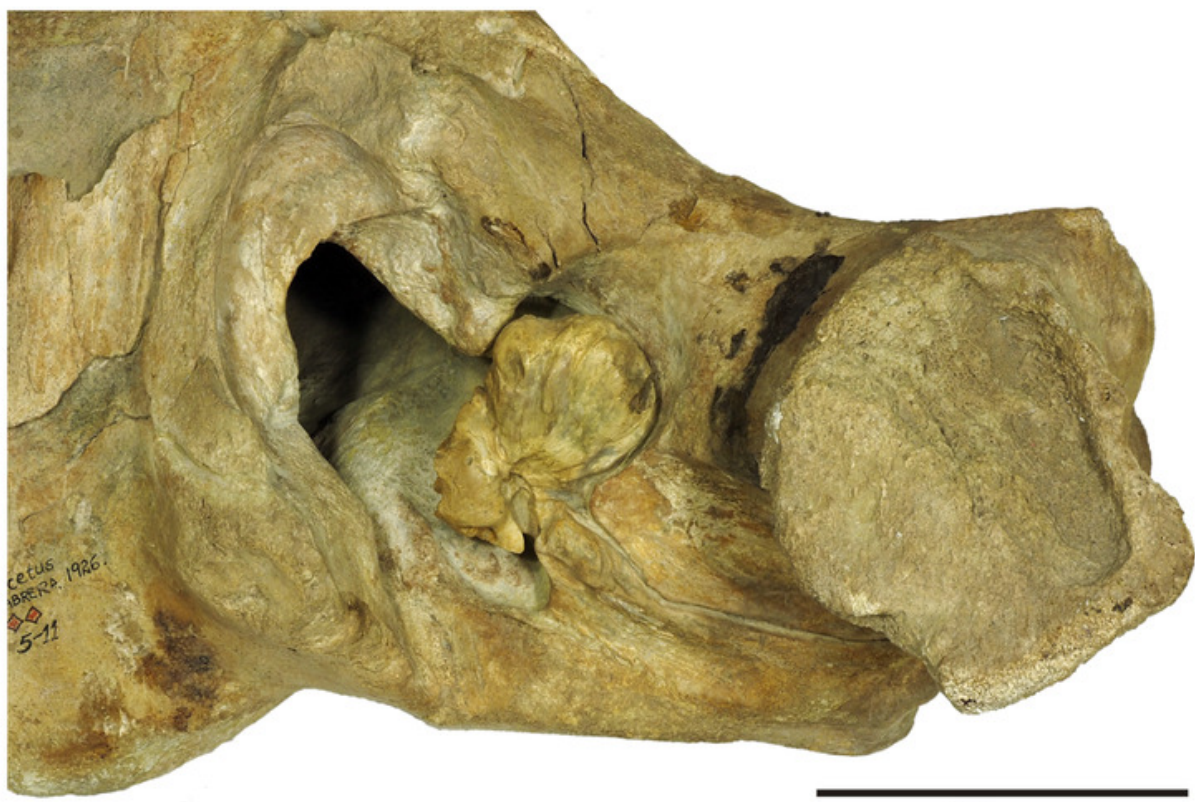

$10 \mathrm{~cm}$

B

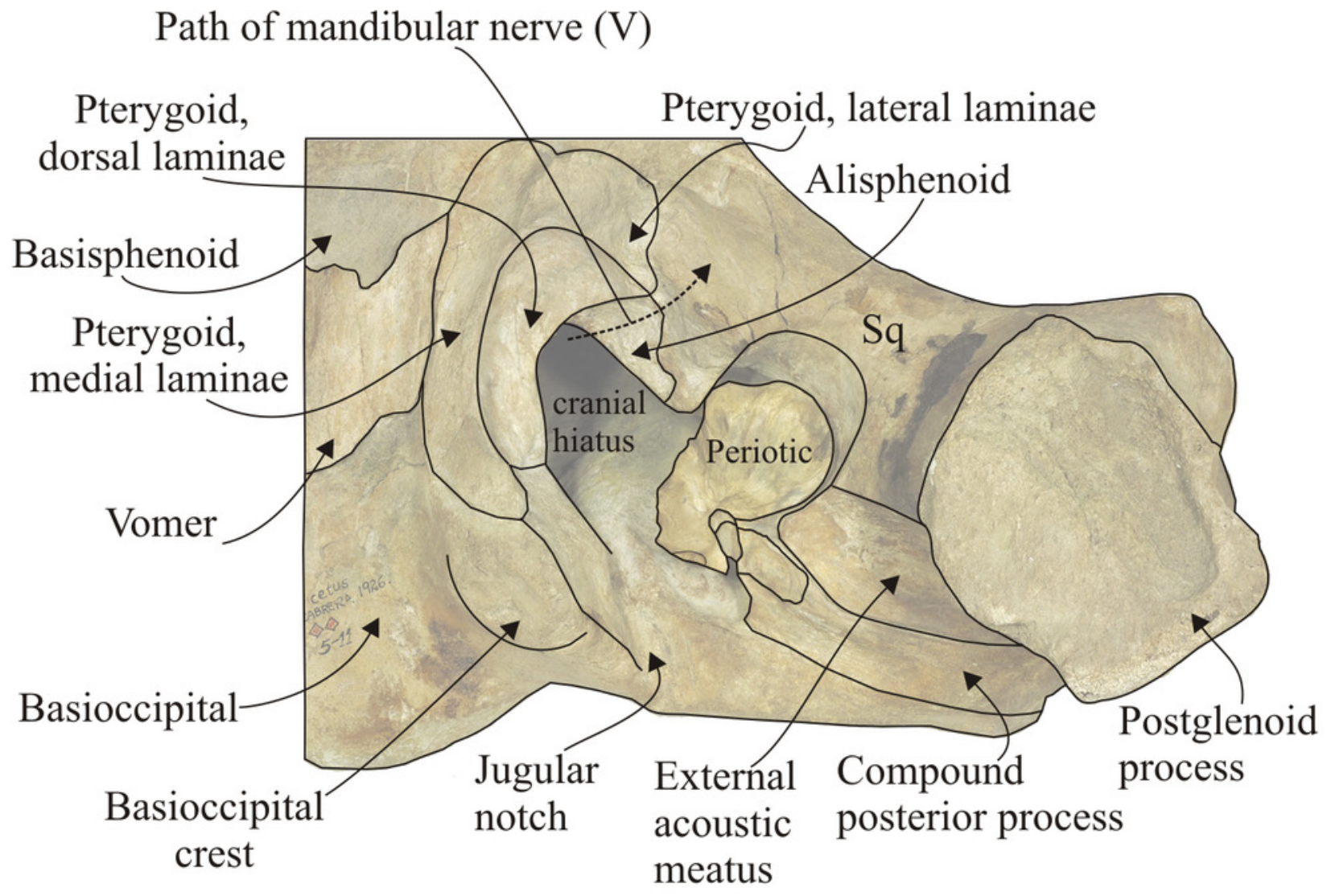


Figure 9

Morenocetus parvus, holotype, MLP 5-11, cranium.

(A) Anterior view. (B) Key features in anterior view. (C) Left anterolateral view. (D) Key features in left anterolateral view. 


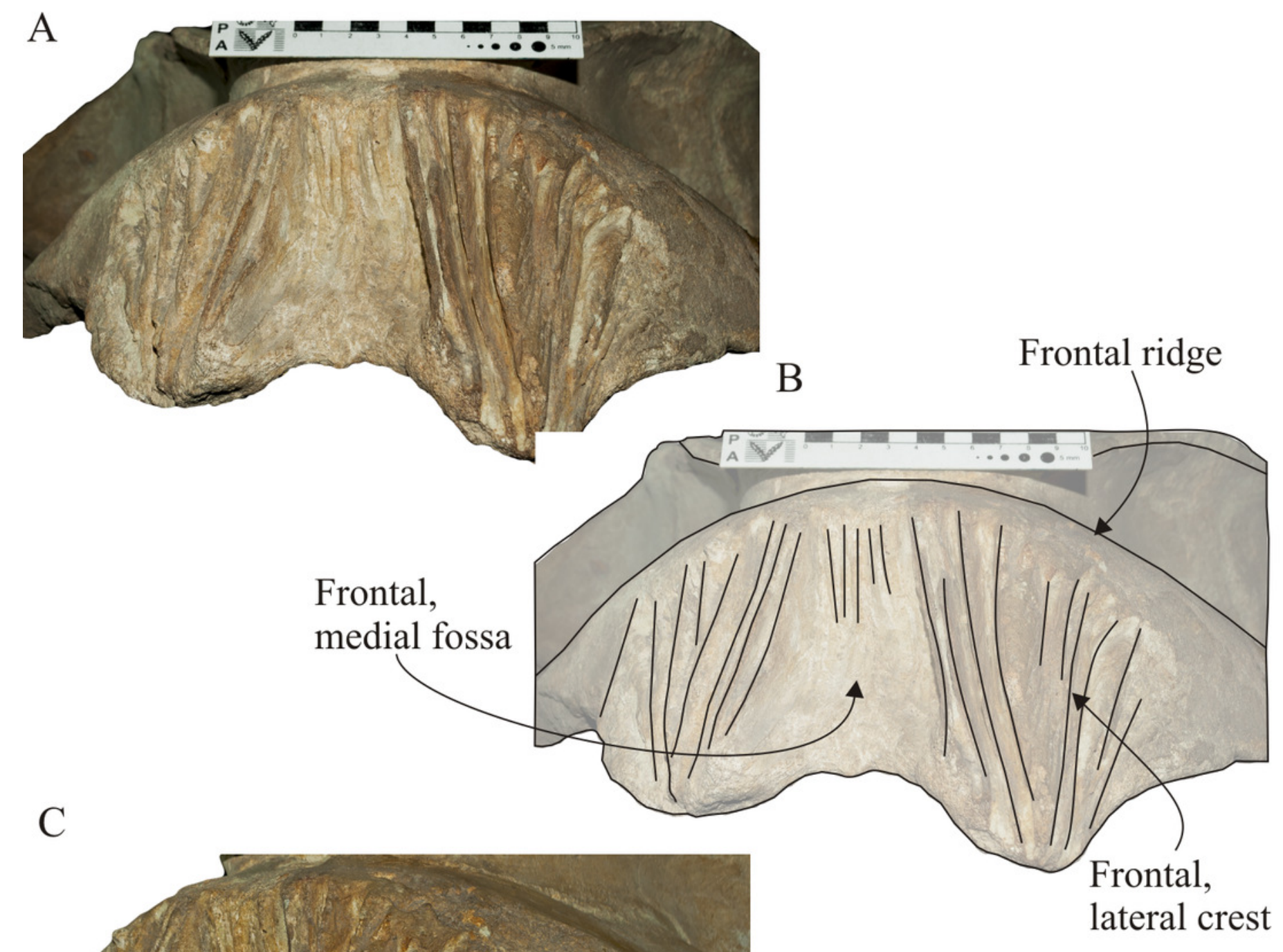




\section{Figure 10}

Morenocetus parvus, holotype, MLP 5-11, left periotic.

(A) Ventral view. (B) Key features in ventral view. Abbreviations: Mf., mallear fossa; Pc., pars cochlearis; Pp., posterior pedicle; Sp., spiny process. 
A

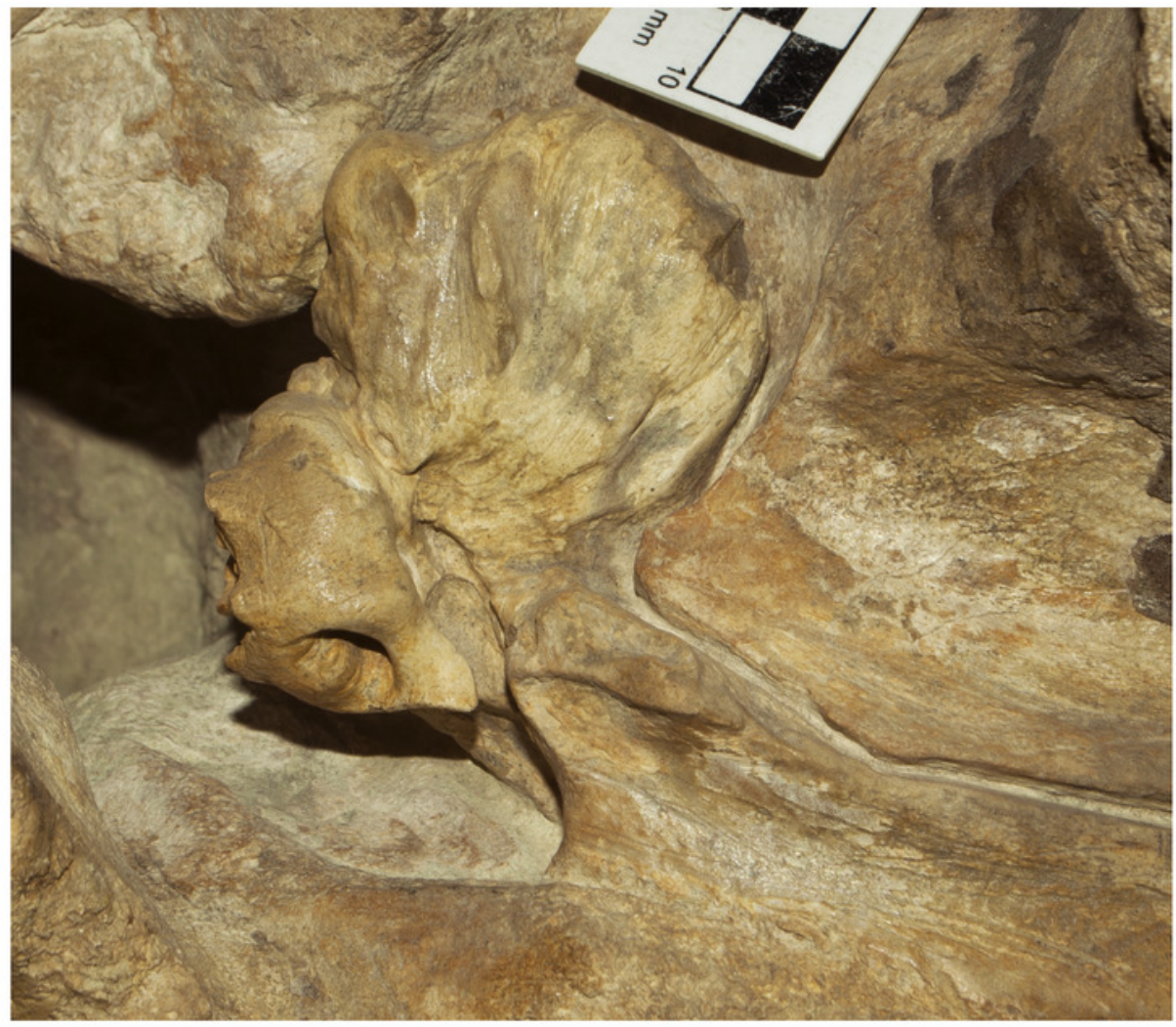

B

Hypertrophied body of periotic

Anterior process

Inferred insertion of tensor tympani muscle

Path of the facial nerve (VII)

Fenestra ovalis

Fenestra rotunda

Caudal tympanic

Anterior pedicle

Squamosal

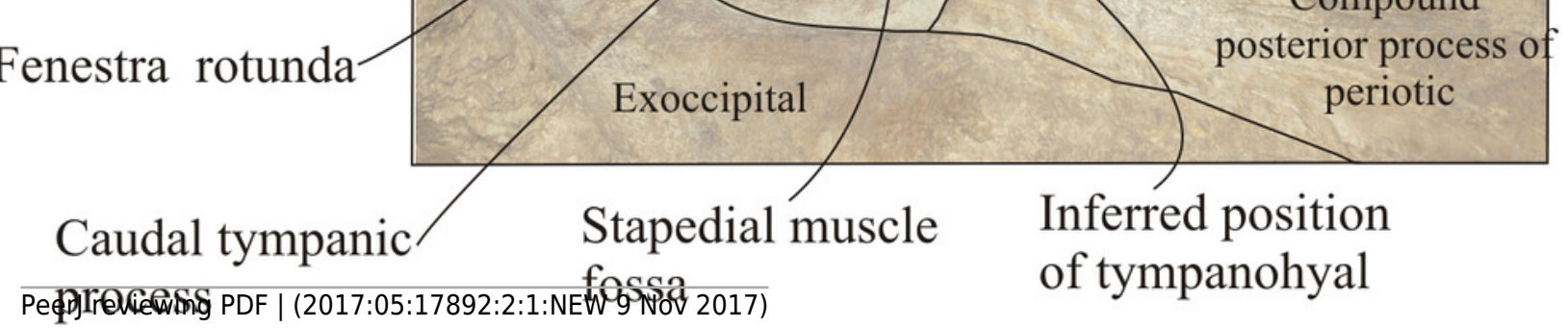




\section{Figure 11}

Morenocetus parvus, holotype, MLP 5-11, left periotic.

(A) Posterior view. (B) Key features in posterior view. (C) Dorsomedial view. (D) Key features in dorsomedial view. Abbreviations: Pc., pars cochlearis; Ctp., caudal tympanic process; Sf., suprameatal fossa; Stf., stylomastoid fossa. 


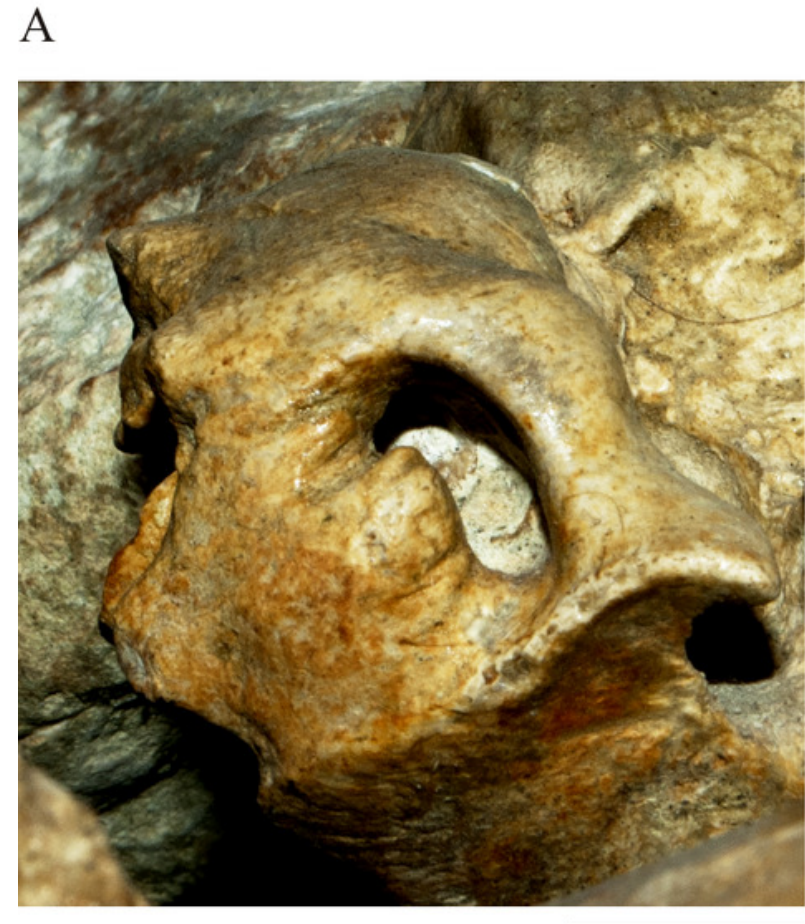

$\mathrm{C}$

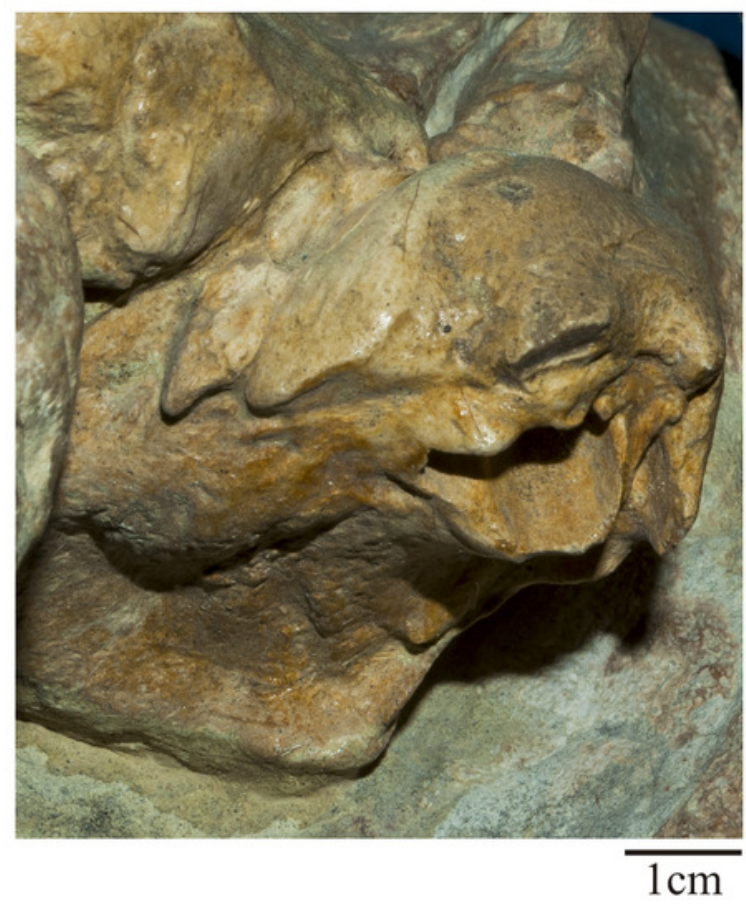

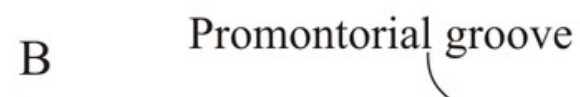

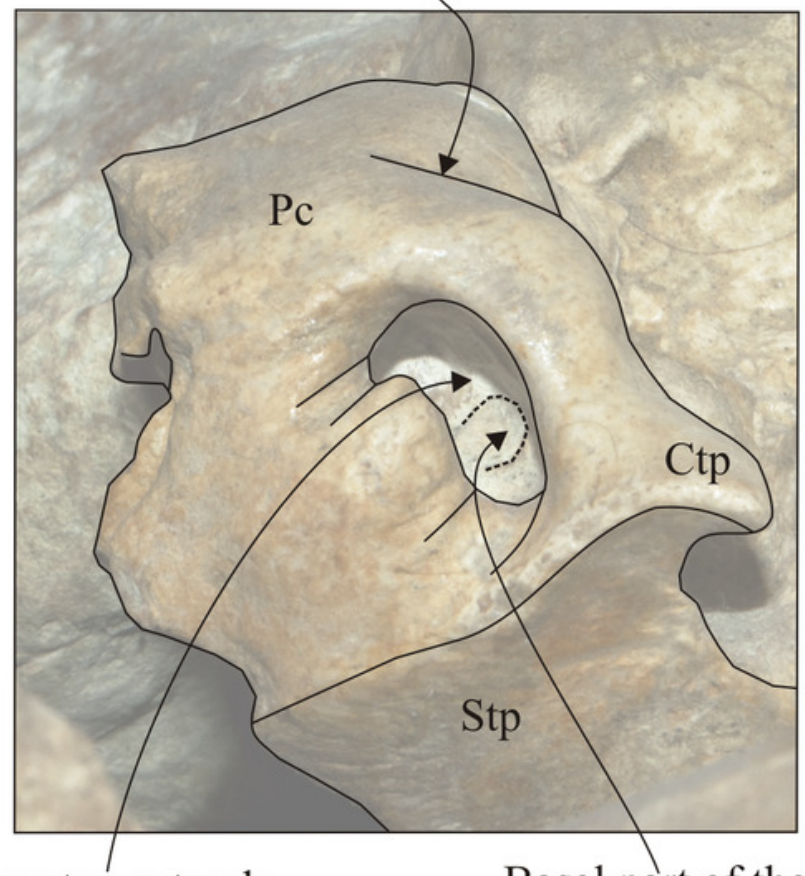

Fenestra rotunda

D laminar gap

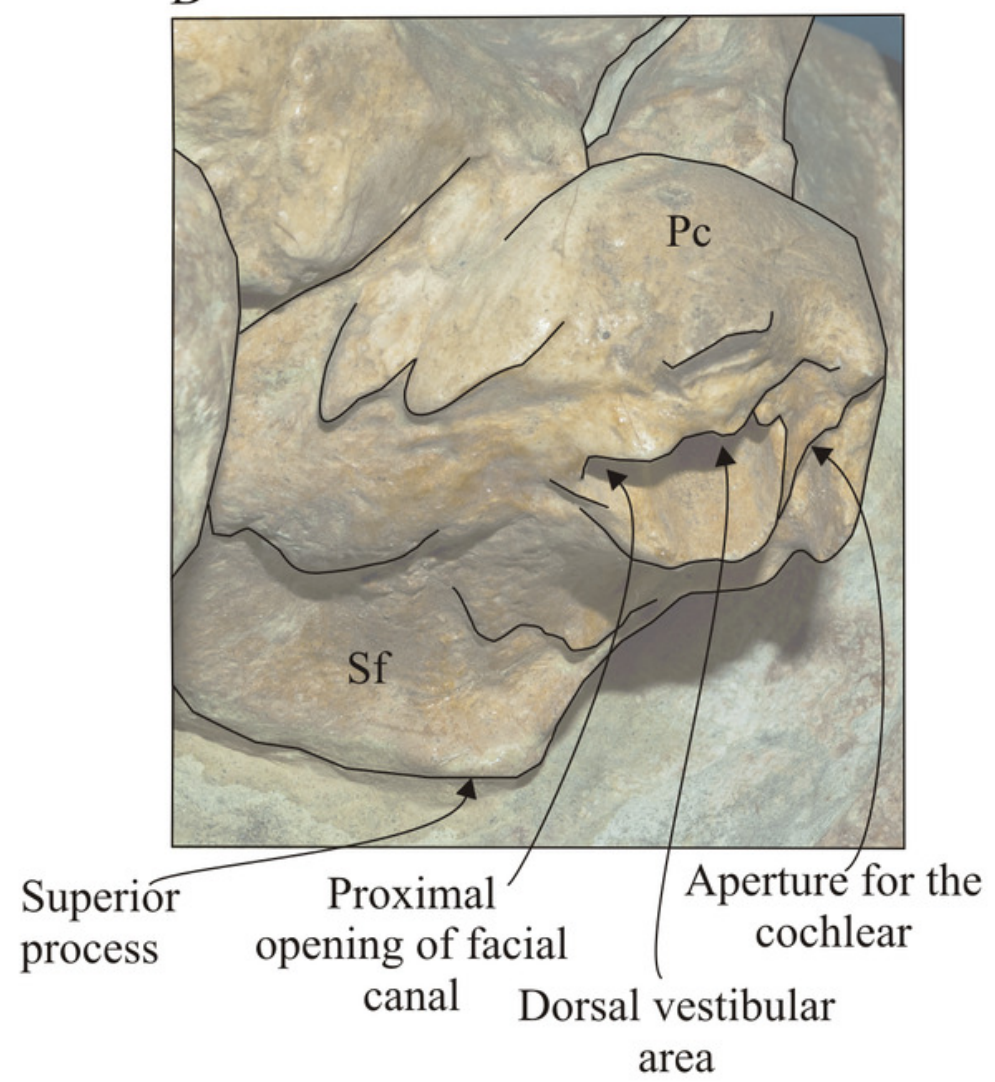




\section{Figure 12}

Phylogenetic relationships of Morenocetus parvus based on morphological analysis.

(A) Strict consensus tree of equally weighted analysis (842 steps; $\mathrm{Cl}=0.41 ; \mathrm{RI}=0.72$ ).

Single most parsimonious tree of implied weighting analysis $(K=3$; fit $=83.13)$. Numbers at nodes are decay indices.

A

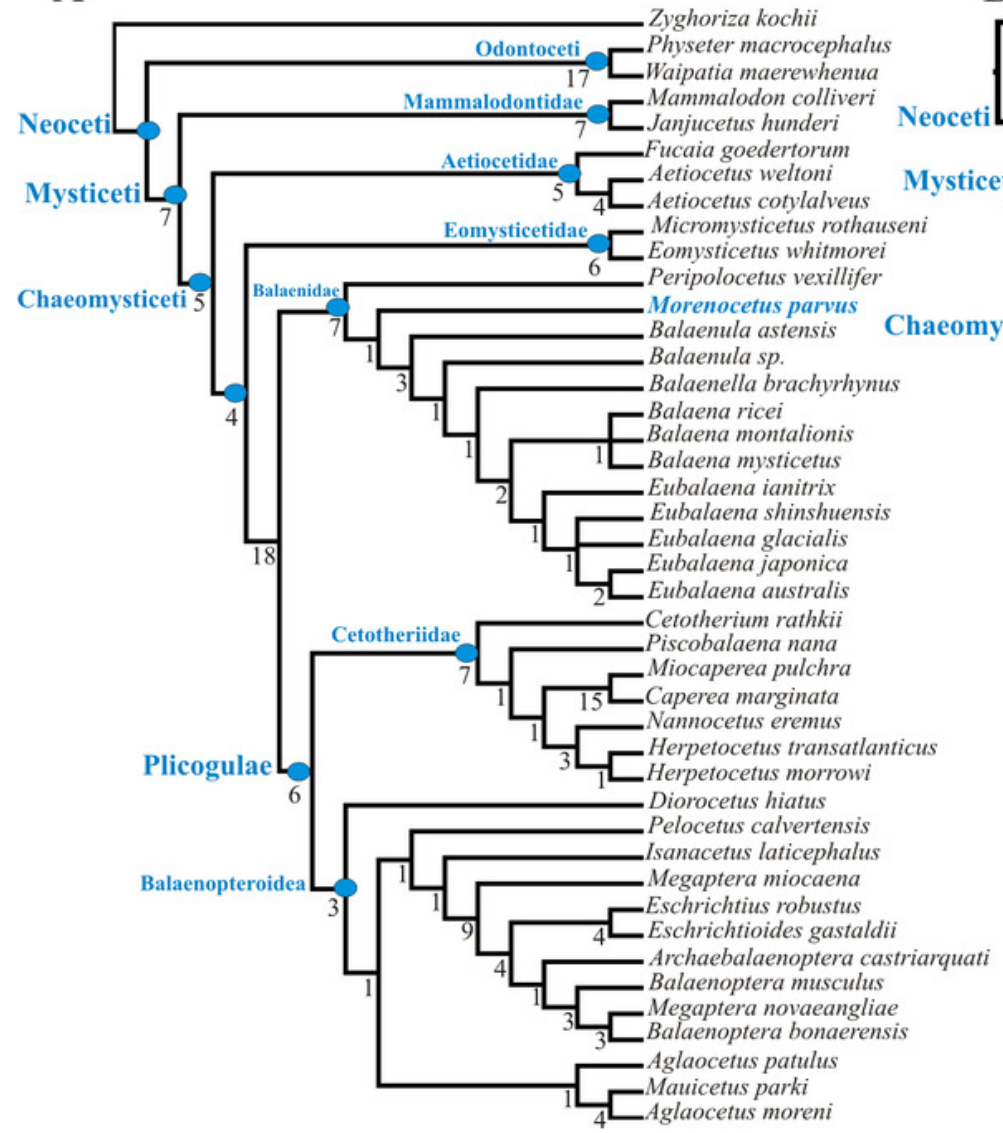

$\mathrm{B}$

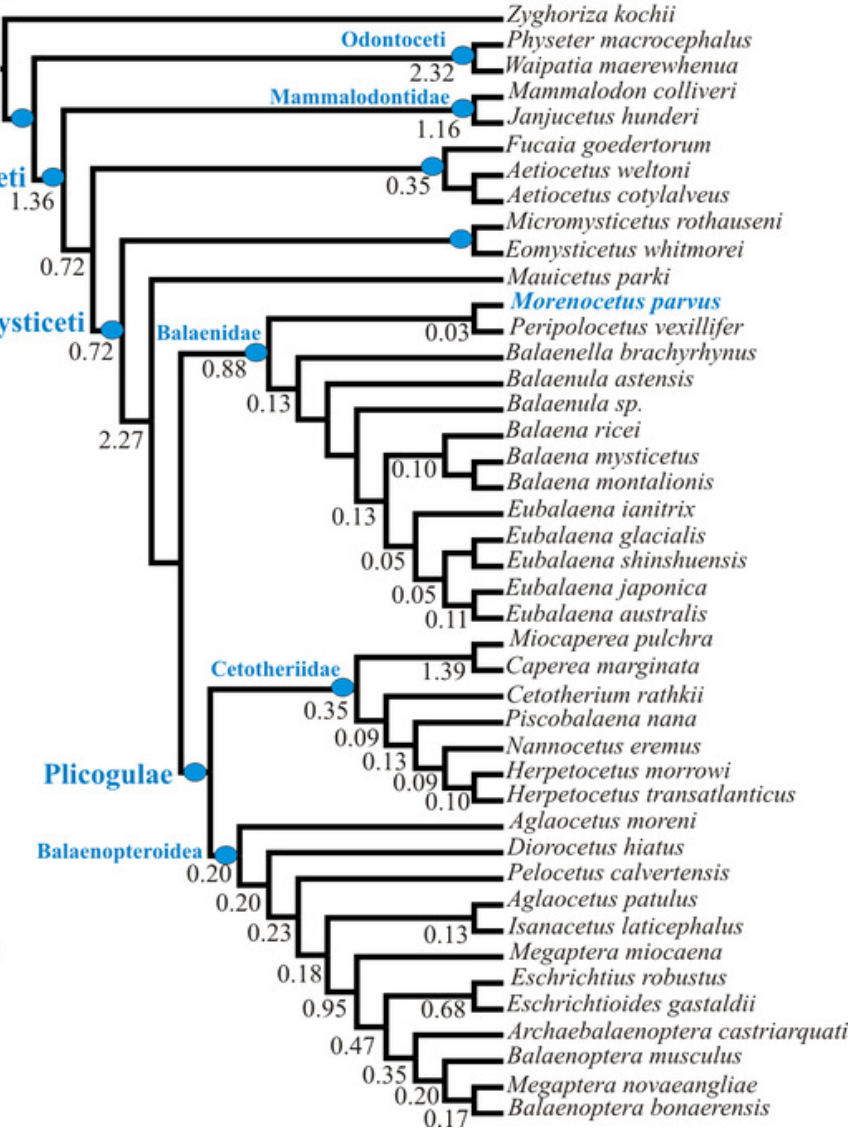




\section{Figure 13}

Reconstructions of balaenid crania in left lateral view, showing relative position of the orbit and eyeball (in blue) with arching of the rostrum.

(A) Morenocetus parvus. (B) Balaenella brachyrhynus. (C) Eubalaena australis. The rostrum in (B) is depicted as preserved in the original specimen. 
A

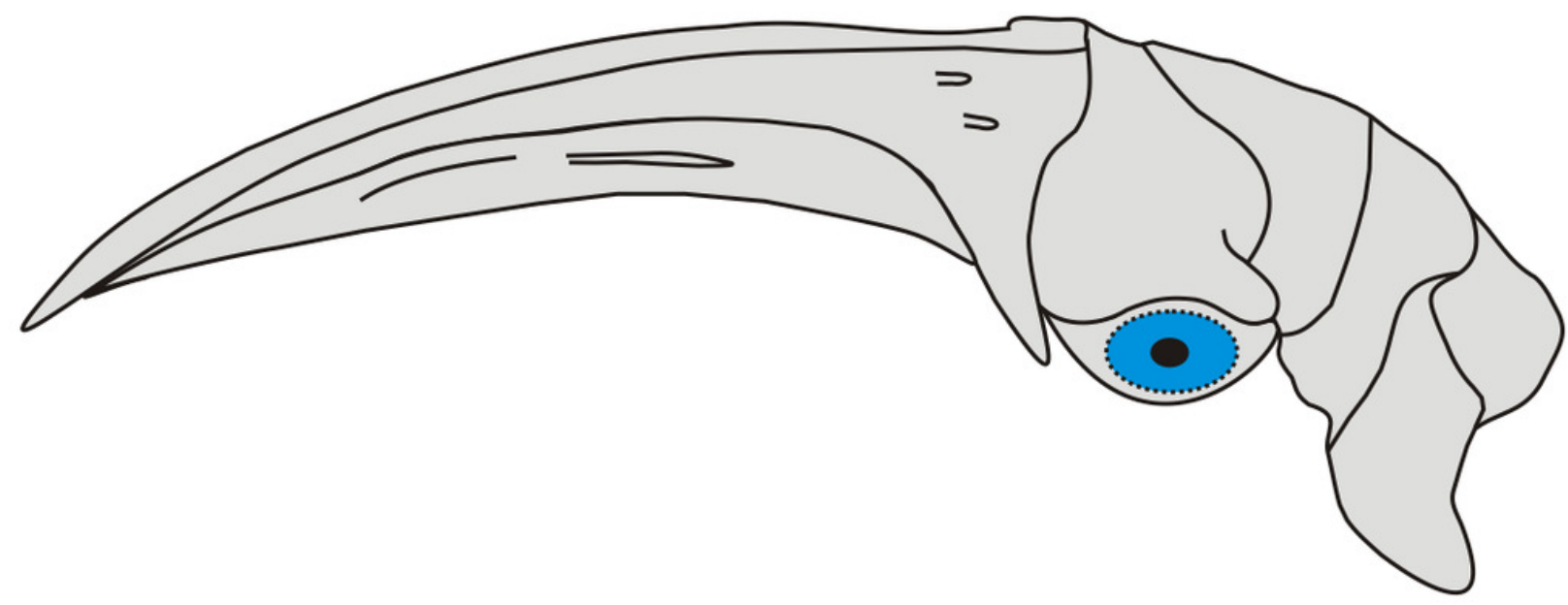

B
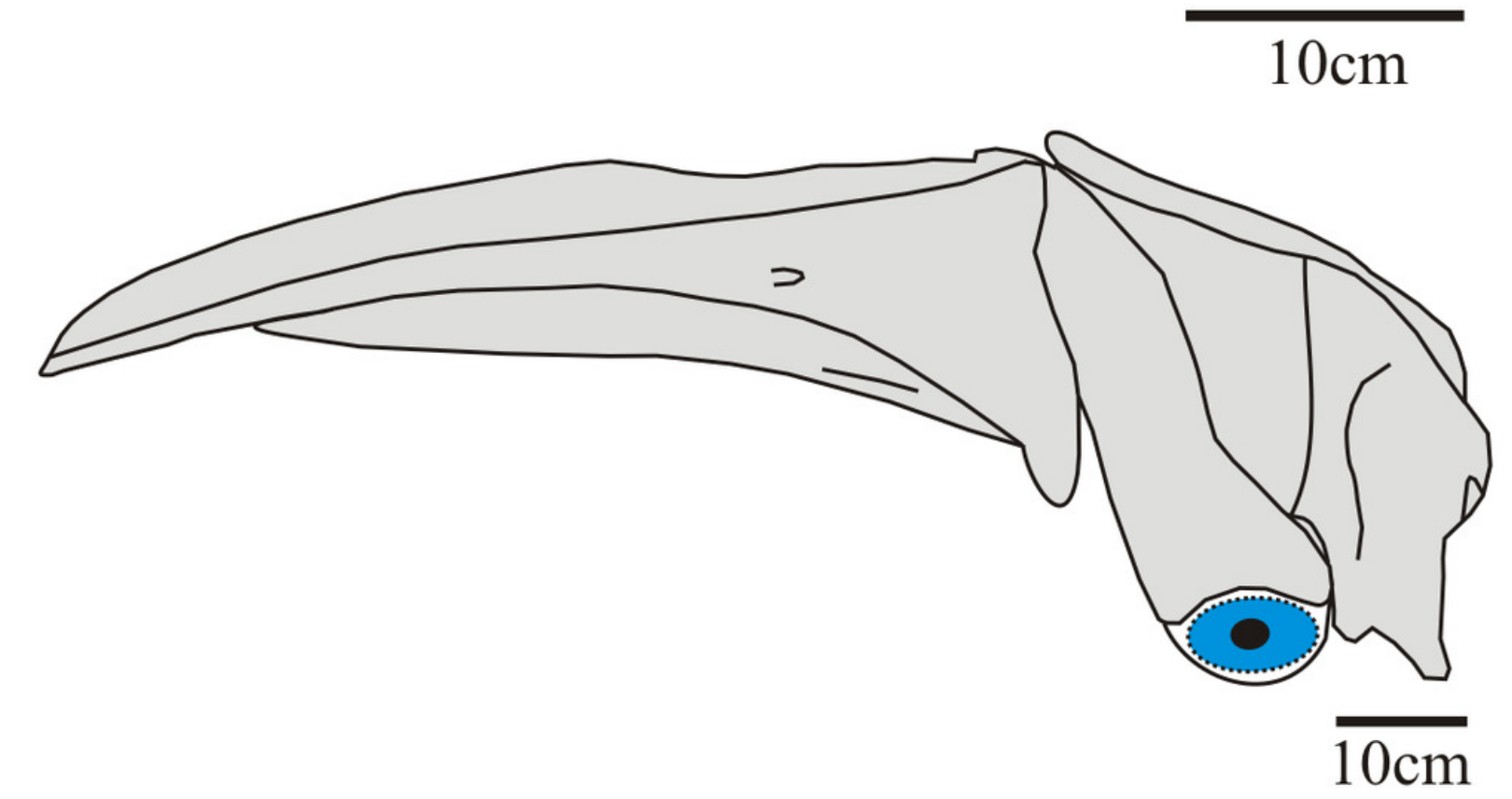

C

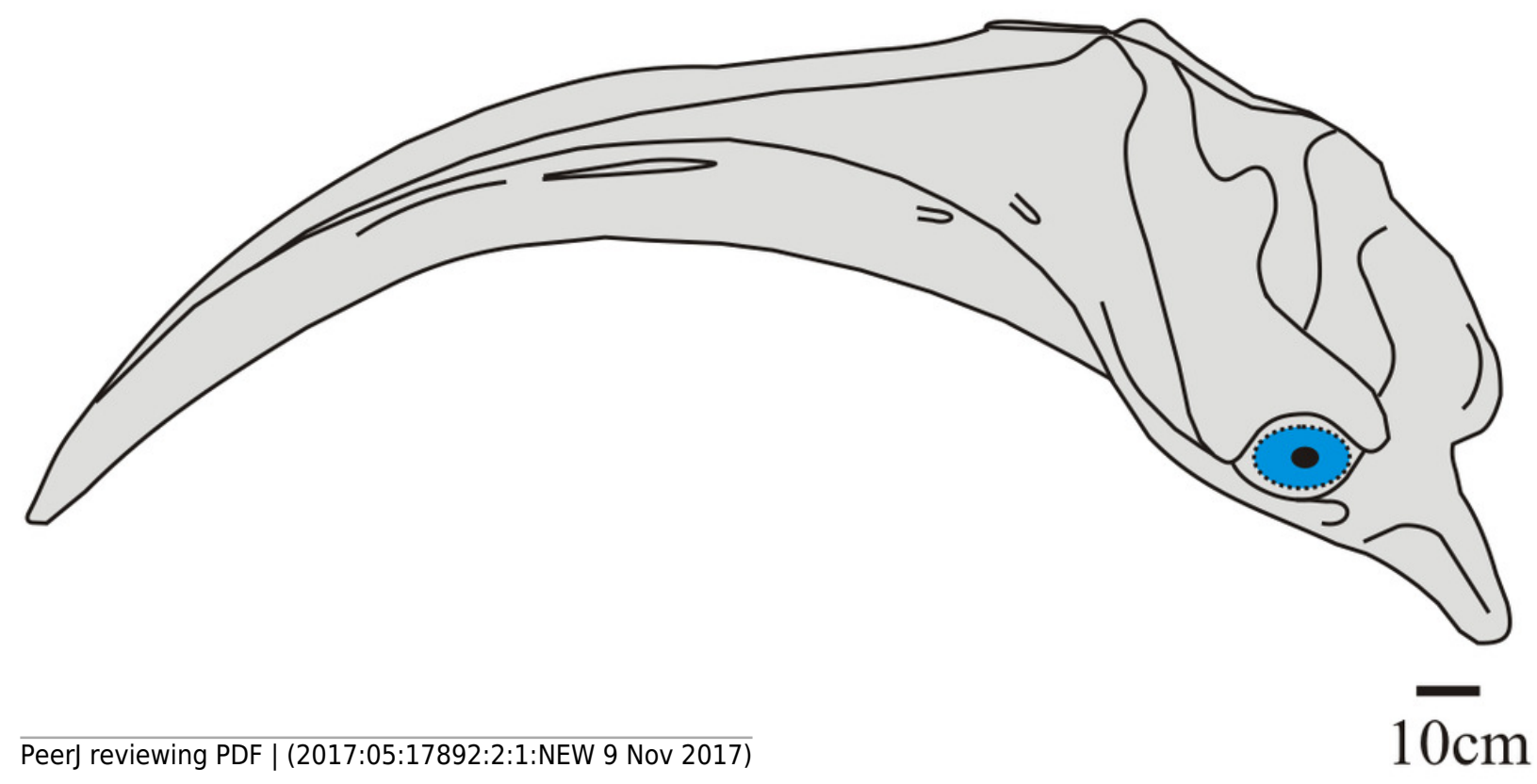




\section{Figure 14}

Stratigraphically calibrated phylogeny of Balaenidae.

Time calibrated phylogeny of Balaenidae pruned from our consensus cladogram in Fig. 12A with Odontoceti, Mammalodontidae, Aetiocetidae, Eomysticetidae and Plicogulae collapsed.

Stratigraphic range data derived from published accounts for each taxon (See supplementary file, Table S2, for source of age data), calibration for major nodes follows mean divergence date estimates by Marx \& Fordyce (2015: Table 1) (Neoceti = 38.80 Ma; Mysticeti $=38.42$ $\mathrm{Ma}$; Chaeomysticeti = 35.5 Ma; crown Mysticeti $30.35 \mathrm{Ma}$; Balaenidae = $23.08 \mathrm{Ma}$; crown Balaenidae $=9.82 ;$ Plicogulae $=28.96 \mathrm{Ma}$ ).

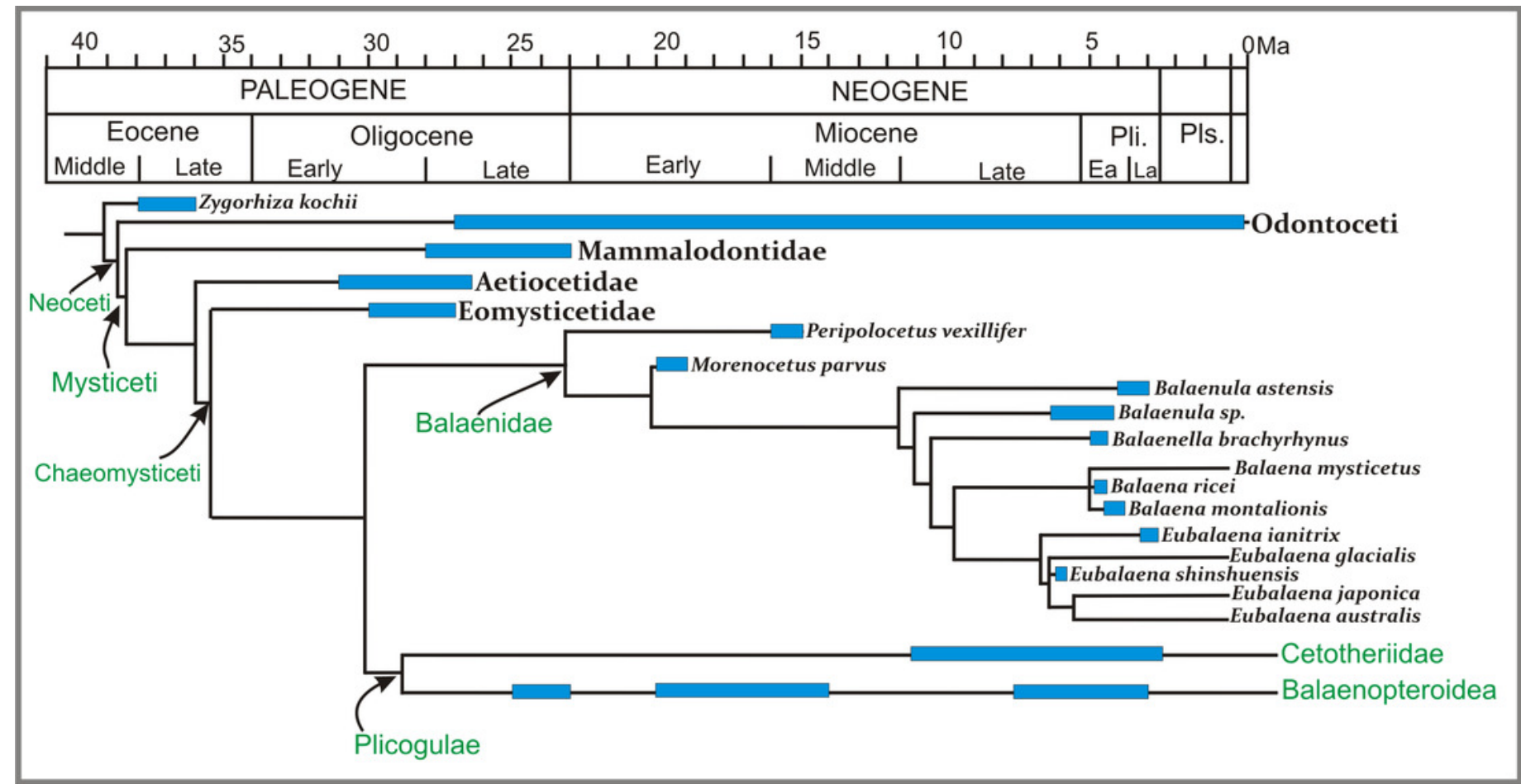




\section{Figure 15}

Artistic restoration of Morenocetus parvus in life.

Art by Jorge Gonzalez.

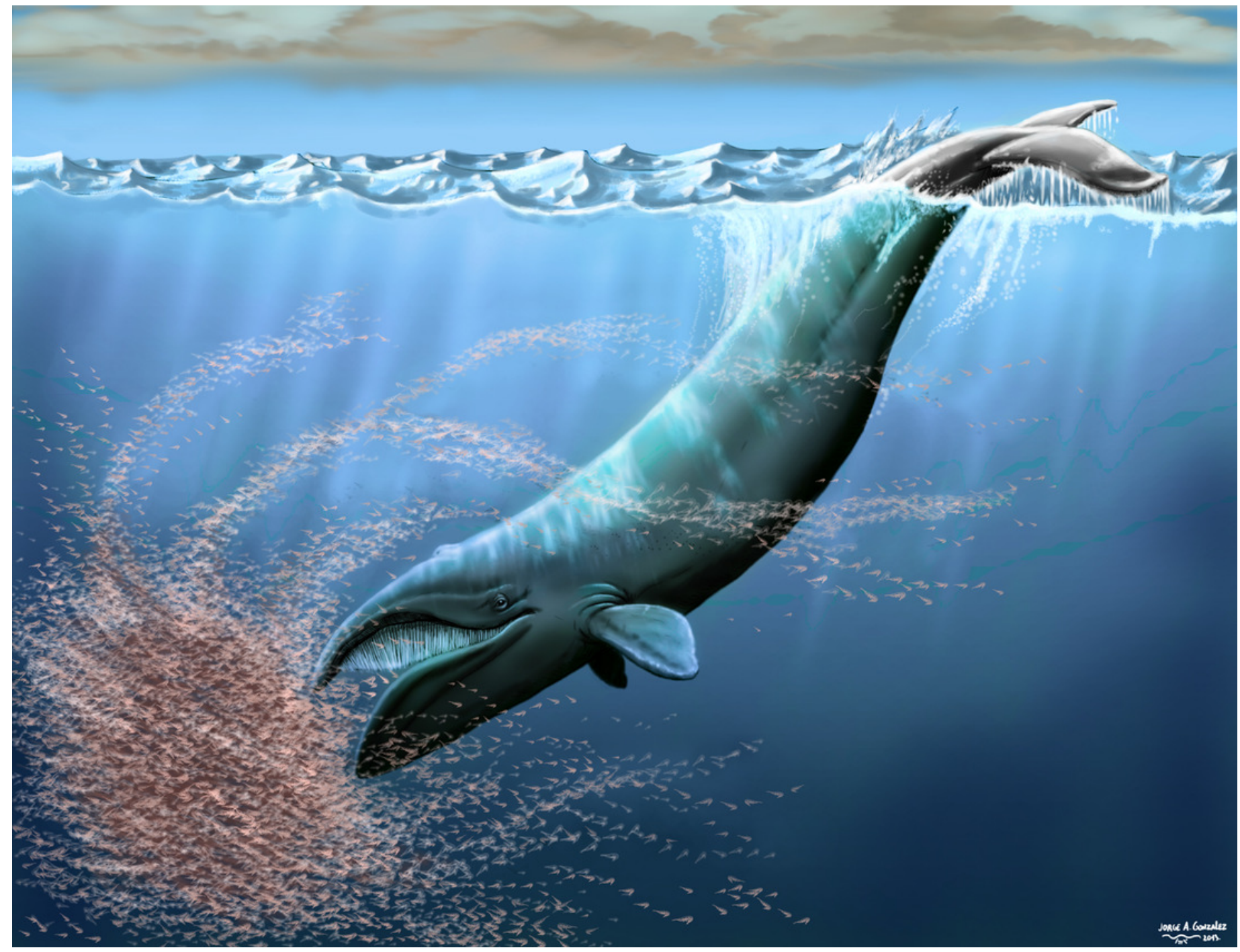

